\title{
$100--1616-14$
}

RECEIVED BY DTIE SEP 109970

United States Atomic Energy Commission

Technical Report No. C00-AT (11-1)-1616-14

\section{STUDIES OF NICKELOUS AND COBALTOUS OXIDE AND EFFECTS OF $n$-TYPE AND P-TYPE DOPANTS}

\section{WILLIAM RIVES HELMS*}

\author{
Physics Department \\ Purdue University \\ Lafayette, Indiana
}

* This report is based on a thesis submitted in partial fulfillment of the requirements of the degree of Doctor of Philosophy at Purdue University. 


\section{DISCLAIMER}

This report was prepared as an account of work sponsored by an agency of the United States Government. Neither the United States Government nor any agency Thereof, nor any of their employees, makes any warranty, express or implied, or assumes any legal liability or responsibility for the accuracy, completeness, or usefulness of any information, apparatus, product, or process disclosed, or represents that its use would not infringe privately owned rights. Reference herein to any specific commercial product, process, or service by trade name, trademark, manufacturer, or otherwise does not necessarily constitute or imply its endorsement, recommendation, or favoring by the United States Government or any agency thereof. The views and opinions of authors expressed herein do not necessarily state or reflect those of the United States Government or any agency thereof. 


\section{DISCLAIMER}

Portions of this document may be illegible in electronic image products. Images are produced from the best available original document. 
United States Atomic Energy Commission

Technical Report No. C00-AT (11-1)-1616-14

\author{
Studies of Nickelous : and Cobaltous Oxide and \\ Effects of n-Type and p-Type Dopants
}

William Rives Helms*

Physics Department, Purdue University

La fayet te, Indiana

* This report is based on a thesis submitted in
partial fulfillment of the requirements of the
degree of Doctor of Philosophy: at Purdue University.

LEGAL NOTICE

This report was prepared as an account of work sponsored by the United States Government. Neither the United States nor the United States Atomic Energy Commission, nor any of their employees, nor any of Commission, nor any of their employees, their contractors, subcontractors, or their or assumes any makes any warranty, express or implied, or assumes any legal liability or responsibility for the accuracy, completeness or usefulness of any information, apparatus, pleteness or usefulness of and or represents that its use product or process disclosed, or represt 


\section{ACKNOWLEDGMENTS}

I would like to express my appreciation to Professor James $G$ 。 Mullen for origina11y. suggesting the topic reported in this thes is and for providing encouragement and professiona 1 guidance throughout the course of this research. I would also like to acknowledge helpful discussions with my fellow graduate students. I would like to thank Professor H. J. Yearian for the generous use of his $x$-ray diffractometer. This work was supported in part by the United States Atomic Energy Commission, the General Electric Company, and the National Aeronautics.: and Space Administration. 
TABLE OF CONTENTS

Page

LIST OF TABLES... ... . . . . . . . . . . . . . . v v

LIST OF FIGURES . . . . . . . . . . . . . . . . vi vi

LIST OF SYMBOLS . . . . . . . . . . . . . . . . . . viii

ABSTRACT........................... . . $x i$

I. INTRODUCTION........................ . . . . 1

II. THEORY . . . . . . . . . . . ........ . 12

A. Recoil-free Fraction . . . . . . . . . . . . . . 12

B. Magnetic Hyperfine Interaction . . . . . . . . . . . . 14

C. Superparamagnetism . . . . . . . . . . . . 15

D. Née1 Temperature............... 16

III. EXPERIMENTAL TECHNIQUES ................. 21

A. Mössbauer Spectrometry............... . 21

B. Sample Preparation... . . . . . . . . . . 24

C. X-ray Technique... . . . . . . . . . . . . 27

D. Gas Pickup and Surface Area Measurements . . . . . 28

E. Particle Size and Superparamagnetism Studies... . . 30

IV. X-RAY AND CHEMICAL MEASUREMENTS. . . . . . . . . . . 31

A. Stoichiometry. ................. . 31

B. Density. . . . . . . . . . . . . . . . 33

C. X-ray Patterns . . . . . . . . . . . . . . 36

D. Gas Pickup and Surface Area Measurement Results. . . . 42

V. MÖSSBAUER MEASUREMENTS . . . . . . . . . . . . . 47

A. Reduction of Data and Error Analysis ... . . . . . . . 47

B. Mössbauer Spectra for NiO Samples . . . . . . . 50

C. Mössbauer Spectra for Doped Samples. . . . . . . . 55

D. Temperature Dependence of Recoil-free Fraction..... 63

E. Néel Temperature................ . 67

F. Search for Superparamagnetism and Particle

Size Effects................. 68 
TABLE :OF CONTENTS (Contd)

G. Absorber Experiments... . . . ........... . 70

H. Single-Line Sources . . . . . . . . . . . . . . . . . . 74

VI. DISCUSSION : . . . . . . . . . . . . . . . . . . . . . . . . . 77

LIST OF REFERENCES . . . . . . . . . . . . . . . . . . . . . 87

APPENDIX A: A GEOMETRICAL EFFECT'IN MO̊SSBAUER SPECTROSCOPY • • 91

VITA. . . ... . . . . . . . . . . . . . . . . . . . . . 96 


\section{LIST :OF :TABLES}

Table

1. Stoichiometry of nickelous oxide. Gravimetric determinations of $\mathrm{x}$, written as $\mathrm{NiO}_{\mathrm{x}}$. . . . ..... 32

2. Densities : of $\mathrm{C} \odot \mathrm{O}$ and $\mathrm{NiO}$. Density measurements in $\mathrm{g} / \mathrm{cm}^{3}$................... 35

3. Bragg peak positions for NiO using Mo $\mathrm{K}_{\alpha}$ radiation :. . . . . . . .......... . . 39

4. Compilation of ion sizes. Values listed are in $\stackrel{\AA}{A}$.... 83

5. Correction factors for geometrical effect . . ....... 94 
1. Decay scheme of $\mathrm{Co}^{57}$................ 5

2. Schematic diagram of Mössbauer spectrometer . . . . . . 22

3. Schematic diagram of sample preparation . . . . . . . 26

4. Holder for gas pickup and surface area measurements ..: . . 29

5. X-ray diffraction patterns for (a) $\mathrm{NiO}$. prepared at $300^{\circ} \mathrm{C}$, (b) NiO(II) prepared at $400^{\circ} \mathrm{C}$, (c) NiO(I) prepared at $1000^{\circ} \mathrm{C}$, using Mo $\mathrm{K}_{\alpha}$ radiation .......... . . 37

6. X-ray diffraction patterns for $\mathrm{COO}(\mathrm{II}) \cdot \mathrm{n} 0$ as a function of n.......................4 41

7. Temperature dependence of Mössbauer spectra for $\mathrm{Ni}^{*}$ prepared at $300^{\circ} \mathrm{C}$. A $1.00 \mathrm{mg} / \mathrm{cm}^{2}$ sodium ferrocyanide absorber was used . . . . . . . . . . . . . 51

8. Temperature dependence of Mössbauer spectra for NiO(II) prepared at $400^{\circ} \mathrm{C}$. A $1.0 \mathrm{mg} / \mathrm{cm}^{2}$ sodium ferrocyanide absorber was used . . . . . . . . . . . . 53

9. Temperature dependence of magnetic hyperfine field at $\mathrm{Fe}^{57}$ site in $\mathrm{NiO}$ (II) prepared at $400^{\circ} \mathrm{C}$. The solid curve shows the Brillouin function for $s=5 / 2 \ldots . . . . .54$

10. Effect of substitutionally doping with $\mathrm{Li}^{1+}$. on the Mössbauer spectra of $\mathrm{NiO}(\mathrm{I}, \mathrm{II})$ prepared at $800^{\circ} \mathrm{C}$. A $1.0 \mathrm{mg} / \mathrm{cm}^{2}$ sodium ferrocyanide absorber was used.... . 56

11. Effect of substitutionally doping with $\mathrm{Cr}^{3+}$ on the Mössbauer spectra of $\mathrm{NiO}(\mathrm{I}, \mathrm{II})$ prepared at $800^{\circ} \mathrm{C}$. A $1.0 \mathrm{mg} / \mathrm{cm}^{2}$ sodium ferrocyanide absorber was used..... 57

12. Effect of substitutionally doping with $\mathrm{Li}^{1+}$ and $\mathrm{Ga}^{3+}$ on the Moossbauer spectra of CoO(I,II) prepared at $1000^{\circ} \mathrm{C}$. A $1.0 \mathrm{mg} / \mathrm{cm}^{2}$ sodium ferrocyanide absorber was used at $81^{\circ} \mathrm{K}$ and a $0.5 \mathrm{mg} / \mathrm{cm}^{2}$ absorber at $298^{\circ} \mathrm{K}$. . . . 58 
13. Temperature dependence of Mössbauer spectra for NiO prepared at $1000^{\circ} \mathrm{C}$ with a $1 \% \mathrm{Li}^{1+}$ doping.

A $1.0 \mathrm{mg} / \mathrm{cm}^{2}$ sodium ferrocyanide absorber was used....

14. Temperature dependence of Mössbauer spectra for.

$\mathrm{Co} 0(\mathrm{I}, \mathrm{II})$. A $0.75 \mathrm{mg} / \mathrm{cm}^{2}$ sodium ferrocyanide

absorber was used . . . . . . . . . . . . . .

15. Temperature dependence of Mössbauer spectra for CoO (I, II) with a .1\% doping of $\mathrm{Li}^{1+}$. A $0.75 \mathrm{mg} / \mathrm{cm}^{2}$ sodium ferrocyanide absorber was used. . . . . . . . . .

16. Temperature dependence of $\operatorname{ln~A}$ for, (a) $\mathrm{Fe}^{3+}$ in $\mathrm{NiO}$ $(1 \% \mathrm{Li})$, (b) $\mathrm{Fe}^{3+}$ in. $\mathrm{CoO}(1 \% \mathrm{Li})$, (c) $\mathrm{Fe}^{2+}$ in $\mathrm{CoO}(\mathrm{I})$, (d) $\mathrm{Fe}^{3+}$ in $\mathrm{NiO}(\mathrm{II})$, (e) $\mathrm{Fe}^{3+}$ in $\mathrm{CoO}(\mathrm{II})$, based on area measurements normalized to unity at $81^{\circ} \mathrm{K}$. The first three samples were prepared at $1000^{\circ} \mathrm{C}$ and the

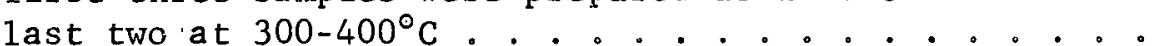

17. Temperature dependence of $\ln \mathrm{A}$ for $\mathrm{Fe}^{3+}$ in (a) $\mathrm{CoO}$ (I, II) with a $.1 \% \mathrm{Li}^{1+}$ doping and (b) $\operatorname{CoO}(\mathrm{I}, \mathrm{II}) \ldots$

18. Effect of a $51 \mathrm{kG}$ external magnet ic field on the Mo̊ssbauer spectra of $\mathrm{NiO}^{*}$ prepared by a very short annea 1 at $300^{\circ} \mathrm{C},(\mathrm{a})$ and $(\mathrm{b})$, and on a sample of $\mathrm{NiO}$ prepared at $600^{\circ} \mathrm{C}$ in $140 \AA$ silica gel, (c) and (d). . .

19. Two absorber resonances, at room iemperature, of $\mathrm{Fe}^{57}$

in NiO prepared at $300^{\circ} \mathrm{C}$. A Co 57 in Pd source was used........................

20. Simultaneous source and absorber Mössbauer spectra, at room temperature, for $\mathrm{Co} 0$ prepared at $1000^{\circ} \mathrm{C}$ in $\mathrm{CO}_{2}$. The source resonance, (a), was run with a $0.25 \mathrm{mg} / \mathrm{cm}^{2}$ sodium ferrocyanide:absorber, and the absorber resonance, (b), with : a Co 57 in cu source........

21. Effects of dopants on Mössbauer spectra at room temperature of $\mathrm{CoO}$, (a) $\mathrm{CoO}$ (I, II), (b) $\mathrm{CoO}(.3 \% \mathrm{Ga})$, (c) $\mathrm{CoO}(1 \% \mathrm{Li})$. A11 of the samples were prepared at $1000^{\circ} \mathrm{C}$. (d) an unsplit $\mathrm{Pd}$ source. A $0.1 \mathrm{mg} / \mathrm{cm}^{2}$ sodium ferrocyanide absorber was used in these experiments...

22. Experimenta1 geometry illustrating the solid angle subtended by the detector of a Mössbauer spectrometer. . . 
Symbo 1

$\mathrm{CoO}, \mathrm{NiO}$

$\mathrm{CoO}(\mathrm{I}), \mathrm{NiO}(\mathrm{I})$

$\operatorname{CoO}(I, I I), \operatorname{NiO}(I, I I)$

$\operatorname{CoO}(1 \% \mathrm{Li}), \mathrm{NiO}(1 \% \mathrm{Li})$

$\mathrm{CoO}(\mathrm{II}), \mathrm{NiO}(\mathrm{II})$

$\mathrm{CoO}^{*}, \mathrm{NiO}{ }^{*}$

$\mathrm{CoO} \cdot \mathrm{n} 0$

MO

$\mathrm{v}$

c

E $Y$

$\mathrm{A}(\mathrm{v})$
Name

Generic terms denoting cobaltous oxide or nickelous oxide

High temperature forms of $\mathrm{CoO}$ or $\mathrm{NiO}$, having perfect translational symmetry and revealing only $\mathrm{Fe}^{2+}$ in the Mössbauer resonance resulting from the decay of $\mathrm{Co}^{57}$

$\mathrm{High}$ temperature forms of $\mathrm{CoO}$ or $\mathrm{NiO}$ indicating both $\mathrm{Fe}^{2+}$. and $\mathrm{Fe}^{3+}$. in the Mössbauer resonance

High temperature preparations of $\mathrm{CoO}$ or $\mathrm{NiO}$ with $1 \% \mathrm{Li}^{1+}$ doping

Low temperature forms of $\mathrm{CoO}$ or $\mathrm{NiO}$ which are pure and nominally stoichiometric, and give only $\mathrm{Fe}^{3+}$ in the Mössbauer resonance

Non-stoichiometric $\mathrm{CoO}$ or $\mathrm{NiO}$ prepared..at low temperature containing impurities from the nitrate or carbonate used as starting material

CoO(II) which has been allowed to pickup excess oxygen from the initial stoichiometric composition, but which has the basic $x$-ray pattern of cobaltous oxide

Mullen : and ok

Relative velocity between source and absorber in a Mössbauer experiment, taken as positive when the absorber moves toward the source

Speed of light

Nuclear transition energy

Fractional Mössbauer effect as a function of : velocity 


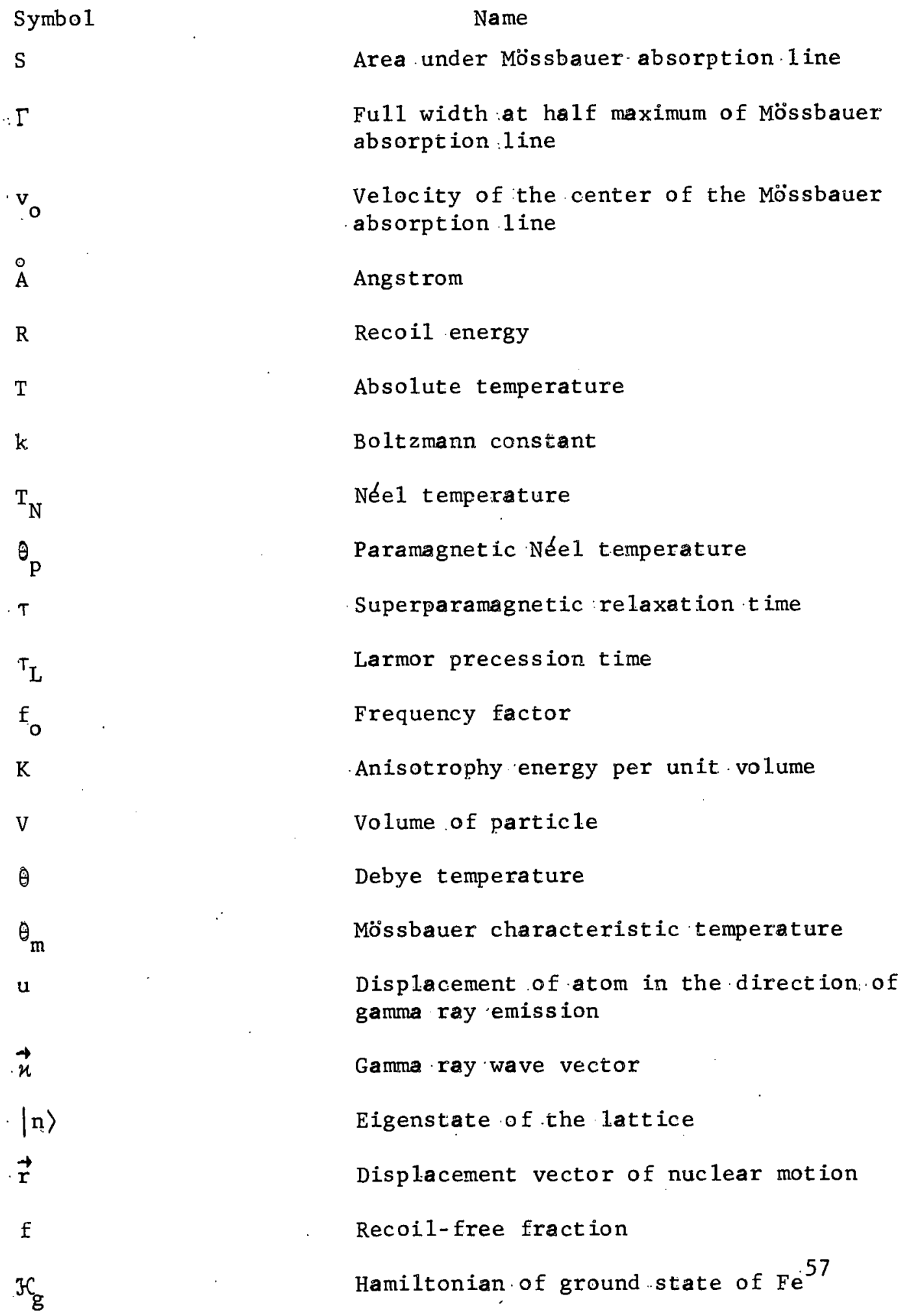


Symbo1

$\mathcal{H C}_{\mathrm{e}}$

$\mathrm{g}_{0}$

$\mathrm{g}_{1}$

$\mu_{\mathrm{N}}$

$\overrightarrow{\mathrm{I}}$

$\overrightarrow{\mathrm{H}}$

$\mathrm{E}$

m
Name

Hamiltonian of first excited state of $\mathrm{Fe}^{.57}$

Nuclear gyromagnetic ratio of the ground state of $\mathrm{Fe}^{57}$

Nuclear gyromagnetic ratio of the first excited state of $\mathrm{Fe}^{57}$

Nuclear Bohr magneton

Nuclear spin

Magnetic field at nucleus

Eigenvalue of magnetic hyperfine interaction

Magnetic quantum number 
ABSTRACT

Helms, William Rives. Ph.D., Purdue University, August 1970. Studies of Nickelous : and Cobaltous Oxide and Effects of n-type and p-type Dopants. Major Professor: James G. Mullen.

Mössbauer, chemical, and $x$-ray studies establish that the low temperature preparations of cobaltous and nickelous oxide have significant structural differences from high temperature preparations. The data cannot be explained by electronic effects alone, and ion size effects have been ruled out. The structural model most compatible with experiment involves:a combination of Schottky vacancies :and porosity. The low temperature stoichiometric preparations, CoO(II) and $\mathrm{NiO}$ (II), may be viewed as a sponge-like structure, with a large concentration of dispersed anion and cation vacancies. Schottky defects appear to be responsible for most of the observed differences between high and low temperature forms. The data:are consistent with the charge stabilization of the $\mathrm{Fe}^{3+}$ ion by electron trapping at oxygen vacancies. Our results do not indicate that stoichiometric variations are the main cause of differences in the properties of the high and low temperature forms. Nominally stoichiometric and pure $\mathrm{NiO}(\mathrm{II})$ can be prepared at low temperature, analogous to an earlier preparation of $. \mathrm{CoO}(\mathrm{II}) . \mathrm{NiO}(\mathrm{II})$ and. $\mathrm{CoO}(\mathrm{II})$ represent a saturated non-equilibrium density of Schottky defects and porosity. Attempts to increase this defect density result in impure and non-stoichiometric materials, denoted as $\mathrm{NiO}^{*}$ and $\mathrm{COO}^{*}$. The Mössbauer patterns of $\mathrm{NiO}(\mathrm{II})$ and 
CoO(II) exhibit only the $\mathrm{Fe}^{3+}$ resonance. The density of $\mathrm{NiO}(\mathrm{II})$ is $6.0 \pm .2 \cdot \mathrm{g} / \mathrm{cm}^{3}$, or about $12 \%$ below the value expected from $\mathrm{x}$-ray data. The Née1 temperature, $T_{N}$, is measured to be $515 \pm 5^{\circ} \mathrm{K}$. ${ }$. for a high temperature sample is measured to be $525 \pm 1^{\circ} \mathrm{K}$. The temperature de: pendence of the magnetic hyperfine field for NiO(II) follows the Brillouin function for $S \cdot=5 / 2$, approximately. NiO(II) shows only the expected $\mathrm{x}$-ray diffraction peaks, although broadened, and. it has :a Mössbauer characteristic temperature, $\theta_{\mathrm{m}}$, of $350 . \pm 10^{\circ} \mathrm{K}$. The physical adsorption of Ar:: and $\mathrm{Ne}$ gases by $\mathrm{CoO}$ (II) and $\mathrm{NiO}$ (II) gives:an estimate of particle size of order $100 \AA$, in accord with $x$-ray line broadening. The pickup of oxygen by $\mathrm{CoO}(\mathrm{II})$ is in sharp contrast to $\mathrm{NiO}(\mathrm{II})$, which is inert in oxygen. An explanation for the magnitude of the oxygen pickup of $\operatorname{co0}$ (II) (in excess of $60 \%$ of the stoichiometric value) has not been found, although we show that the process cannot be a physical adsorption. The application of an external magnetic field to $\mathrm{NiO}^{*}$ gives evidence for superparamagnetism resulting from small particle size, which is not found for form II samples. Experiments in which $\mathrm{NiO}$ and $\mathrm{CoO}$ are doped with $\mathrm{Li}, \mathrm{Cr}$, and $\mathrm{Ga}$ have shown that significant changes in the ratio $\mathrm{Fe}^{2+} / \mathrm{Fe}^{3+}$ are obtained. $\mathrm{Li}$ doping enhances the $\mathrm{Fe}^{3+}$ resonance, while $\mathrm{Cr}$ and $\mathrm{Ga}$ enhance the $\mathrm{Fe}^{2+}$ resonance. The qualitative effects of the dopants:are explained using:a band model for these semiconducting oxides. The value of $\theta_{m}$ for the $\mathrm{Fe}^{3+}$ resonance induced by $\mathrm{Li}$ in high temperature preparations is $410 \neq 10^{\circ} \mathrm{K}$ for $\mathrm{CoO}(1 \% \mathrm{Li})$ and $420 \pm 10^{\circ} \mathrm{K}$ for $\mathrm{NiO}(1 \% \mathrm{Li})$. These results, compared with the earlier value of: $\theta_{\mathrm{m}}$ for $\mathrm{COO}$ (II), which has been determined with improved accuracy for this study, demonstrate the structural 
differences between high and low temperature preparations. By measuring changes in the Néel temperature in high temperature lithium doped samples, and in $\mathrm{C} \odot \mathrm{O}(\mathrm{II})$ and $\mathrm{NiO}(\mathrm{II})$, we are able to estimate the relative partitioning of Schottky defects as compared with porosity. The results indicate that about $1 / 4$ of the $25 \%$ density lowering in $\operatorname{Co} 0(\mathrm{II})$ is due to Schottky defects and $3 / 4$ is due to porosity. In $\mathrm{NiO}(\mathrm{II})$ it is estimated that about $1 / 6$ of the $12 \%$ density lowering is due to Schottky defects and $5 / 6$ is due to porosity. The ratio of the fractional reductions in $\theta_{\mathrm{m}}$ for $\mathrm{CoO}(\mathrm{II})$ and $\mathrm{NiO}(\mathrm{II})$ is the same as the ratio of the estimated fractional amounts of Schottky defects in $\mathrm{CoO}(\mathrm{II})$ and $\mathrm{NiO}(\mathrm{II})$, which gives :added support to the above analysis based on changes in the Néel temperature. The doping experiments indicate that the unusual increase of the $\mathrm{Fe}^{3+}$ resonance with temperature, in forms which contain both $\mathrm{Fe}^{2+}$ and $\mathrm{Fe}^{3+}$, is : a consequence of the semiconducting properties of these materials and does not require a diffusion of cation or anion vacancies, as had been speculated earlier. Our results indicate that the doping technique should be:a useful tool in studying the semiconducting properties of the transition metal oxides. We have found a very useful application for cobaltous oxide, doped with lithium, in the preparation of compact, single line sources, which have very narrow linewidths: and exceptionally large recoil-free fractions. 


\section{INTRODUCTION}

In 1958 Rudolf Mössbauer ${ }^{1}$ discovered that nuclei bound in a crystalline lattice can emit and absorb gamma rays, which display the natural linewidth and possess the full transition energy, with no recoil energy transferred to lattice vibrations. The importance of this condition is that the recoil energy of a nucleus (required by momentum conservation) emitting a gamma ray is several orders of magnitude greater than the minimum linewidth of the gamma ray. The recoil energy causes:absorption and emission lines to be shifted so that no overlap or resonance can occur. Previous to Mössbauer's work various methods to compensate for the recoil energy loss had been tried. These involved doppler shifting the emitted gamma rays with a high speed rotor, doppler broadening the gamma rays by thermal motion, or using a preceeding nuclear event to impart a momentum to the emitting nucleus. Mössbauer showed, however, with the aid of Lamb's theory of resonant neutron scattering, that there is a finite probability that a nucleus will emit or absorb a gamma ray without a change in the phonon states of the crystal with the recoil momentum being carried away by the entire crystal and not the individual nucleus. In this case the loss of energy by the gamma ray due to the recoil process is negligible, and the gamma ray will also have the minimum width determined by the uncertainty principle from the half-life of the excited state of the nucleus. In the case of $\mathrm{Fe}^{57}$, the most commonly used Mosssbauer 
isotope, the recoil energy carried away by the nucleus from the 14.4 $\mathrm{keV}$ gamma ray would be about $10^{-3} \mathrm{eV}$ if the nucleus were assumed to recoil. But the energy characteristic of lattice vibrations is larger (typically of the order of $10^{-2}$ to $10^{-1} \mathrm{eV}$ ). Since the lattice is a quantized system it cannot be excited in an arbitrary fashion, and therefore there is : a finite probability of zero-phonon emission. For the $14.4 \mathrm{keV}$ transition of $\mathrm{Fe}^{57}$ the zero-phonon gamma ray will have a width of order $10^{-8} \mathrm{eV}$, so that its energy is defined to 1 part in $10^{12}$.

In a typical Mössbauer experiment one measures the transmission of gamma rays from a source through a resonant absorber. By imparting a relative velocity $v$ between source and absorber, the energy spectrum of the gamma rays from the source can be doppler shifted by an amount $\frac{\mathrm{v}}{\mathrm{c}} \mathrm{E}_{\gamma}$, where $\mathrm{E}_{Y}$ is the nuclear transition energy and $\mathrm{c}$ is the velocity of light. The counting rate at the detector drops whenever the relative doppler velocity shifts the energy of a gamma ray emitted by the source into coincidence with an absorption energy of the absorber。 The data are usually put into the form of a plot of percent absorption versus velocity in $\mathrm{mm} / \mathrm{sec}$. An energy spectrum of the source can thus be obtained. This new type of spectroscopy is one of the primary tools used to study cobaltous and nickelous oxide in this thesis. An important property of the Moossbauer effect in $\mathrm{Fe}^{57}$ is that the gamma ray linewidth is smaller than the characteristic energy splittings of nuclear levels in crystalline fields, and therefore Mo̊ssbauer spectroscopy permits:a direct observation of these interactions. Because the nucleus possesses a magnetic dipole moment the nuclear levels will be split if a magnetic field is present at the nuclear 
site. In the case of $\mathrm{Fe}^{57}$ the magnetic hyperfine interaction splits the excited state and the ground state such that there are six allowed transitions, and the Mössbauer pattern will have six lines. The charge distribution of the nucleus will interact with the distribution of external charge. The lowest order interaction is the monopole interaction between the nucleus and the electron density at the nucleus. This interaction produces a shift in the centroid of the Mössbauer pattern, and this isomer shift can be correlated with the valence of the ion because the total electron density at the nucleus will depend upon the valence state. In the case of $\mathrm{Fe}^{57}$, for example, the isomer shift can be used to clearly differentiate between the $\mathrm{Fe}^{2+}$ and $\mathrm{Fe}^{3+}$ ions, even without :an explicit determination of the nuclear splittings ${ }^{2}$. The valence state of the ion may also be correlated with the magnitude of the magnetic field at the nuclear site to further confirm the charge state of the Mössbauer ion. The second non-vanishing term of the electrostatic interaction of the nucleus with its surrounding charge is the quadrupole interaction. For $\mathrm{Fe}^{-57}$, an electric field gradient at the nucleus interacts with the quadrupole moment of the excited state such that there are two allowed transitions. For an $\mathrm{Fe}^{57}$ nucleus in a combined magnetic field and electric field gradient, there will be in general eight allowed transitions.

The area under the Mössbauer curve is proportional to the recoilfree fraction for emission and is:a measure of the binding of the ion in its lattice site. The stiffer the lattice the greater the probability : that an emitted gamma ray will be a zero-phonon. or Mössbauer event. The theory of this effect will be discussed in detail in Section II-A, 
and it will be applied in discussing our observations.

Since Wertheim's ${ }^{3}$ original work on Co0 in 1961 much interest has been shown in the Mössbauer spectra of $\mathrm{Fe}^{57}$ doped in the transition metal oxides $\mathrm{COO}$ and $\mathrm{NiO}$. The initial interest centered on the observation that the charge state of the $\mathrm{Fe}^{57}$ was found to be not only the expected $2+$, but also $3+$. It was found by different groups ${ }^{4-14}$ that depending upon the method of sample preparation, various ratios of the $2+$ to $3+$ resonance were observed, with lower temperatures of preparation generally giving more $\mathrm{Fe}^{3+}$. The first explanation for the appearance of the $\mathrm{Fe}^{3+}$ resonance was due to Wertheim. He interpreted the $\mathrm{Fe}^{3+}$ resonance in terms of an Auger electron process, which has sometimes been referred to as.:an Auger aftereffect. Fig. 1 shows the decay scheme of $\mathrm{Co}^{57}$, which decays via electron capture to $\mathrm{Fe}^{57}$. The $\mathrm{Fe}^{57}$ nucleus is initially in an excited state and has the electronic structure of $\mathrm{Co}^{57}$, with an inner electron missing. The resulting hole, which is generally a missing $\mathrm{K}$-electron, is filled by an outer electron with the emission of an $x$-ray, or alternatively the excitation energy is transmitted to an outer electron referred to as:an Auger electron. Each time an Auger electron is emitted, the charge state of the $\mathrm{Fe}^{57}$ ion is increased by one. Following this buildup to a high charge state, the highly charged ion will capture electrons until electronic equilibrium is reached. One critical parameter in this process is the time required to reach electronic equilibrium following the Auger cascade. If this time is of the order of or greater than the $10^{-7}$ second half-1ife of the $14.4 \mathrm{keV}$ gamma ray used in the Mössbauer measurement, then the higher charged.states, caused by the Auger 


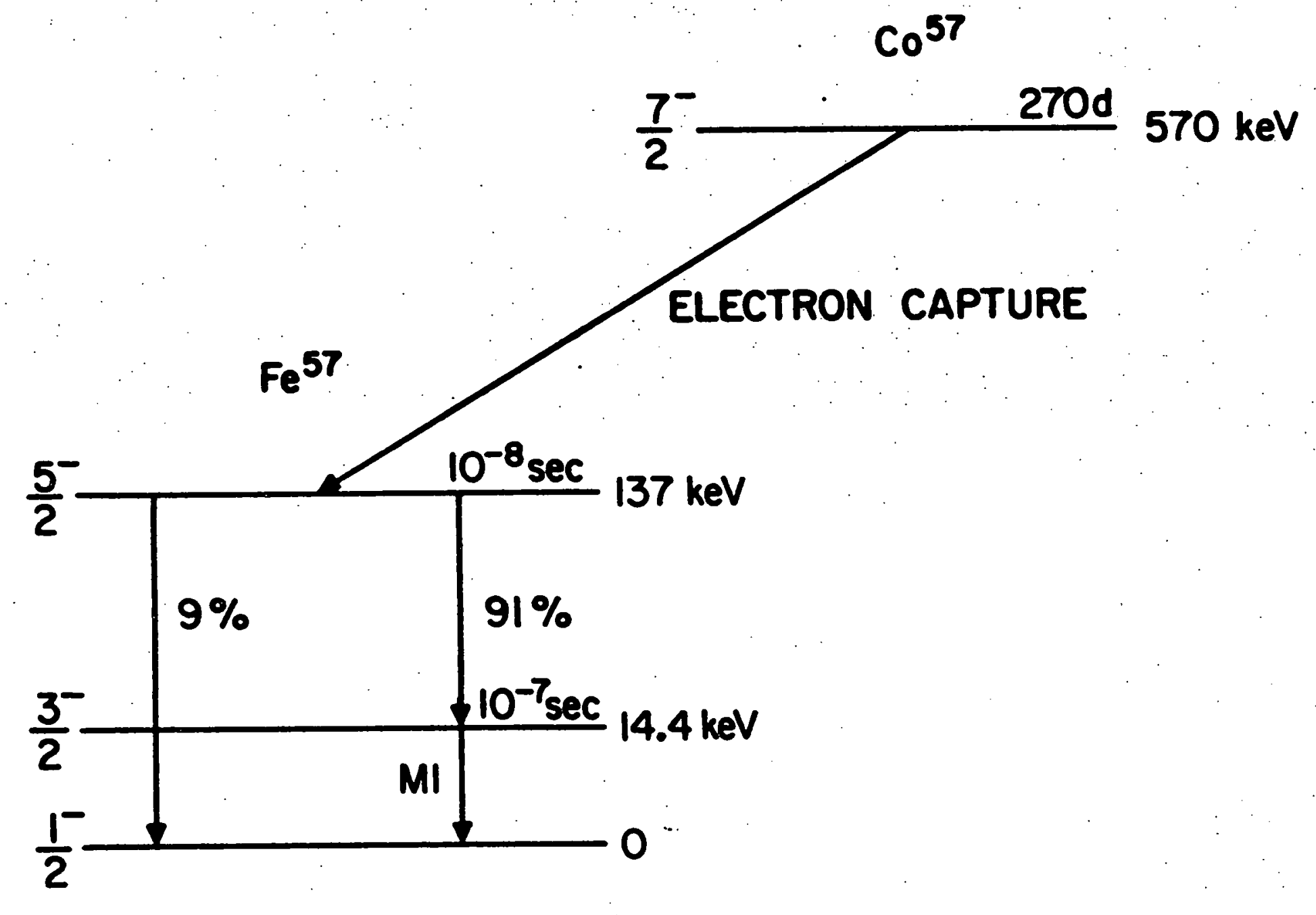

Figure 1. Decay scheme of $\mathrm{Co}^{57}$. 
process, will be detected. In metals this return to electronic equilibrium takes place in a time very short compared to the $10^{-7}$ second half-life of the $14.4 \mathrm{keV}$ gamma ray because of the abundance of conduction electrons. In a dielectric material such as CoO it was not known initially whether this process of capturing electrons would be completed before the Mössbauer observation. Recently Mullen and ok', hereafter referred to as MO, proposed that the stabilization of $\mathrm{Fe}^{3+}$ in hydrated salts is due to the radiolysis of water by Auger electrons, and this point has been amplified by Wertheim. ${ }^{15}$ This Auger related mechanism, of course, would not apply to anhydrous salts . Bhide and Shenoy ${ }^{4-5}$ found similar results in NiO and CoO. They also proposed that the equilibrium fraction of the $\mathrm{Fe}^{3+}$ resonance was connected with the semiconducting properties of these oxides. In 1966, two groups simultaneously proved that an Auger aftereffect was not responsible for the $\mathrm{Fe}^{3+}$ resonance in these oxides. Triftshauser and Crai.g ${ }^{7-8}$ used delayed coincidence techniques to show that no time effects were observed which could not be attributed to the delayed coincidence technique itself. That is, the return to electronic equilibrium following the Auger process was:already completed on the time scale of the Mössbauer observation. They proposed that the appearance of the $\mathrm{Fe}^{3+}$ resonance was a result of the deviation of the samples from ideal stoichiometry, caused by a small amount of cation vacancies. $\mathrm{MO}^{6,11}$ also found no evidence for Auger aftereffects in their studies of $\mathrm{CoO}$ and the hydrates of $\operatorname{CoC}_{2} 2^{\circ}$ MO isolated two forms of nominally stoichiometric $\mathrm{CoO}$, which showed remarkably different physical properties and were referred to as $\mathrm{COO}(\mathrm{I})$ and $\mathrm{COO}(\mathrm{II}) \cdot \mathrm{CoO}$ (I) 
prepared at $1000^{\circ} \mathrm{C}$ had ideal stoichiometry: and density, and showed only the $\mathrm{Fe}^{2+}$ Mössbauer line. $\mathrm{Co}\left(\right.$ II) prepared at $300^{\circ} \mathrm{C}$ had nominal stoichiometry, but a density about $25 \%$ below the theoretical value indicated from the lattice parameter and crystal structure. It was assumed that the $25 \%$ reduction in density could be accounted for by point vacancies of $\mathrm{Co}$ and $0 . \mathrm{COO}$ (II) showed only the $\mathrm{Fe}^{3+}$ resonance, and its $x$-ray diffraction peaks were broader than the ideal high temperature preparation. It was found that the Mössbauer characteristic temperature for the $\mathrm{Fe}^{3+}$ resonance was about half that of the $\mathrm{Fe}^{2+}$ resonance, and $\mathrm{CoO}$ (II) was observed to pickup about $60 \%$ excess oxygen when exposed to air. A sample showing both $\mathrm{Fe}^{2+}$ and $\mathrm{Fe}^{3+}$ resonances was assumed to be a simple mixture of $\operatorname{CoO}($ I) and $\mathrm{CoO}$ (II) below a certain temperature and was designated as $\operatorname{COO}(I, I I)$. The work of MO represented the first attempt to compare Mössbauer data with other physical..and chemical measurements carried out directly on the same samples.

Ando and Kundig ${ }^{9}$, along with Schroeer and Triftshauser ${ }^{12}$, have explained the differences between the high and low temperature preparations of these oxides. as due to particle size effects. Following this: approach Schroeer and Triftshauser postulated that $\mathrm{CoO}$ (II) consisted of microcrystals of average diameter 50-100 . For example, they. postulated that the packing of spheres could result in a density lowering if it were assumed that the liquid used in the density measurement could not get into spaces between the particles. The dramatic oxygen pickup of $\mathrm{CoO}$ (II) would be due to oxygen settling into defect lattice-sites at the surface of the microcrystals, and the $\mathrm{Fe}^{3+}$ 
resonance was caused by a cation vacancy excess which increased as the microcrystal size decreased. Schroeer and Triftshauser attempted to explain the lower Mössbauer characteristic temperature for $\mathrm{CoO}$ (II) as resulting from modifications in the lattice vibrational spectrum due to surface effects and lattice spacing changes. Ando and Kundig ${ }^{9}$ used the silica gel technique for restricting particle size, and they found that a sample of $\mathrm{NiO}$ prepared at $500^{\circ} \mathrm{C}$ of average particle size $100 \AA$ showed only the $\mathrm{Fe}^{3+}$ resonance. They also supported the view that stoichiometric imbalances caused by the small particle size were responsible for the $\mathrm{Fe}^{3+}$ resonance. It was quickly pointed out ${ }^{13}$, however, that there were serious difficulties with the quantitative arguments of Schroeer and Triftshauser.

We will show that the data on the oxides can best be explained as a synthesis of several earlier ideas. ${ }^{14}$ There is converging agreement toward..a model involving both point vacancies and porosity, i。e。, the low temperature forms of $\mathrm{CoO}$ and $\mathrm{NiO}$ contain microscopic or point vacancies (both cation and:anion). and holes or pores resulting from sintered microcrystals. Our discussion will assume that there are significant structural differences in the low and high temperature preparations, and we will.attempt to correlate our observations with this structural model.

The present thesis will deal mainly with the low temperature preparations of $\mathrm{COO}$ and $\mathrm{NiO}$, whose structure has been a subject of recent controversy ${ }^{4-14}$. $\mathrm{MO}^{11}$ have carefully studied the high temperature preparations of $\mathrm{CoO}$, and $\mathrm{Siegwarth}^{10}$ has studied the high temperature preparations of NiO. We will use our earlier notation, i.e., 
$\mathrm{CoO}(\mathrm{I})$ and $\mathrm{NiO}(\mathrm{I})$ will designate high temperature preparations, showing only the $\mathrm{Fe}^{2+}$ resonance, and $\mathrm{CoO}(\mathrm{II})$ and $\mathrm{NiO}$ (II) will designate pure and nominally stoichiometric low temperature preparations, exhibiting only the $\mathrm{Fe}^{3+}$ resonance. $\mathrm{CoO}(\mathrm{I}, \mathrm{II})$ and $\mathrm{NiO}(\mathrm{I}, \mathrm{II})$ will denote samples showing both $\mathrm{Fe}^{2+}$ and $\mathrm{Fe}^{3+}$ resonance. The original basis of this notation is the radical empirical differences found for the high and low temperature preparations. Although it was first thought that CoO(II) might be a different phase than $\mathrm{CoO}(\mathrm{I})$, subsequent evidence has not supported this view. There is a conceptual basis, however, for differentiating forms $\mathrm{I}$ and II as follows: COO(II) and $\mathrm{NiO}$ (II) appear to represent a saturated non-equilibrium density of Schottky defects in these oxides, accompanied by significant porosity, in contrast to the nearly perfect translational symmetry of $\mathrm{CoO}(\mathrm{I})$ or $\mathrm{NiO}(\mathrm{I})$. Attempts to increase the Schottky defect density beyond the values indicated for $\mathrm{CoO}$ (II) or $\mathrm{NiO}$ (II), from either carbonate or nitrate preparations, did not yield pure stoichiometric oxides, but resulted in nonstoichiometric materials with large-amounts of the nitrate and carbonate radicals as impurities. The quantities of these impurities is sufficiently great in typical cases that we will refer to them as $\mathrm{NiO}^{*}$ and $\mathrm{CoO}^{*}$, where the asterisk indicates that these are not pure-stoichiometric materials. We will show that the main features of the original MO model are still indicated in that Schottky defects are the main cause of the observed differences between high and low temperature forms. The charge stabilization of the $\mathrm{Fe}^{3+}$ ion by electron trapping at negative ion vacancies originally proposed by $M O$ is consistent with the present data, and we do not require an explanation 
based on stoichiometric variations. We will show that porosity, neglected in the original model of MO, is necessary for: a satisfactory description of the present data. Also, we will show that the observed increase in intensity of the $\mathrm{Fe}^{3+}$ resonance in $\mathrm{CoO}(\mathrm{I}, \mathrm{II})$ or $\mathrm{NiO}(\mathrm{I}, \mathrm{II})$ with temperature does not require a dispersal of oxygen vacancies as first suggested by $\mathrm{MO}^{11}$.

Following up earlier work on $\mathrm{C}_{0} 0^{6,11,14}$, we have applied simultaneous Mössbauer, $\mathrm{x}$-ray, and chemical methods to $\mathrm{NiO}$, and we have extended the earlier measurements on co0. In particular we have performed gas adsorption measurements which were valuable in estimating porosity effects. We have also extended the measurements with applied magnetic fields and have studied superparamagnetism in these materials. We attempted to make direct measurements of particle size effects by preparing samples with the silica gel technique.

One of the most fruit ful and interesting new techniques of investigating these oxides has involved the substitutional doping of cations of $1+$ and $3+$ valence, especially $\mathrm{Li}^{1+}$, in the oxides. Significant changes in the ratio of the $\mathrm{Fe}^{3+}$ to $\mathrm{Fe}^{2+}$ resonance have been observed, as a result of doping, which are discussed from the-semiconducting model of these materials. By comparing the Néel temperatures of doped and undoped samples, an estimate of the ratio of porosity to point defects in these oxides has been made. By comparing the Mo̊ssbauer characteristic temperatures of resonances in doped and undoped samples, confirmation of the structural differences of high and low temperature forms has been made. The doping experiments have also shed light on the unusual behavior of the $\mathrm{Fe}^{3+}$ resonance in mixed 
forms $\mathrm{CoO}(\mathrm{I}, \mathrm{II})$; and $\mathrm{NiO}(\mathrm{I}, \mathrm{II})$. A practical application of $\mathrm{Li}^{1+}$ doping in $\mathrm{Co} 0$ has been the preparation of a compact single-1ine source. 


\section{A. Recoil-free Fraction}

The probability that the nucleus will emit or absorb a gama ray without a change in the phonon states of the crystal is known as the recoil-free fraction $f$. Using the quantum mechanical formalism of the interaction of radiation with matter, the quantity $f$ can be shown ${ }^{16}$ to be given by

$$
\mathrm{f}=\left|\left\langle\mathrm{n}\left|\mathrm{e}^{\dot{i \vec{u} \cdot \vec{r}}}\right| \mathrm{n}\right\rangle\right|^{2},
$$

where $|n\rangle$ is an eigenstate of the lattice (which is unchanged in the emission process), $\vec{r}$ is the displacement vector of the nuclear motion, and $\vec{x}$ is the momentum vector of the gamma ray divided by $\vec{n}$. If the interatomic forces of the solid are harmonic, the matrix element may be simplified to give

$$
f=\exp \left(-x^{2}\left\langle u^{2}\right\rangle\right)
$$

where $u$ is the displacement of the atom in the direction of emission of the gamma ray. The standard practice is to regard the crystal as : a Debye solid with a characteristic Mössbauer temperature, $\theta_{m}$, analogous to the Debye temperature, $\theta$, determined from specific heat theory. The Debye model is strictly applicable only to monatomic lattices with a Debye phonon spectrum, but this method has proved to be useful in characterizing the recoil-free fraction $f$, even for 
impurities in complex host lattices. It should be noted that $\theta_{\mathrm{m}}$ and $\theta$ may have different values if the binding of the Mössbauer ion is quite different from the host ions. Using this Debye approximation the value of $\mathrm{f}$ becomes

$$
f=\exp \left[\frac{-3 R}{2 k \theta_{m}}\left(1+4 \frac{T^{2}}{\theta_{m}^{2}} \int_{0}^{\theta_{m} / T} \frac{x d x}{e^{x}-1}\right)\right],
$$

where $R$ is the recoil energy, $k$ is the Boltzmann ${ }^{\hat{y}}$ constant, and $T$ is the absolute temperature. For values of $\mathrm{T}$ such that $\mathrm{T}<\theta_{\mathrm{m}} / 2$, the integral may be approximated by its limiting value as $\mathrm{T} \rightarrow 0$,

$$
\int_{0}^{\infty} \frac{x d x}{e^{x}-1}=\frac{\pi^{2}}{6}
$$

giving

$$
f=\exp \left[\frac{-3 R}{2 k \theta_{m}}\left(1+\frac{2 \pi^{2} T^{2}}{3 \theta_{m}^{2}}\right)\right]
$$

Since the area under the Mössbauer absorption spectrum is proportional 17 to $f$, it is common practice to plot $\ln A$ versus $\mathrm{T}^{2}$ using the following relation

$$
\ln \mathrm{A}=\mathrm{C}+\mathrm{BT}^{2}
$$

where $B$ and $C$ are constants and $B$ gives $\theta_{m}$ through the relation

$$
\mathrm{B}=\frac{-\mathrm{R}_{\pi}^{2}}{\mathrm{k} \theta_{\mathrm{m}}{ }^{3}}
$$

Thus, the slope of the curve obtained will yield the value of $\theta_{m}$. A more accurate method which is applicable for all values of $\mathrm{T}$ is to 
calculate the integral

$$
\int_{0}^{\theta_{m} / x} \frac{x d x}{e^{x}-1}
$$

numerically by computer. In the present work a computer program was used which found the best value of $\theta_{m}$ from the data points of area versus temperature, calculating the exact value of the integral when needed.

\section{B. Magnetic Hyperfine Interaction}

A magnetic field at the nucleus interacts with the magnetic dipole moment of both the ground and excited states, and the interaction is described by the following Hamiltonians:

$$
F_{e}=-g_{I} \cdot \mu_{N} \cdot \vec{H} \cdot \vec{I} \text {, and } F_{g}=-g_{0} \mu_{N} \vec{H} \cdot \vec{I} \text {, }
$$

where $g_{0}$ and $g_{1}$ are the nuclear gyromagnetic ratios of the ground and excited states respectively, $\mu_{\mathrm{N}}$ is the nuclear Bohr magneton, $\vec{I}$ is the nuclear spin, and $\vec{H}$ is the magnetic field at the nucleus. The eigenvalues of this type of Hamiltonian are:

$$
\mathrm{E}_{\mathrm{m}}=-\mathrm{g} \mathrm{H}_{\mathrm{N}} \mathrm{mH} \text {, }
$$

where $\mathrm{m}$ is the magnetic quantum number. In the case of $\mathrm{Fe}^{57}$ the excited state is split into four states, and the ground state is split into two states. Of the eight possible transitions between the excited and ground state levels two are forbidden by the selection rule for magnetic dipole transitions, $(\Delta m= \pm 1,0)$. Once the line positions 
and therefore the relative energies of the six lines of a magnetic hyperfine spectrum have been measured, the value of $\mathrm{H}$ can readily be determined by a best fit of the data. The value of the gyromagnetic ratio of the ground state of $\mathrm{Fe}^{57}$ is known from nuclear magnetic resonance experiments. 18

\section{Superparamagnetism}

If the average particle size of a powder sample becomes small enough (roughly of the order of $100 \AA$ ) the thermal energy of the particle can play.a significant role in its magnetic behavior, because the spin orientation in:a small particle can change due to thermal relaxation $^{19,20}$. Néel derived the condition under which an assembly of such particles would come to thermal equilibrium in a given time, and the relaxation time for this process is:

$$
\tau=\frac{1}{f_{0}} e^{K V / k T}
$$

where the frequency factor, $f_{0}$, is of the order of $10^{9} \mathrm{sec}^{-1} \cdot \mathrm{K}$ is the anisotrophy energy per unit volume depending upon such things : as the external shape and imposed stresses of the particle, and it is assumed that each particle is.a single domain with two anti-parallel easy directions. The source of the exponential arises from a simple statistical argument of the type used in reaction rate theory, where in the present case the energy barrier is. KV . If the superparamagnetic relaxation time is long compared to the Larmor precession time, $T_{\mathrm{L}}$, of the first excited state of the $\mathrm{Fe}^{57}$, a six-line magnetic hyperfine pattern will be observed below the Néel temperature. If $T$ and 
$\tau_{\mathrm{L}}$ are comparable-a partial collapse of the magnetic hyperfine pattern will be-observed, and:as: $T$ becomes less than $\tau_{L}$ the pattern will be converted to a broadened single line.

- An applied external magnetic field will increase the superparamagnetic relaxation time. This is because fine particles, even though antiferromagnetic, have permanent magnetic moments, which are generally parallel to the alignment of the antiferromagnetic spin system and which result froman imperfect compensation of the magnetic sublattices. Such moments depend on the lack of structural perfection and on the surface form of the particle, and the moment will be larger as the particle size decreases. If the strengths of the six-line pattern and the unresolved broad single line are comparable, the application of an external magnetic field would be expected to convert some of the broad pattern into the resolved pattern for particles which:are sufficiently sma 11 .

It has been estimated ${ }^{14}$ that the energy of the magnetic moments of $\mathrm{CoO}$ or NiO microcrystals of order $50 \AA$, in an external field $\mathrm{H}_{\mathrm{o}}$ of order $50 \mathrm{kG}$, is the same order of magnitude as the thermal energy $\mathrm{kT}$ at $100-300^{\circ} \mathrm{K}$. This is the condition which must be satisfied if a large change in the relaxation time of microcrystals in an external field is to be seen.

\section{Néel Temperature}

Née1 developed the theory of antiferromagnetism treating the case in which the exchange interaction is negative instead of positive. ${ }^{21}$ Néel's theory, a generalization of the Weiss molecular field theory, 
predicted a completely ordered spin arrangement at absolute zero, with two spontaneously magnetized equivalent sublattices. The directions of the ordered spins in the two sublattices are anti-parallel to each other. As the temperature is raised, the spontaneous magnetization decreases and goes to zero at a transition temperature usually called the Néel temperature, $\mathrm{T}_{\mathrm{N}}$. A simple two-sublattice model predicts that $\theta_{\mathrm{p}} / \mathrm{T}_{\mathrm{N}}=-1$, where $\theta_{\mathrm{p}}$ is the paramagnetic Néel temperature used in the Curie-Weiss 1aw; but this two-sublattice model fails for compounds such as NiO or Co0, which have face-centered cubic lattice arrangements. For the fcc arrangement two nearest neighbors of a given atom can themselves be nearest neighbors. The simple two-sublattice mode1 also fails for $\mathrm{CoO}$ and $\mathrm{NiO}$, because it does not consider second and more distant neighbor exchange interactions. The difference between the paramagnetic Néel temperature, $\theta_{p}$, and the Néel temperature, $T_{N}$, can be quite large.

There has been some controversy over the actual arrangement of spins in antiferromagnetic $\mathrm{COO}$, as has been recently discussed by Khan and Erickson. 22 In what follows, the assumption of a single spin axis, as opposed to multispin axes, will be made. We will assume the simpler model for purposes of investigating the possible effect of impurities and cation vacancies on the Néel temperature. The basic conclusion should not be changed by the complication of a possible multispin structure.

Following an analysis by Smart, ${ }^{21}$ using the generalized molecular. field theory approach, the Néel temperature can be written as

$$
T_{N_{s}}=\frac{c}{n} \sum_{j=1}^{n} n_{i j} \gamma_{i j} \text {, }
$$


where $i$ and $j$ refer to spin sublattices, and where $n_{i j}=0$ or \pm 1 reflects the relative spin arrangements between the $i$ and $j$ sublatticeso The value of $Y_{i j}$ is

$$
\gamma_{i j}=C^{\prime} z_{i j} J_{i j}
$$

and $C$ and $C^{\prime}$ are constants. The value of $\gamma_{i j}$, the molecular field coefficient for the field exerted on an atom of the $i$ sublattice by its neighbors in the $j$ sublattice, is thus proportional to $z_{i j}$, the number of $j$ neighbors of an $i$ atom, and the exchange interaction between and $i$ atom and one of its $j$ neighbors, $J_{i j}$. The number of sublattices is $\mathrm{n}$, and the subscript $\mathrm{s}$ in the term $\mathrm{T}_{\mathrm{N}_{\mathrm{S}}}$ is:an index which labels which of the transition temperatures, corresponding to the different types of possible antiferromagnetic ordering, is being discussed. Some of the types are usually translationally degenerate. The solutions of $\mathrm{T}_{\mathrm{N}_{\mathrm{S}}}$ for the face-centered cubic lattice correspond to three values of the Néel temperature, because there are three possible types of antiferromagnetic ordering for this lattice arrangement. The three solutions may be written as follows:

$$
\begin{aligned}
& \mathrm{T}_{\mathrm{N}_{1}}=\mathrm{C}^{\prime \prime}\left(-\frac{1}{3} \cdot \gamma_{1}+\gamma_{2}\right) \\
& \mathrm{T}_{\mathrm{N}_{2}}=-\mathrm{c}^{\prime \prime} \gamma_{2} \\
& \mathrm{~T}_{\mathrm{N}_{3}}=\frac{1}{3} C^{\prime \prime}\left(-\gamma_{1}+\gamma_{2}\right),
\end{aligned}
$$

where $\gamma_{1}$ denotes the molecular field coefficient for the 12 nearest neighbors, $\gamma_{2}$ denotes the molecular field coefficient for the $6 \cdot$ second 
nearest neighbors, and $C^{\prime \prime}$ is. a constant. The type of ordering predicted from theory and also experimentally observed for $\mathrm{NiO}$ and $\mathrm{CoO}$ is of the second type. This second type corresponds to a magnetic structure in which there are four independent antiferromagnetic simple cubic lattices, where each cation has six anti-paralle1 second nearest neighbors and is completely uncorrelated with its nearest neighbors. For the uniaxial model assumed, a set of planes perpendicular to a cube diagonal are ferromagnetically ordered, with the spin direction of adjacent planes being anti-parallel.

Therefore, the value of $\mathrm{T}_{\mathrm{N}}$ for $\mathrm{NiO}$-and $\mathrm{CoO}$ is

$$
\mathrm{T}_{\mathrm{N}}=\mathrm{C}_{1} \cdot \mathrm{z}_{2} \cdot \mathrm{J}_{2}
$$

where $z_{2}$ is the number of second nearest neighbors, $J_{2}$ is the exchange interaction between second nearest neighbors, and $C_{1}$ is a constant. It is reasonable to expect, therefore, that if $1 \%$ of the nickel or cobalt atoms in an oxide sample are randomly replaced by a substitutional dopant such as lithium, the value of $\mathrm{T}_{\mathrm{N}}$ will be lowered by approximately $1 \%$. An average performed over $z_{2}$, the number of second nearest neighbors, will be less than the normal value by $1 \%$. This has been experimenta11y observed for $1 \%$ dopings of $\mathrm{Li}$ in both $\mathrm{CoO}$ and $\mathrm{NiO}$, as will be discussed in section V-E. Therefore, this derivation based on a single spin axis model confirms the plausibility of the experimental results for lithium doped samples. Nickel or cobalt vacancies would also be expected to lower the Néel temperature in a similar manner, as long as the number of these point defects is small compared 
to the number of cobalt or nickel ions. This latter condition is only. roughly satisfied in $\mathrm{C} O \mathrm{O}$ (II) and NiO(II), as will be shown later. 


\section{EXPERTMENTAL TECHNIQUES}

\section{A. Mössbauer Spectrometry}

The majority of the data were taken with a mechanical velocity spectrometer which produced.a crank motion at the absorber. 23 A schematic drawing of the mechanical system and the accompanying electronics is shown in Fig. 2. This type of spectrometer is:a rapid scan device in that it repetitively scans through the entire range of velocities in a time interval ( $1 \mathrm{sec})$ short compared to typical electronic drifts. A synchronous motor and a 100:1 gear reducer, mounted on a separate table to avoid vibration, provided power for the crank assembly through a Tilton elastic belt. Various pulleys, which were concentric to 0.0002 inch, were attached to the motor system output and to the crank assembly to give various velocity limits. Large flywheels were connected to the motor output and crank assembly to insure a uniform rate of rotation, which was experimentally verified to within $\pm 0.5 \%$, as measured with a photodiode gating circuit. The absorber was :attached to the reciprocating shaft driven by the crank arm connected to the flywheel. The flywheel turned with:a constant angular speed $\omega_{\text {, }}$ and the velocity of the absorber as.a function of could be calculated from the geometrical constants of the crank assembly, a and b. While the absorber moved back and forth through a range of velocities, the $14.4 \mathrm{keV}$ gamma rays transmitted through the absorber were analyzed by a gas-filled proportional tube, 


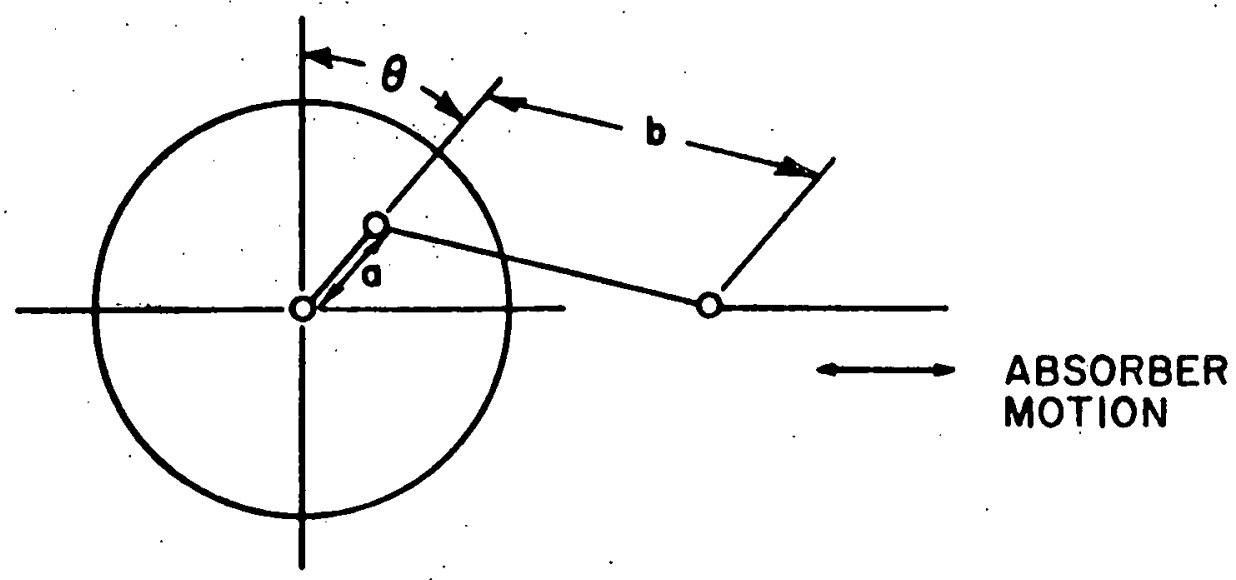

FLYWHEEL CRANK MOTION

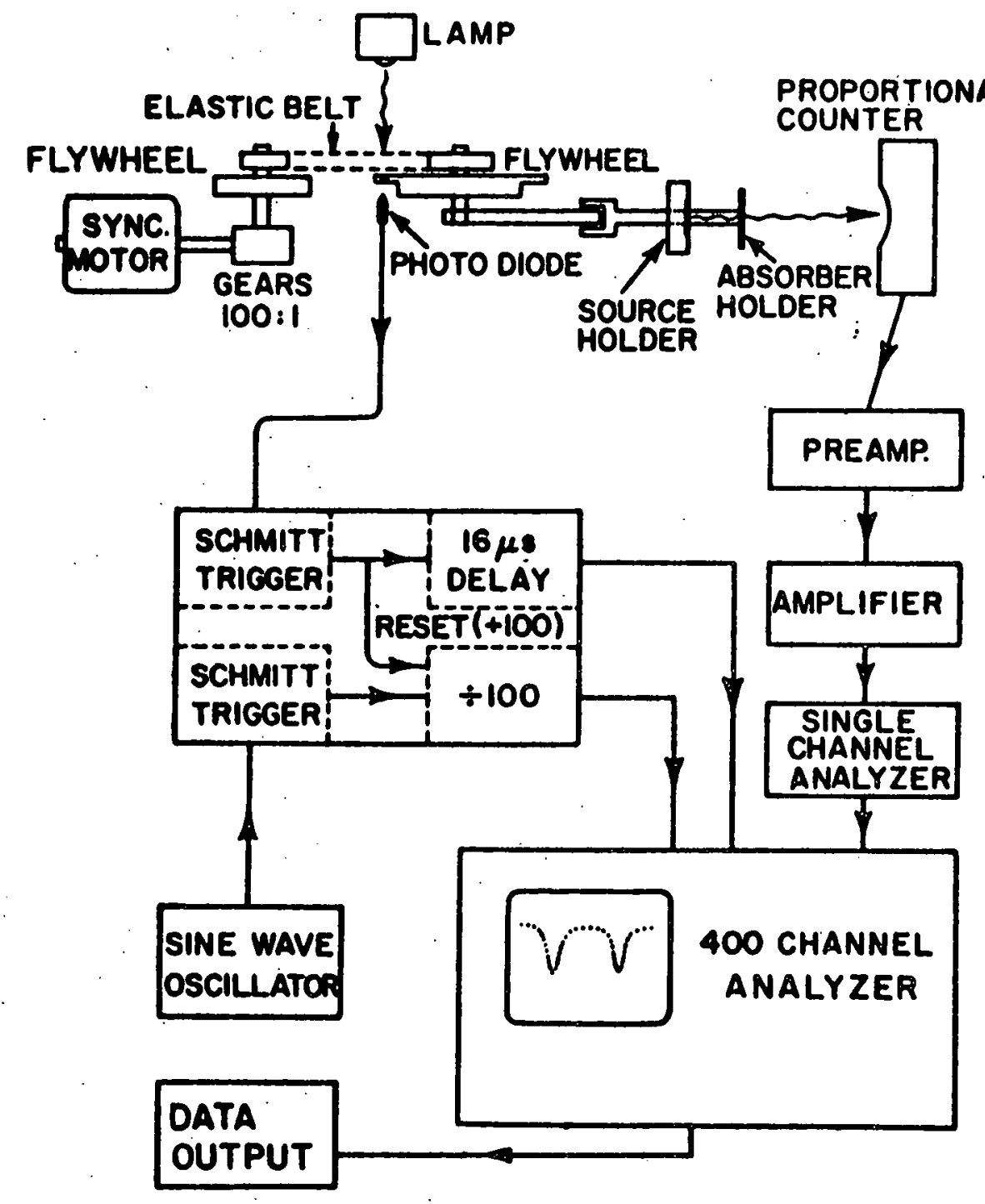

Figure 2. Schematic diagram of Mössbauer spectrometer. 
preamplifier; amplifier, and a single channel analyzer. The gamma rays were counted and stored in a 400 channel RIDL multichannel analyzer operated in the multichannel scaler mode. The sine wave output of an independent oscillator was converted by a Schmitt trigger and two decade scalers into approximately 200 evenly spaced pulses per crank revolution which advanced the channel address. Each channel of the analyzer therefore represented the count rate at a certain velocity of the absorber. The multichannel analyzer was reset synchronously with the reciprocating motion by a pulse from a photodiode, and synchronism in the reset was kept to within 0.01 channel by operating the sine wave oscillator at 100 times the channel - stepping frequency. A sma11. phase angle parameter was determined which gave the best overlap of the mirror image spectra stored in the analyzer. The frequency of crank rotation and of the channel stepping oscillator were measured by counting the pulses in:a timer-scaler unit. The output of the analyzer could be converted, therefore, into a record of gamma ray transmission through the absorber as a function of absorber velocity. A very smal1 amount of data was taken with an automated constant velocity spectrometer. 24 This spectrometer had..a unique feature which:allowed a selection of velocities with a programmed paper tape. This type of spectrometer has the advantage that a spectrum can be taken with fewer points and in the region of interest only.

The temperature of the source could be varied with a dewar-heater arrangement. For low temperatures the source was attached to a copper block on the bottom of the dewar filled with a coolant. An insert in the copper block, for a Watlow heater rod, made it possible to warm 
the block relative to the coolant temperature. By using the Wat low heater without a coolant, temperatures above room temperature could be maintained. A temperature contro11er, manufactured by the BarberColman Company, was used for controlling temperature within $\pm 1^{\circ} \mathrm{C}$. Temperature measurement was made with calibrated thermocouples.

For experiments involving sources, narrow unsplit sodium ferrocyanide absorbers $\left(\mathrm{Na}_{4} \mathrm{Fe}(\mathrm{CN})_{6}{ }^{\prime} 10 \mathrm{H}_{2} \mathrm{O}\right)$ of various effective thicknesses were used $\left(0.1,0.25,0.75\right.$, and $1.0 \mathrm{mg} / \mathrm{cm}^{2} \mathrm{Fe}^{57}$ concentration), purchased from New England Nuclear Corporation. The standard absorbers were kept at room temperature while the temperature of the source was varied. For experiments involving the preparation of a $\mathrm{Fe}^{57}$ doped $\mathrm{NiO}$ or CoO absorber, standard unsplit sources with a Pd or Cu host matrix were used.

\section{B. Sample Preparation}

Cobaltous: oxide and nickelous oxide are frequently prepared by heating the various salts of cobalt and nickel, such as the carbonate or nitrate, to temperatures above $250^{\circ} \mathrm{C}$ in various : atmospheres. They can also be prepared by heating the metal in an oxidizing atmosphere such as oxygen or carbon dioxide 25,26 . In genera1, the properties of the oxide formed appear to be influenced more by the annealing temperature and atmosphere than the choice of starting materials. MO prepared CoO.(II) by decompos.ing $\mathrm{CoCO}_{3}$ in vacuum at $300^{\circ} \mathrm{C}$ or by reducing a higher oxide, formed from a nitrate, in hydrogen at even lower temperatures. $\operatorname{CoO}(\mathrm{I})$ was prepared by oxidizing co metal in a carbon dioxide atmosphere at $1000^{\circ} \mathrm{C}$ in a sealed quartz tube, and $\mathrm{CoO}$ (I, II) 
was prepared by heating cobalt metal or cobaltous nitrate in air at $1000^{\circ} \mathrm{C}$. The high temperature samples were quenched in an inert atmosphere from $1000^{\circ} \mathrm{C}$ to $0^{\circ} \mathrm{C}$ to $77^{\circ} \mathrm{K}$. The samples of cobaltous oxide needed in this investigation were prepared using the methods of MO. We attempted to prepare $\mathrm{NiO}$ (II) by heating nickelous nitrate in various :atmospheres. at temperatures from $250^{\circ} \mathrm{C}$ to $400^{\circ} \mathrm{C}$. Some experiments were carried out on samples prepared around $300^{\circ} \mathrm{C}$ in vacuum, and more extensive experiments were carried out on samples prepared at $400^{\circ} \mathrm{C}$ in argen. The starting material of $99.999 \%$ pure nickel metal was dissolved in: nitric acid, and carrier free, radioactive $\mathrm{Co}^{57}$ was added to the solution in the form of $\operatorname{Cocl}_{2}$. The solution was dried on a hotplate and then:annealed in a horizontal glass tube in the desired atmosphere. After losing the water of hydration, the nitrate decomposes:as follows:

$$
2 \mathrm{Ni}\left(\mathrm{NO}_{3}\right)_{2} \longrightarrow 2 \mathrm{NiO}+4 \mathrm{NO}_{2}+\mathrm{O}_{2}
$$

The horizontal glass tube was placed inside. a cylindrical piece of inconel in the furnace in order to reduce thermal gradients, as shown in Fig. 3. A vacuum pump, a mercury manometer, and gas tanks were used as necessary to maintain the atmosphere used in the sample preparation. The samples were kept in an inert atmosphere, such as argon, using a glove box and sealed sample holders until it was determined that the low temperature preparations of nickelous oxide did not pickup oxygen as did the low temperature cobaltous oxide samples. Only those samples annealed at $400^{\circ} \mathrm{C}$ for several hours (5 to 10 ) yielded the pure stoichiometric $\mathrm{NiO}(\mathrm{II})$. Those annealed at $300^{\circ} \mathrm{C}$ generally 


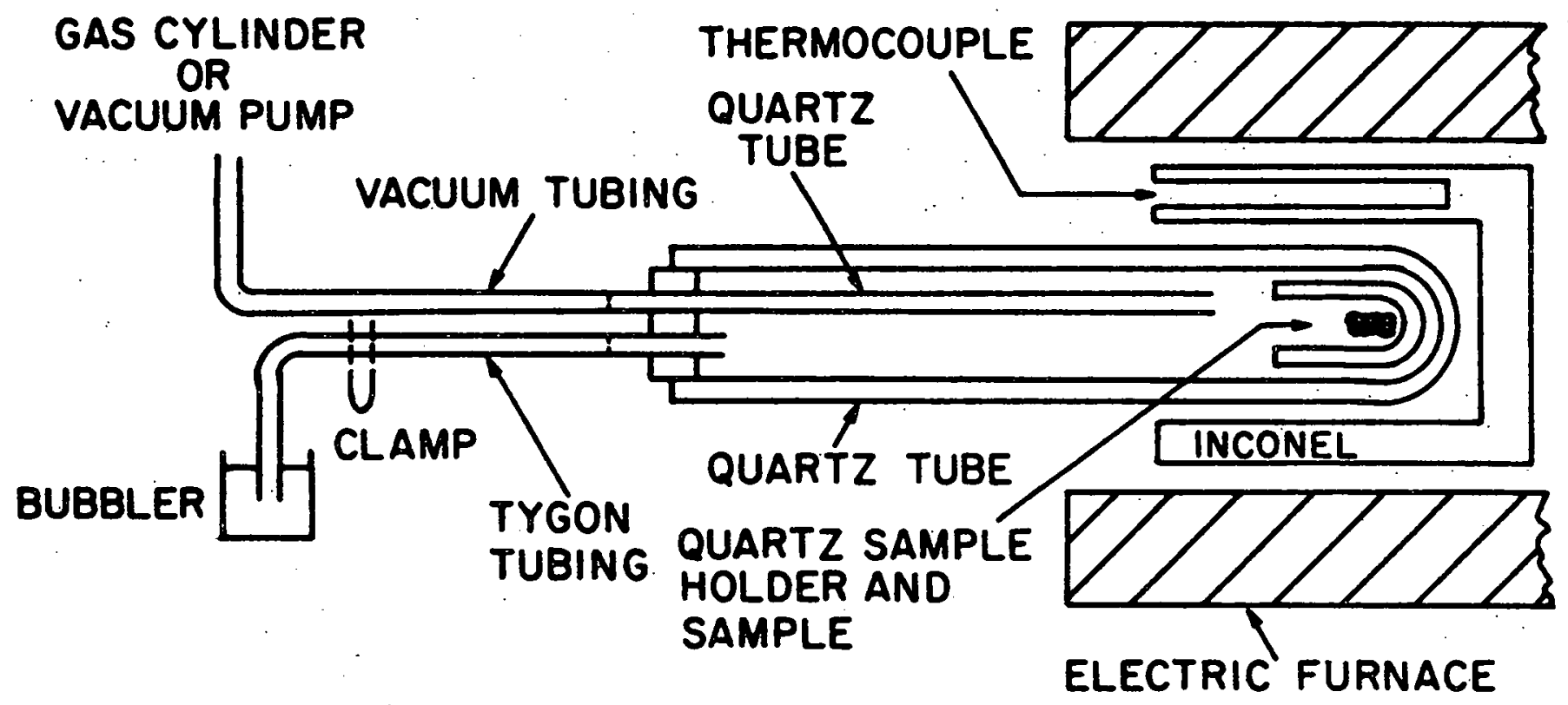

Figure 3. Schematic diagram of sample prieparation. 
gave considerable deviation from stoichiometry and were found to contain appreciable nitrate impurity. These latter impure specimens are referred to as $\mathrm{NiO}^{*}$ and are discussed in greater detail in section IV. For samples containing dopants of other cations, the dopant was :added in the form of its nitrate to the initial solution of nickelous or cobaltous nitrate. This insured that the dopant was initially dispersed before the annealing process. To avoid the added complications found for low temperature preparations, all of the doped samples were prepared at elevated temperatures similar to form I preparations. The small amounts of dopants added necessitated careful weighing on a Mettler semimicro balance, and often a larger amount of the nitrate of the dopant was diluted with water and an appropriate aliquot taken. Otherwise the doped samples were prepared in an identical manner to the undoped form I samples. Mössbauer spectra of the doped samples indicated that the dopants dispersed into the CoO and NiO lattices, and other investigators 27-29 have indicated that the dopants occupy substitutional sites randomly dispersed within the host lattice without affecting the crystal structure. X-ray diffraction patterns of doped and undoped samples were the same within experimental errors.

\section{X-ray Technique}

The $x$-ray diffraction patterns of various samples were made on a powder diffractometer made by the North American Philips Company Either Mo $\mathrm{K} \alpha$ radiation $\left(\mathrm{K} \alpha_{1}=0.70926 \AA\right.$ and $\left.\mathrm{K} \alpha_{2}=0.71354 \AA\right)$. or $\mathrm{Cu} \mathrm{K} \alpha$ radiation $\left(K \alpha_{1}=1.540 .50\right.$ and $\left.K \alpha_{2}=1.54434 \AA\right)$ was used to yield the Bragg peaks.. The Mo tube was used with a zirconium filter which 
absorbed about $96 \%$ of the $\mathrm{K}_{\beta} 1$ ine $\mathrm{s}^{30}$, and the Cu tube was used with a nicke1 filter to absorb:about $98 \%$ of the $\mathrm{K} \beta$ line. The operating voltage-and current of the Mo tube were set at $40 \mathrm{kV}$ and $15 \mathrm{~mA}$, and the $\mathrm{Cu}$ tube was run at $35 \mathrm{kV}$ and $15 \mathrm{~mA}$. The NiO samples could be examined with either tube, but the Co0 samples could not be measured with the copper tube because the $\mathrm{Cu} \mathrm{K}_{\alpha}$ radiation will excite the fluorescence lines of the $K$ series of cobalt. ${ }^{31}$ A Geiger counter and chart drive were used to record the Bragg peaks:and the diffractometer had provisions for using various scanning speeds and beam slits. The electronics of the Geiger tube circuit allowed a selection of time averaging to smooth out the counting current. Plexiglass specimen holders constrained the sample to a disk of diameter $10 \mathrm{~mm}$ and a thickness of $1 \mathrm{~mm}$, which was greater than the minimum thickness required for maximum diffracted intensity. 30

\section{Gas Pickup and Surface Area Measurements}

The holder used in the gas pickup and surface area measurements is shown in Fig. 4. The volume of the container was approximately $25 \mathrm{~cm}^{3}$, and the weight of the entire holder was:approximately $40 \mathrm{~g}$. The holder weight was kept down by using aluminum in the bottom so that with $10 \mathrm{~g}$ of the sample the total weight was small enough to be measured on the Mettler semimicro balance. The holder could be sealed by placing a wire clip on the tygon tubing at the top of the holder, and a piece of rubber maintained the seal between the top and bottom. Since the container could be evacuated or filled with a gas through the tygon tubing on the top without transfer to a glove box, the process 

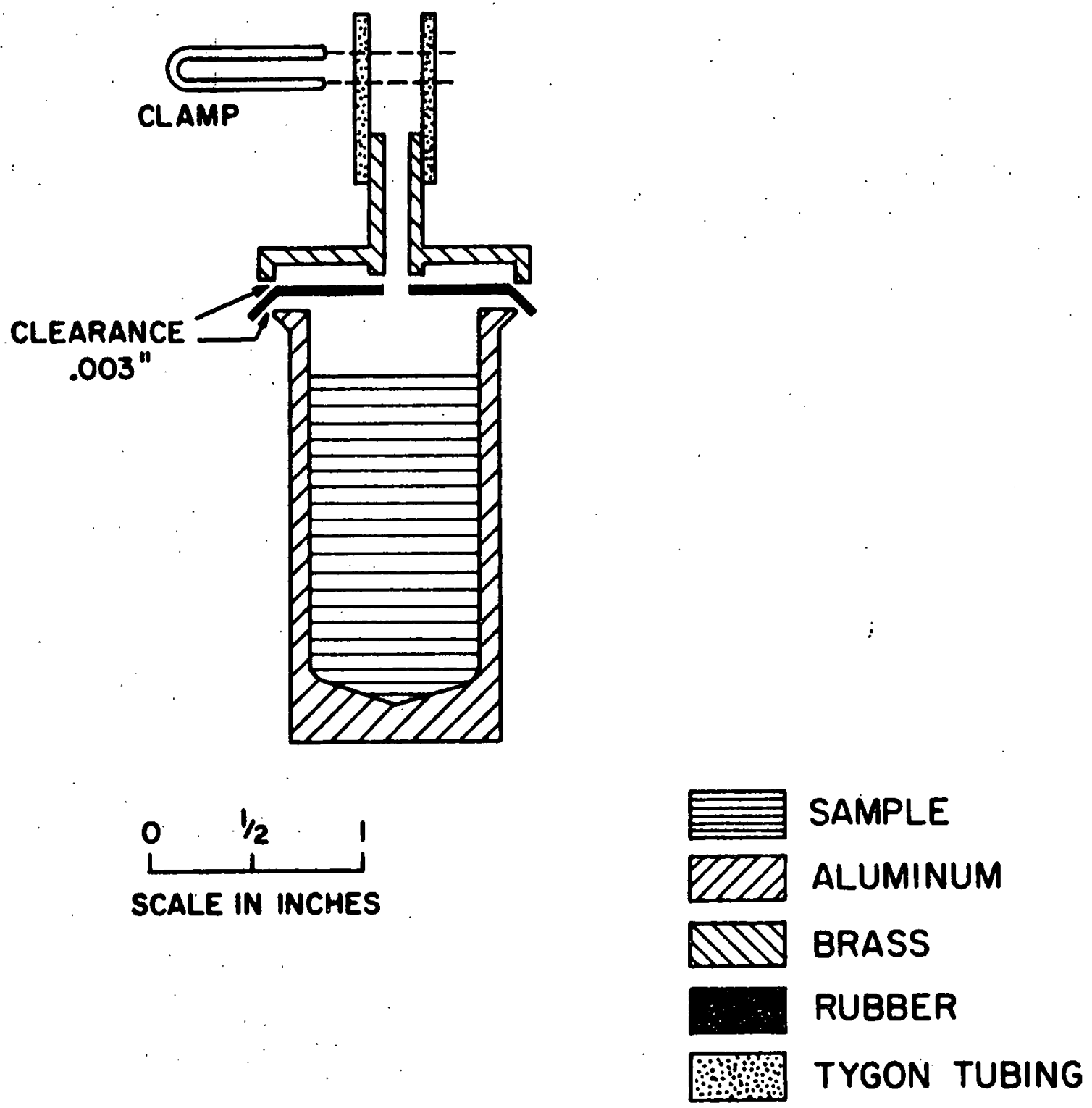

Figure 4. Holder for gas pickup and surface area measurements. 
of weighing the sample in various atmospheres could be performed within a few minutes. It was experimentally verified that the vacuum:seal of the holder was : adequate by observing the weight of the evacuated holder over:a period of ten minutes. During the processes of filling and transfer to the balance, the holder was handled with plastic gloves to give the accuracy needed in weighing.

\section{E. Particle Size and Superparamagnetism Studies}

In $: a$ few experiments : an external magnetic field $\mathrm{H}_{\mathrm{O}}$ was :applied to a source. This external magnetic field was produced by a superconducting. magnet designed by the Eastern Scientific Company with a dewar made by Janis Company. The direction of the field was along:a horizonta 1 axis, and the absorber was moved along this same axis. The superconducting magnet was capable of fields up to about $55 \mathrm{kG}$, and it had been calibrated with a rotating coil gaussmeter. The dewar, whose hold time was 6-8 hours, had provisions for mounting the source on the helium jacket, the nitrogen jacket, or on the outside at room temperature. In order to restrict the particle size of one sample used in the magnetic studies, the preparation was carried out in silica gel which had been supplied by the W. R. Grace Company. The particular grade used, No.: 59, had an average pore diameter of $140 \AA$ and was $99.5 \%$ $\mathrm{SiO}_{2}$ with a small amount of impurities, mainly $\mathrm{Al}_{2} \mathrm{O}_{3} \cdot$ The silica gel was heated initially to remove water vapor and then allowed to pickup by capillary action the solution of nickelous nitrate into its pores. The resultant heating of the sample at $600^{\circ} \mathrm{C}$ produced $\mathrm{NiO}$ with an upper bound on the average particle size of $140 \AA$. 


\section{X-RAY AND CHEMICAL MEASUREMENTS}

\section{A. Stoichiometry}

The stoichiometries of the cobaltous: and nickelous oxide samples were determined by a direct gravimetric measurement. Samples were weighed, reduced to metallic form by heating in hydrogen at $500^{\circ} \mathrm{C}$, and then weighed again. MO showed that $\operatorname{CoO}(\mathrm{I}), \operatorname{CoO}(\mathrm{II})$, and $\operatorname{CoO}(\mathrm{I}, \mathrm{II})$ were ail nominally stoichiometric, and the results of measurements on the nickelous oxide system are shown in Table 1. The two low temperature preparations for NiO listed were checked independently for undecomposed nitrate, which was being sought as a possible contaminant from the starting material of nickel nitrate. A typical sample of the first preparation 1 isted (prepared at $300^{\circ} \mathrm{C}$ ) having an indicated stoichiometry of $\mathrm{NiO}_{1.4}$ was:analyzed for nitrate in a microanalys is laboratory in the chemistry department of Purdue University. The result of this analysis indicated that about half of the indicated excess stoichiometry was due to undecomposed nitrate, and therefore the stoichiometry of the sample would be $\mathrm{NiO}_{1.22} \pm .05$ if the nitrate were accounted for. A typical sample of the second preparation 1 isted (prepared at $400^{\circ} \mathrm{C}$ ) was sent to the Schwarzkopf Microanalytical Laboratory in Woodside, New York, which was equipped to test for smaller quantities of nitrate. The result of their analysis on a sample of $\mathrm{NiO}_{1.02 \pm .02}$ indicated that the percent of nitrogen by weight was zero or less than $0.008 \%$. 
Table 1

Stoichiometry of nickelous oxide. Gravimetric determinations of $x$, written as $\mathrm{NiO}_{\mathrm{x}} \cdot$

\begin{tabular}{|c|c|c|}
\hline $\mathrm{NiO} * \mathrm{a})$ & $\mathrm{NiO}(\mathrm{II})^{\mathrm{b})}$ & $\mathrm{NiO}(\mathrm{I}) \cdot$ and $\mathrm{NiO}(\mathrm{I}, \mathrm{II})$ \\
\hline $1.39 \pm .02$ & $1.01 \pm .02$ & $.99 \pm .01$ \\
$1.22 \pm .02$ & $1.03 \pm .02$ & $.099 \pm .01$ \\
$1.09 \pm .02$ & $1.02 \pm .02$ & $1.00 \pm .01$ \\
$1.16 \pm .02$ & $1.01 \pm .02$ & \\
\hline
\end{tabular}

a) These samples were prepared at $250-350^{\circ} \mathrm{C}$ in vacuum. Microanalysis indicated that about half of the indicated excess stoichiometry was due to undecomposed nitrate from the starting material of nickelous nitrate, as discussed in the text.

b) These samples were prepared at $400^{\circ} \mathrm{C}$. in argon. Microanalys is indicated that these samples were essentially free of undecomposed nitrate. 
The results of the microanalysis therefore indicate that the first preparation listed has some undecomposed nitrate still in it, but that the second preparation 1isted is essentially free of undecomposed nitrate. The analyses for nitrate were carried out using the standard Dumas method ${ }^{32}$ for determining nitrogen content. The sample was mixed with powdered cupric oxide and ignited in a stream of $\mathrm{CO}_{2}$ gas in a combustion tube, and any nitrogen was converted primarily to the elemental state with a small amount of oxides of nitrogen. The nitrogen oxides were reduced to elemental nitrogen by passing the gases over.a bed of hot copper. The products of the ignition were then swept into a gas buret filled with highly concentrated $\mathrm{KOH}$ which completely absorbed $\mathrm{CO}_{2}, \mathrm{H}_{2} \mathrm{O}$, and other products of combustion. $\mathrm{N}_{2}$. remained und is solved in the $\mathrm{KOH}$ solution and its volume was directly measured.

\section{B. Density}

One of the interesting and pertinent differences between the low and high temperature preparations of these oxides is the density, as measured by the standard volume-gravimetric technique. Mo showed that $\mathrm{CoO}$ (I) had a density of $6.4 \pm 1 \mathrm{~g} / \mathrm{cm}^{3}$ as predicted from its known $\mathrm{NaC} 1$ structure and its lattice parameter of $4.25 \AA^{33}$. They found that $\operatorname{coO}$ (II) had .an average density of only $4.8 \pm . .5 \mathrm{~g} / \mathrm{cm}^{3}$. These density measurements were made on large samples (of order $3 g$ ). Our results have demonstrated that their basic method can be reliably used on smaller samples (of order $300 \mathrm{mg}$ ) to substantiate that the Mössbauer samples of $\mathrm{CoO}$ (II) have the same average density as the larger samples. We have also found that $\mathrm{NiO}$ samples can exhibit an analogous lowering of 
density as shown in Table 2. The average density of $\mathrm{Ni}^{*}$ : samples prepared at $250-350^{\circ} \mathrm{C}$ was found to be $5.1 \pm .2 \% \mathrm{~g} / \mathrm{cm}^{3}$, and the average density of $\mathrm{NiO}(\mathrm{II})$ samples prepared at $400^{\circ} \mathrm{C}$ was found to be $6.0 . \pm .2$ $\mathrm{g} / \mathrm{cm}^{3}$. The density of $\mathrm{NiO}(\mathrm{II})$ samples therefore is about $12 \%$ below the value of $6.8 \mathrm{~g} / \mathrm{cm}^{3}$ based on a perfect NaCl structure of $\mathrm{NiO}(\mathrm{I})$ and a lattice constant of $4.19 \AA^{34,35}$.

The density. measurement technique was the standard volume-gravimetric approach using carbon tetrachloride as a non-reactive liquid in which the sample was immersed in a volumetric flask. The necessary weighings were made on a Mettler semimicro balance, and the $\mathrm{CCl}_{4}$ used in the measurements was high purity Mallinkrodt spectrophotometric grade of density $1.584 \pm .001 \mathrm{~g} / \mathrm{cm}^{3}$, which was checked against the same volume of triply distilled water. The density of standard materials such as $\mathrm{NaCl}$ and $\mathrm{Ni}$ in amounts as small as $0.06 \mathrm{ml}$, corresponding. to about $300 \mathrm{mg}$ of $\mathrm{NiO}$ (II) or $\mathrm{CoO}$ (II), were measured to within about $4 \%$ of the expected values, and for larger samples of order $2 . g$ or more the accuracy was within $2 \%$. The accuracy in density measurement achieved with the samples of order $300 \mathrm{mg}$ required careful handing of the volumetric flask. with plastic gloves during the weighing process, and a syringe. was used to add the $\mathrm{CCl}_{4}$ to the flask. The exact volume of the volumetric flask was measured before the sample was added, and the samples immersed in the $\mathrm{CCl}_{4}$ were evacuated with a fore pump in an at tempt to eliminate gas bubbles.

It is natural to ask whether a density measurement made with a liquid such as carbon tetrachloride on $\mathrm{CoO}$ (II) or NiO(II) samples reflects a density lowering due only to point vacancies :and whether it 
Table 2

Densities of CoO and NiO. Density measurements in $\mathrm{g} / \mathrm{cm}^{3}$.

\begin{tabular}{|c|c|c|c|}
\hline Sample·Size & $\mathrm{CoO}(\mathrm{II})$ & $\mathrm{NiO} \mathrm{O}^{*: a)}$ & $\mathrm{NiO}$ (II) \\
\hline$\sim 300 \mathrm{mg}$ & $\begin{array}{l}4.7 \pm .2 \\
5.0 \pm .2\end{array}$ & $\begin{array}{l}4.7 \pm .2 \\
5.3 \pm .2 \\
5.0 \pm .2\end{array}$ & $6.0 \pm .2$ \\
\hline$\sim 2 \mathrm{~g}$ & & $: 5.4 \pm .1$ & $\begin{array}{l}5.9 \pm .1 \\
6.1 \pm .1\end{array}$ \\
\hline
\end{tabular}

a) These samples were prepared at $250-350^{\circ} \mathrm{C}$ in vacuum.

b) These samples were prepared at $400^{\circ} \mathrm{C}$ in argon. 
would also reflect porosity or holes resulting from a microcrystal structure. Schroeer and Triftshauser suggested that the carbon tetrachloride could'not get into'sma11. pores in the samples because of surface tension. When these density measurements were correlated with subsequent Mössbauer and:gas.adsorption measurements, it became-apparent that the density lowering was : a result:of both point defects and porosity. An estimate of the fractional partitioning between point or Schottky defects:and porosity was obtained from Mössbauer data and will be discussed in Section VI.

\section{X-ray Patterns}

The $\mathrm{x}$-ray diffraction technique is : useful.tool for determining the composition of a sample, for estimating particle size, and for observing changes in the lattice constant of materials. $30,31,36$ MO found that the $x$-ray diffraction patterns of $\mathrm{CoO}(\mathrm{I})$ and $\mathrm{CoO}$ (II) had essentially identical line positions and relative intensities. The diffraction peaks for $\operatorname{Co}($ II) were broader, however, and this broadening gave an estimate of a domain size in CoO(II) of order $50 \AA$. The absence of extra 1 ines in the $x$-ray diffraction pattern of CoO(II) indicated that there was no long range ordering of vacancies. This was plausible because of the many different possible-arrangements of vacancies. Similar results have been found for samples of $\mathrm{NiO}$ as shown in Fig. 5. X-ray diffraction patterns are shown for samples of NiO* and $\mathrm{NiO}(\mathrm{II})$ prepared at $300^{\circ} \mathrm{C}$ and $400^{\circ} \mathrm{C}$, and for $\mathrm{NiO}$ (I) prepared at $1000^{\circ} \mathrm{C} \cdot \mathrm{CoO}(\mathrm{I})$ and $\mathrm{NiO}(\mathrm{I})$ are isomorphous, having the $\mathrm{NaCl}$ structure with the following coordinates: 


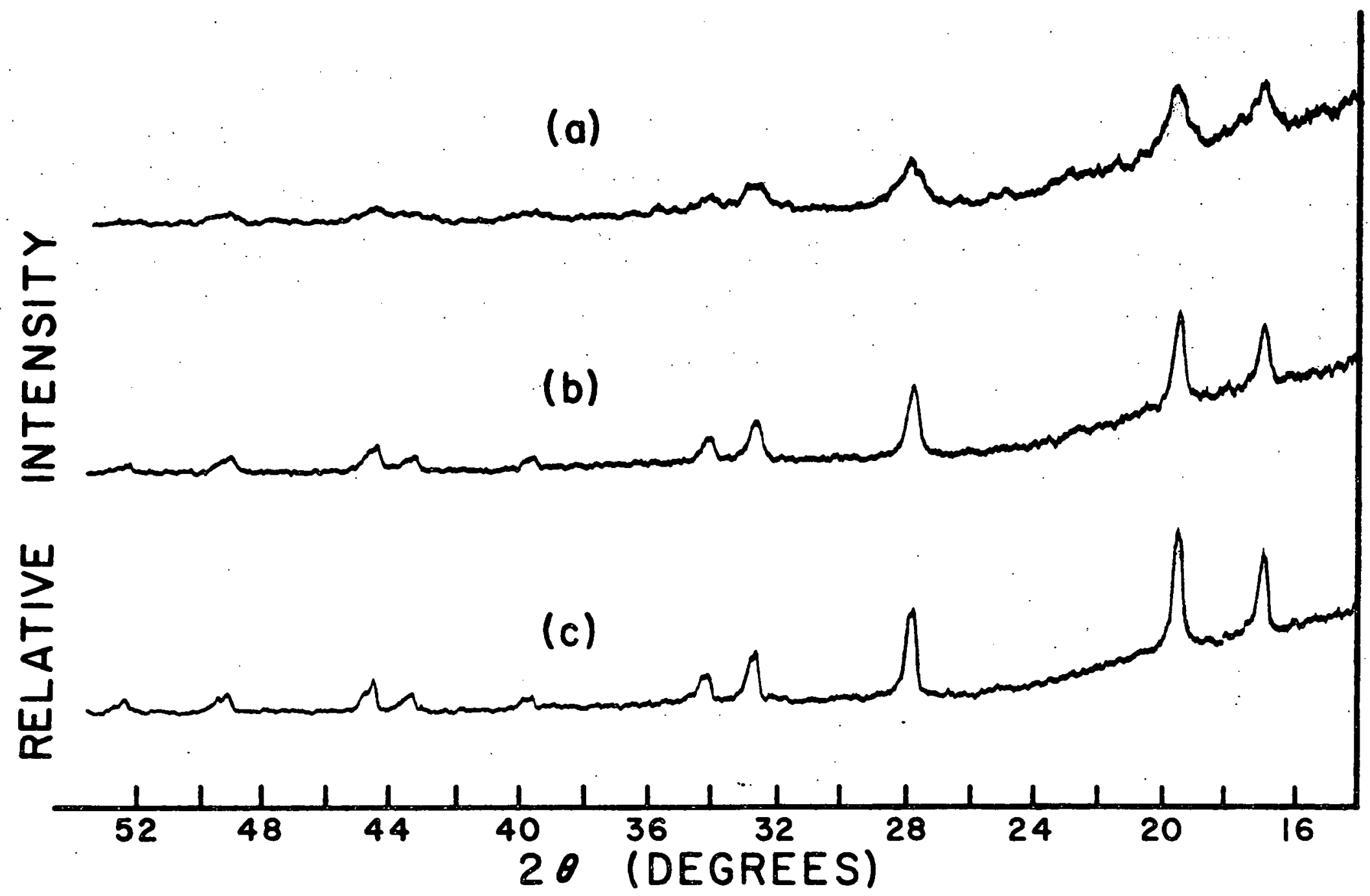

Figure 5. X-ray diffraction patterns for (a) $\mathrm{NiO}^{*}$ prepared at $300^{\circ} \mathrm{C}$, (b) $\mathrm{NiO}$ (II) prepared at $400^{\circ} \mathrm{C}$, (c) $\mathrm{NiO}(\mathrm{I})$ prepared at $1000^{\circ} \mathrm{C}$, using Mo $\mathrm{K} \alpha$ radiation. 


$$
\begin{array}{cl}
\text { Co or Ni } & (000),\left(0 \frac{1}{2} \frac{1}{2}\right),\left(\frac{1}{2} 0 \frac{1}{2}\right),\left(\frac{1}{2} \frac{1}{2} 0\right) \\
0 & \left(\frac{1}{2} 00\right),\left(0 \frac{1}{2} 0\right),\left(00 \frac{1}{2}\right),\left(\frac{11}{2} \frac{1}{2} \frac{1}{2}\right) \ldots
\end{array}
$$

Using the spacings of the crystal planes, ${ }^{37} \mathrm{~d}$, the $\mathrm{x}$-ray peak positions were calculated using Bragg's Law with Mo $\mathrm{K} \alpha$ radiation, and the results are given in Table 3. Within experimental errors the experimental peak positions were the same as the calculated ones. The broadening of the $\mathrm{Ni}^{*}$. and $\mathrm{NiO}$ (II) diffraction patterns, as compared with the pattern for the high temperature sample, was used to obtain:an estimate of particle-size. The mean dimension $D_{c}$ of a crystallite composing a powder is related to the pure $x$-ray diffraction broadening $\beta$ (in radians) as follows: ${ }^{30}$

$$
D_{c}=\frac{C \lambda}{\beta \cos \theta}
$$

where $D_{C}$ represents the -average length over which $x$-rays are scattered coherently, C:is a constant approximately equal to unity for different crystallite shapes, and $\theta$ is the diffraction angle. $\beta$ is the pure breadth of a powder reflection free of all broadening due to the experimental method, and it is related to the experimentally observed breadth $B$ in the following way:

$$
B^{2}=\beta^{2}+b^{2}
$$

The width of the particular line being considered in a high temperature form, b, serves as a standard since it is assumed to represent the broadening due to experimental-geometry.: and electronics, without any 
Table 3

Bragg peak positions for $\mathrm{NiO}$ using Mo $\mathrm{K}_{\alpha}$ radiation.

\begin{tabular}{|l|c|c|}
\hline HKL & $d(\AA)$ & $2 \theta$ \\
\hline 111 & 2.410 & 16.93 \\
200 & 2.088 & 19.56 \\
220 & 1.476 & 27.82 \\
311 & 1.259 & 32.73 \\
222 & 1.206 & 34.20 \\
400 & 1.044 & 39.70 \\
331 &. .958 & 43.44 \\
420 & .934 & 44.66 \\
422 & .853 & 49.12 \\
511 & .804 & 52.30 \\
\hline
\end{tabular}


particle-size-effects. The results of this analysis applied to the three patterns shown in Fig. 5 indicated that the particle size was of the order of $100 \AA$ for the first sample, $\mathrm{NiO}{ }^{*}$ (prepared at $300^{\circ} \mathrm{C}$ ), and of the order of $200 \AA$ for the second sample, NiO(II) (prepared at $400^{\circ} \mathrm{C}$ ). It should be stated that this $\mathrm{x}$-ray particle size method has some limitations in absolute accuracy because of variations in crystallite shapes, geometry, and electronics used. It is very good, however, for comparing the relative particle size of a series of samples。

In order to learn more about the mechanism of oxygen pickup in CoO(II), $x$-ray diffraction measurements were correlated with the amount of oxygen picked up. Fig. 6 shows the $x$-ray powder pattern for $\mathrm{CoO}(\mathrm{II}) \cdot \mathrm{n} 0$ as : a function of $\mathrm{n}$. It should be noted that the oxygen pressure had: to be increased slowly in order to avoid a strong exothermic reaction that would convert the $\mathrm{CoO}$ to $\mathrm{Co}_{3} \mathrm{O}_{4}$. In the early stages of oxygen pickup the $x$-ray pattern is practically unchanged within experimental errors, although in the latter stages $(n \geq .3)$ the relative intensities change, the positions of the lines shift slightly, and the 1 ines begin to broaden. The:point at which the $x$-ray pattern begins to change-significantly corresponds to.a rather sharp knee in the curve representing the time dependence of the oxygen pickup. The sharp knee in the $n(t)$ curve with the accompanying $x$-ray pattern changes seems to indicate that the oxygen pickup is a two stage process。 The -results : are.suggestive of an initial surface pickup or oxidation followed by:a slower diffusion of the oxygen into point oxy.gen vacancies in the sample. The density. of Schottky defects, however, 


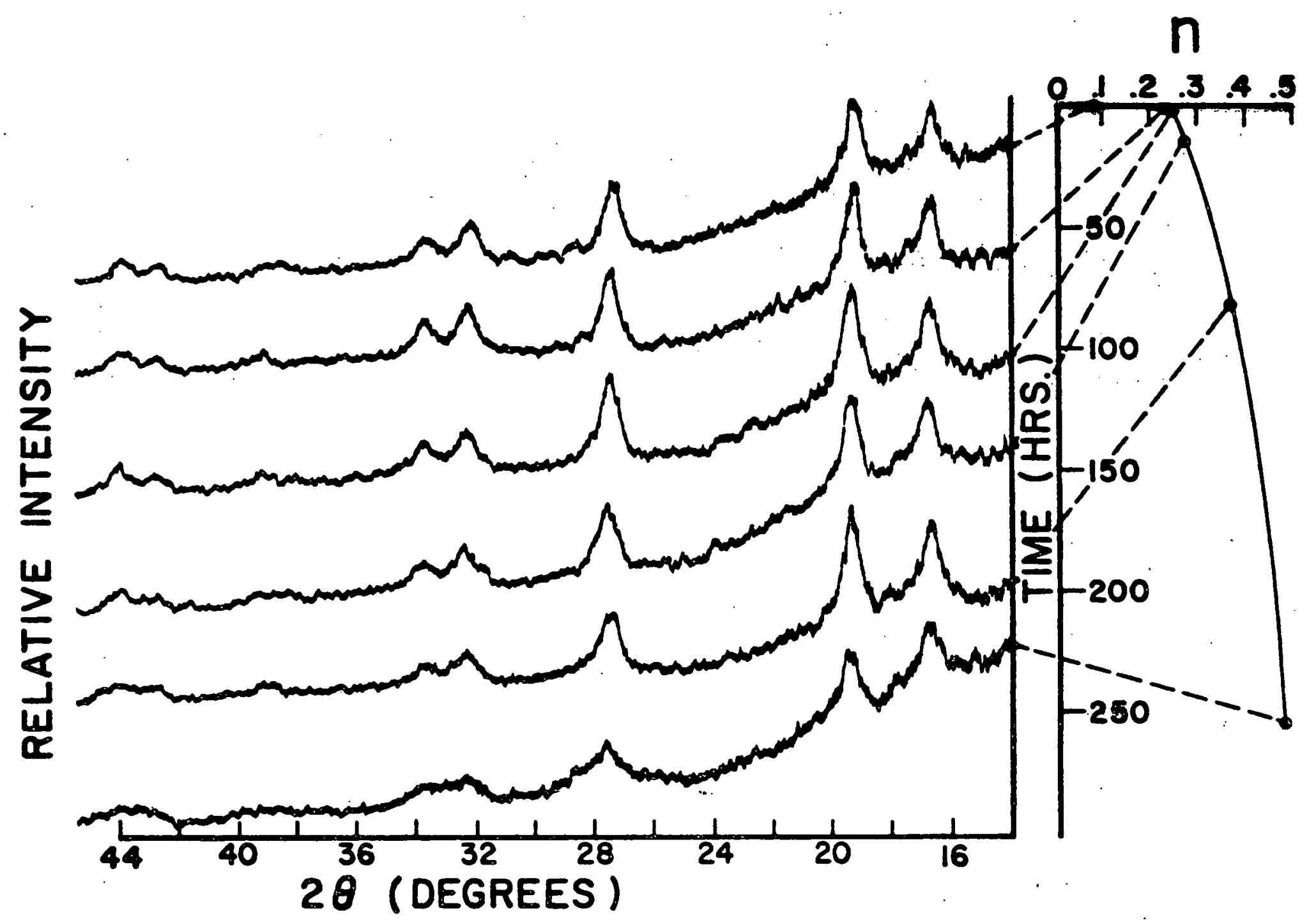

Figure 6. X-ray diffraction patterns for $C o 0(I I) \cdot n 0$ as a function of $n$. 
which is shown in section VI to be of order $6 \%$ of the lattice sites, does not appear to be great enough to account for the large $0_{2}$ pickup after the knee of the $n(t)$ curve is reached. Thus, even this rather involved picture is unable to explain the large remnant Co0(II) Mössbauer pattern ${ }^{11,14}$ after the $0_{2}$ content has increased by 50 to $60 \%$ 。 Also, it is not clear why the changes in the Mössbauer pattern upon oxidation of $\mathrm{CoO}(\mathrm{II})$ do not appear to reflect a two stage process, although this might be accountable on the basis of a resolution problem in the first stage of $0_{2}$ pickup. Whatever the detailed mechanism of oxygen pickup, the results appear. to require a large surface area, which is consistent with a spongelike structure and an appreciable amount of Schottky defects. Further investigation will be required before the detailed mechanisms of oxygen pickup are fully understood.

\section{Gas Pickup and Surface Area Measurement Results}

The purpose of making measurements on samples in the holder described in Section III-D was to $100 \mathrm{k}$ for effects indicating a large surface area for $\mathrm{CoO}(\mathrm{II})$ or $\mathrm{NiO}(\mathrm{II})$ and to study the oxygen pickup of Co0(II) more carefully.

In order to study the pickup of oxygen by $\mathrm{CoO}$ (II) more carefully, a sample of approximately $10 \mathrm{~g}$ was placed in the holder. The holder was then evacuated with a diffusion pump and weighed carefully on the semimicro balance. A very small partial pressure of oxygen was then admitted to the holder. for a period of a few minutes, and upon evacuating the holder plus sample and weighing, it was found that the sample had picked up weight. This is in contrast to the pickup of 
argon and neon, which will be discussed later in this section, in which the gas picked up could be reversibly removed by placing the sample under diffusion pump vacuum. This measurement shows that the oxygen pickup of $\mathrm{CoO}$ (II) in the early stages cannot be a physical adsorption, but must either be: a chemical adsorption or process in which the oxygen diffuses into the lattice.

In contrast to the pickup of oxygen observed in $\mathrm{C} \circ 0$ (II), measurements with $\mathrm{Ar}$ :and $\mathrm{Ne}$ on $\mathrm{CoO}(\mathrm{II})$ and $\mathrm{NiO}$ (II) have demonstrated the we11-known physical adsorption of gases, and these were used to estimate the surface area of the $\mathrm{CoO}$ (II) and NiO(II) samples. The holder and the weighing technique used in these measurements were checked by measuring the density of standards of large particle size such as.Co and $\mathrm{NaC} 1$ with gases. Since the densities of gases are lower by at least a factor of 1000 than liquids such as $\mathrm{CCl}_{4}$, the measuring technique must be very precise. It is easy in theory to find a method for measuring the density of a sample with gases. We let $W_{1}$ denote the weight of the holder when filled with gas 1 (with density $D_{1}$ ) and $W_{2}$ denote the weight of the holder when filled with gas 2 (with density $\mathrm{D}_{2}$ ). The volume of the holder is then

$$
v_{c}=\frac{w_{2}-w_{1}}{D_{2}-D_{1}} \text {. }
$$

The measurement is repeated with a sample in the container. If $W_{3}$ is the weight of the holder plus sample in gas 2 and $W_{4}$ the weight of the holder plus sample in gas 1 , then the volume of the holder minus that of the sample is 


$$
v_{c}-v_{s}=\frac{w_{3}-w_{4}}{D_{2}-D_{1}}
$$

The volume of the sample is, therefore,

$$
v_{s}:=\frac{w_{2}-w_{1}-w_{3}+w_{4}}{D_{2}-D_{1}} .
$$

The weight of the sample can be shown to be

$$
\mathrm{w}_{\mathrm{s}}=\mathrm{w}_{3}-\mathrm{w}_{2}+\mathrm{v}_{\mathrm{s}} \cdot \mathrm{D}_{2}
$$

The density of the sample can therefore be found after algebraic manipulation to be

$$
D=\frac{\left(w_{2}-w_{3}\right) D_{1}+\left(w_{4}-w_{1}\right) D_{2}}{w_{2}+w_{4}-w_{1}-w_{3}} .
$$

It should be noted that this formula is valid. if either $D_{1}$ or $D_{2}$ is zero, which would correspond to the case in which one set of weighings is made in vacuum. The densities of the gases must be corrected to the temperature and pressure of the experimental environment. The densities of Co and NaC1 of large particle size were measured by this technique and found to be reproducibly within:about $5 \%$ of the theoretical values. This confirmed that the holder and weighing technique were accurate enough and reproducible.

When we applied this technique to study $\mathrm{NiO}$ (II) and $\mathrm{COO}$ (II) we found that our measurements of the density of these materials, with 
99.998\% pure Ar and $99.995 \%$ pure Ne, gave results far outside the expected range. ${ }^{38}$ The results were off in such a direction as to indicate that the samples had a large surface-area, and therefore a large surface-adsorption. This result was consistent with the $\mathrm{x}$-ray patterns of $\mathrm{C} \odot \mathrm{O}(\mathrm{II})$ and $\mathrm{NiO}(\mathrm{II})$ samples, indicating an $\mathrm{x}$-ray particle size of the order of $100: \AA$ in contrast to the standards Co and $\mathrm{NaCl}$, which had very sharp $x$-ray diffraction peaks。 By working back it was found that the density values would be in the correct range if the samples of Ni0(II) and $\mathrm{CoO}(\mathrm{II})$, which were of order $10 \mathrm{~g}$, were physically adsorbing of the order of $4 \mathrm{mg}$ of argon and $.1 \mathrm{mg}$ of neon, and it was experimentally verified that the argon and neon could be removed by pumping with a diffusion pump.

Surface adsorption can be of two types, ${ }^{39}$ usually referred to as physical and chemical-adsorption. In chemical adsorption a reaction takes place at the surface, and the gas generally cannot be pumped off by a diffusion pump : vacuum. In physical adsorption:a weak van der Waals force holds the gas.: atoms or molecules on the surface, and the gas can be pumped off with a diffusion pump vacuum. The amount of physical adsorption is related to the surface area of the sample and the critical temperature of the gas. Physical adsorption is nonspecific in that many gases may be physically adsorbed on a surface, but chemical adsorption is obviously more specific, which is demonstrated by the difference between the pickup of Ar and $\mathrm{O}_{2}$ by $\mathrm{CoO}$ (II). The rate of adsorption is very rapid, because the gas atoms or molecules are adsorbed as soon as they reach the-surface. 
From the amount of gas :adsorbed on the surface of a sample an estimate can be made of the surface area or average particle size. Above the critical temperature of the gas being adsorbed the molecules or :atoms ge onte the surface in a monolayer:at most, but as the temperature approaches the critical temperature the fraction of the surface covered approaches 1 . Since our observations of the adsorption of $\mathrm{Ne}$ and $\mathrm{Ar}$ were carried out at room temperature, which is well above the critical temperature of either gas, the fraction of the surface covered will be much less than 1. The area of a molecule or atom on the surface is usually: approximated by assuming that the adsorbed molecules have the same packing on the surface as the molecules or atoms of the solidified gas in their plane of closest packing. Carrying out such a calculation for a $4 \mathrm{mg}$ :adsorption of argon on $\mathrm{CoO}$ (II) or $\mathrm{NiO}$ (II) led to an estimate of the particle diameter $D_{p}$ of order of

$$
\mathrm{D}_{\mathrm{p}}=\alpha(10,000 \stackrel{\circ}{\mathrm{A}})
$$

where. $\alpha$ is the fraction of a monolayer of gas adsorbed. An assumption of $1 \%$ of the surface being covered by Ar leads to an estimate of the particle size of the same order of magnitude as required to explain the $x$-ray peak broadening for these samples, discussed in Section. IV-C : 


\section{MÖSSBAUER MEASUREMENTS}

\section{A. Reduction of Data and Error Analysis}

The data output of the spectrometer was initially:analyzed in a computer program, which computed the velocity in $\mathrm{mm} / \mathrm{sec}$ and the percent absorption for each datum point. The baseline was estimated by an average of the points in the outer velocity limits, and a rough plot of the data was generated in the computer output. The program also calculated the area under the curve numerically using a trapezoidal area rule and determined the isomer shift. This initial data analysis:gave estimates of the Mössbauer parameters such as peak positions, linewidths, and areas which were then refined in:a curve fitting computer program.

The Breit-wigner theory of radiation ${ }^{40}$ predicts that ideally the curve representing nuclear resonant absorption will have a Lorentzian line shape, which is described by the following expression:

$$
A(v)=\frac{S \Gamma / 2 \pi}{\left(v-v_{0}\right)^{2}+\Gamma^{2} / 4}=\frac{I(\infty)-I(v)}{I(\infty)} .
$$

The term $A(v)$ represents the fractional effect or absorption as a function of absorber velocity, the term $\Gamma$ is the full width at half maximum for the Lorentzian curve, and $v_{0}$ is the velocity of the center of the peak. The area under the curve is $S$, which may be verified by 
integrating $A(v)$ over all velocities. $I(\infty)$ and $I(v)$. are, respectively, the transmitted gamma ray intensity at velocity far removed from the center of the peak and the transmitted gamma ray intensity as a function of velocity. If the Mössbauer pattern consists of more than one line, for example-a six-line magnetic hyperfine spectrum, the absorption curve can be expressed as a superposition or sum of the six individual Lorentzian curves.

The curve fitting of the Mössbauer data to a function as described:above was done with a non-1inear regression, least-squares computer program, which was capable of fitting experimental data to an arbitrary function of one or two independent variables : and a large number of

parameters. In actual practice, the experimental spectra were usually fitted with less than twenty parameters. The theory of a curve fitting program of this type is sophisticated, but in essence its function is to generate a curve which best fits the data as determined by: a minimum of the sum of the squares of the residuals, deviations of the fitted and experimental points.

There was some error in determining the velocity: and gamma ray intensity of each datum point. The error in the velocity using the crank spectrometer was a function of the uniformity of rotation of the flywheel, the-accuracy to which the instrument was machined, and the measurement of the geometric crank parameters. The maximum error in the velocities is estimated to be $0.5 \%$ and should be less on the average. The emission and absorption of the gamma rays is described by Poisson statistics. There are various ways of expressing the error associated with.Poisson statistics, but they all are related to the 
value of $\sqrt{N}$ where $N$ is the total number of gamma rays counted. The standard deviation of the counts at a particular velocity is $\sqrt{\mathrm{N}}$, and the fractional-standard error is $1 / \sqrt{N}$. In most of the experimental data the value of $\mathrm{N}$ was : greater than $10^{5}$ for a fractional standard error of 3/1000. Since the Mössbauer absorption 1 ines were typically $10 \%$, the signal to noise ratio was typieally 30 to 1 . In order to maximize count rate, the single channel analyzer was set wider than the half maximum of the $14.0 \mathrm{keV}$ peak. The gas filled proportional tube was run at the lowest voltage necessary to adequately resolve the $14.4 \mathrm{keV}$ peak from thermal noise.

The curve fitting program calculated a standard error for each parameter, using the statistical techniques for multiparameter analysis, and these standard errors were then used to estimate the error in quantities derived from the fitted Mössbauer data. The error in each parameter is a function of the signal to noise ratio of the data and the deviation of the experimental lineshape from a Lorentzian curve, which is caused by crystal field effects and finite absorber thickness $^{17,41}$. The abosrbers used in all experiments contained enriched $\mathrm{Fe}^{57}$, in the chemical form sodium ferrocyanide, in.a lucite disk matrix, with iron content of 0.1 to $1.00 \mathrm{mg} / \mathrm{cm}^{2}$. In most runs the 1.00 or $0.75 \mathrm{mg} / \mathrm{cm}^{2}$ absorbers were used for maximum percentage effect, since the broadening caused by these-absorbers was within acceptable limits. In the experiments concerned with the preparation of a narrow single line source, however, the 0.1 and $0.25 \mathrm{mg} / \mathrm{cm}^{2}$ absorbers were used so that the linewidth would be closer to natural linewidth. 
The geometry of the experimental setup of the spectrometer also needs to be considered in error analysis. On the crank spectrometer an attempt was made to center the-absorber between the source and detector to minimize an irrelevant intensity fluctuation caused by varying electronic scattering, due to varying solid angle subtended between the source and absorber and the absorber and detector . This effect was completely negligible in the measurements described in this thesis. Another correction resulting from non-ideal geometry was considered in some cases, and the analysis of this effect is derived in Appendix A. This effect is : a result of the fact that the gamma rays passing through the absorber are not strictly parallel, and this effect increases as the distance between source and detector decreases.

\section{B. Mössbauer Spectra for NiO Samples}

The temperature dependence of the Mössbauer spectra for:a sample of $\mathrm{NiO}^{\text {* }}$ prepared at $300^{\circ} \mathrm{C}$ in vacuum is shown in $\mathrm{Fig} \cdot 7$. The spectra can readily be identified as due to $\mathrm{Fe}^{3+}$ ions from the isomer shift ${ }^{42}$ (approximately $-0.4 \mathrm{~mm} / \mathrm{sec}$ relative to $\mathrm{Na}_{4} \mathrm{Fe}(\mathrm{CN})_{6} \cdot 10 \mathrm{H}_{2} \mathrm{O}$ ) and from the hyperfine splitting of the pattern at $81^{\circ} \mathrm{K}$, indicating a magnetic field at the nuclear site of order $500 \mathrm{kG}^{43,44}$. At $81^{\circ} \mathrm{K}$ the pattern is : a simple six-line magnetic hyperfine spectrum, but as the temperature was raised a broad unresolved line appeared.and gradually became a single line as the six-line pattern disappeared. The collapse of the six-line pattern is gradual, and a narrow:single line is reached by $376^{\circ} \mathrm{K}$. This is in contrast to a sample of $\mathrm{NiO}(\mathrm{I})$ which showed a well defined transition from the antiferromagnetic to the paramagnetic 
51

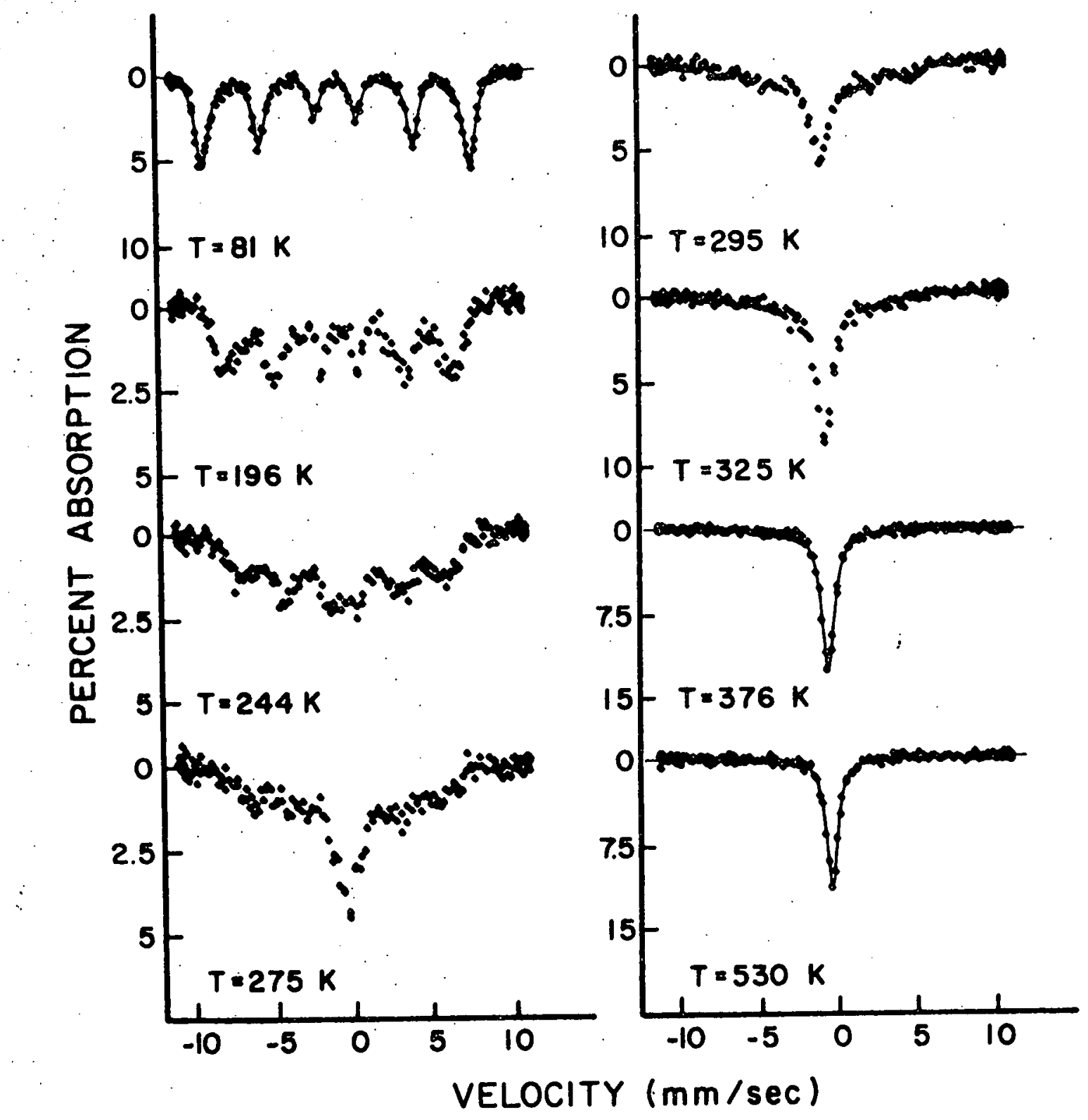

Figure 7. Temperature dependence of Mössbauer spectra for $\mathrm{NiO}$ * prepared at $300^{\circ} \mathrm{C}$. A $1.00 \mathrm{mg} / \mathrm{cm}^{2}$ sodium ferrocyanide absorber was used. 
state at $525^{\circ} \mathrm{K}$. The $\mathrm{x}$-ray particle size indicated for this type of preparation is of order $100 \AA$, and the density measured with a 1 iquid is about $25 \%$ below the theoretical value. Fig. 8 shows the temperature dependence of the Mössbauer spectra for a nominally stoichiometric sample of $\mathrm{NiO}$ (II) prepared at $400^{\circ} \mathrm{C}$ in argon, and again the isomer shift and width of the patterns identify the spectra as due to only the $\mathrm{Fe}^{3+}$ ion $^{42-44}$. As the temperature is raised, there is no emergence of the broad unresolved line as in the $\mathrm{Ni}^{*}$ samples prepared at $300^{\circ} \mathrm{C}$. The higher temperature of preparation appeared to have annealed out the broad component, but the patterns do collapse to a single line below the Néel temperature of defect free NiO(I). A slightly broadened single line is present at $507^{\circ} \mathrm{K}$, and the line reaches minimum width by $519^{\circ} \mathrm{K}$. The Néel temperature was estimated to be $515 \pm 5^{\circ} \mathrm{K}$. Fig. 9 shows the temperature dependence of the magnetic field at the nuclear site as determined from the Mössbauer spectra for the sample of NiO(II) The broadened lines were found to be almost purely magnetic, and their broadening is interpreted as being due to: a quadrupole.interaction with a random electric field gradient, which would arise from the random defect structure proposed for $\mathrm{NiO}$ (II). The low temperature limit of the magnetic hyperfine field approaches $550 \mathrm{kG}$, and this field is characteristic of the $\mathrm{Fe}^{3+}$ ion in compounds as compared with values of the order of $200 \mathrm{kG}^{45}$ for $\mathrm{Fe}^{2+}$. The temperature dependence of the magnetic hyperfine field at the nucleus was found empirically to follow the Brillouin function for $S=5 / 2$, approximately 


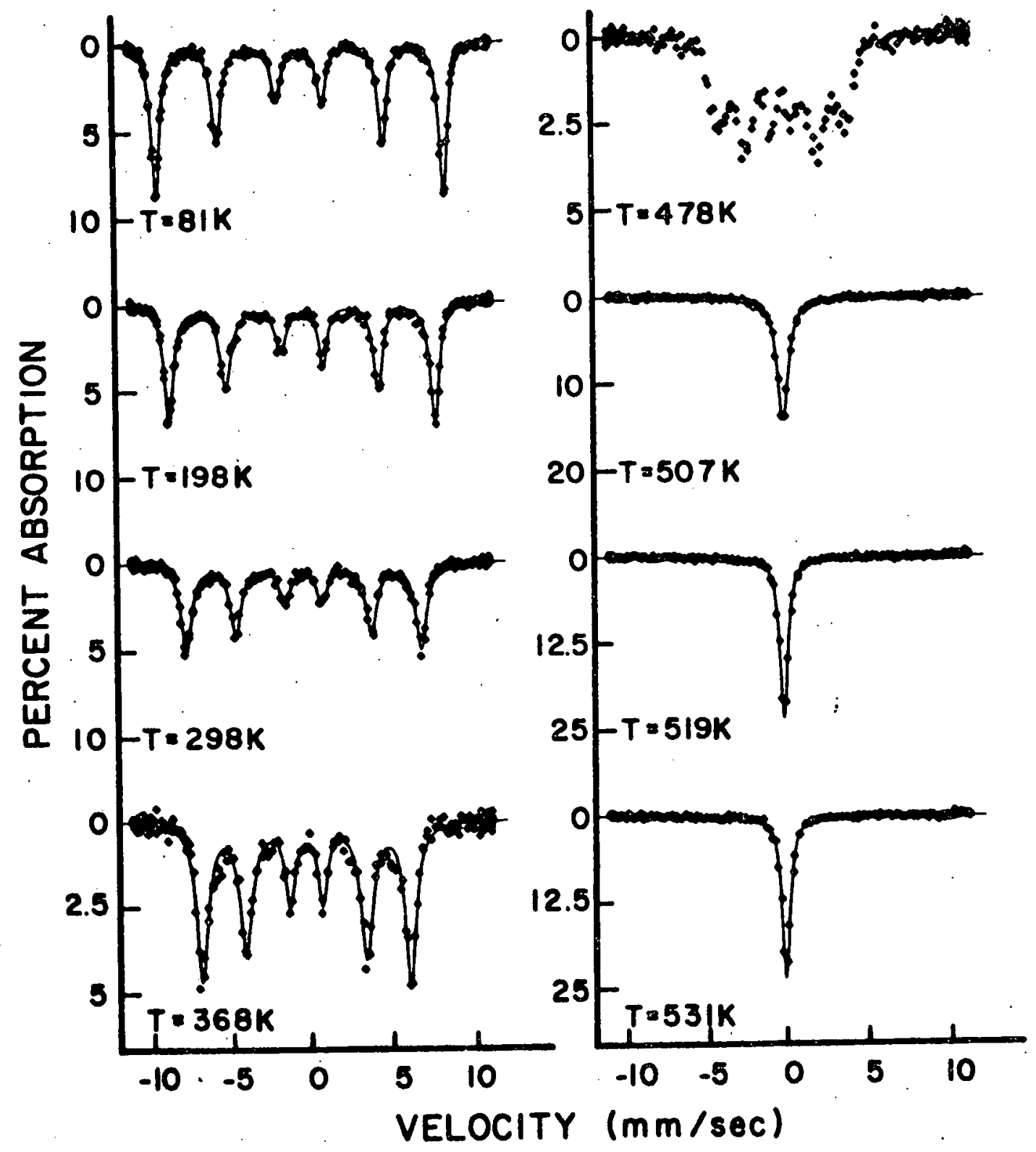

Figure 8. Temperature dependence of Mössbauer spectra for $\mathrm{NiO}$ (II) prepared at $400^{\circ} \mathrm{C}$. A $1.0 \mathrm{mg} / \mathrm{cm}^{2}$ sodium ferrocyanide absorber was used. 


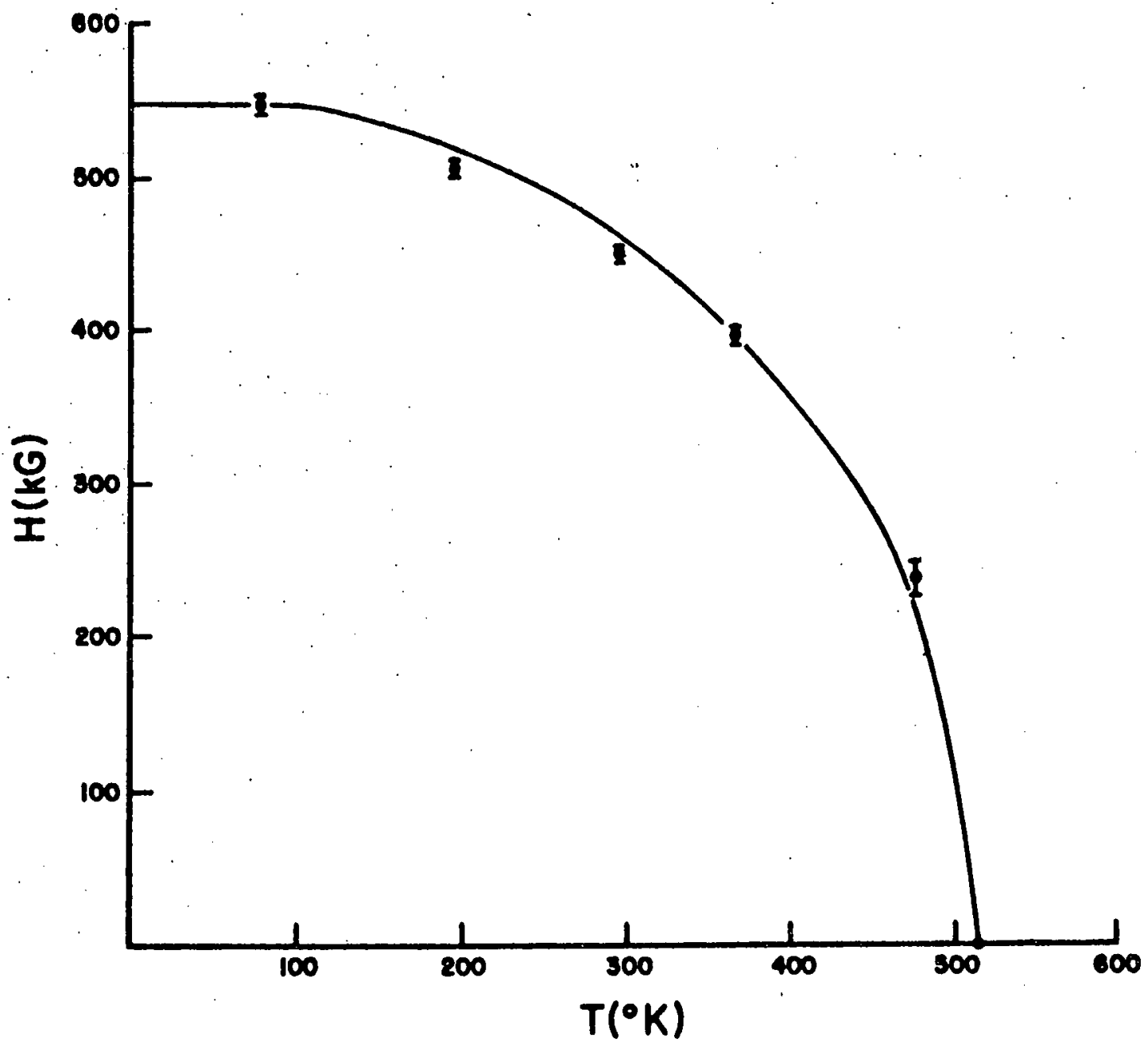

Figure 9. Temperature dependence of magnetic hyperfine field at $\mathrm{Fe}^{57}$ site in $\mathrm{NiO}$ (II) prepared at $400^{\circ} \mathrm{C}$. The solid curve shows the Brillouin function for $S=5 / 2$. 


\section{Mössbauer Spectra for Doped Samples}

Interesting effects have been observed when CoO and NiOare doped with cations of $1+$ and $3+$ valence. Significant changes in the ratio of $\mathrm{Fe}^{2+}$ to $\mathrm{Fe}^{3+}$ resonance have been observed, and these results have added a new dimension to the interpretation of the Mössbauer spectra of these oxides. Fig. 10 shows the effect of adding $: \mathbf{L i}^{1+}$ to nickelous oxide samples prepared at $800^{\circ} \mathrm{C}$ in air. The spectra were initial1y complex with both $\mathrm{Fe}^{2+}$ and $\mathrm{Fe}^{3+}$ patterns in the Mössbauer resonances, but as the concentration of lithium was increased the ratio of $\mathrm{Fe}^{3+} \cdot \mathrm{Fe}^{2+}$ increased until only the $\mathrm{Fe}^{3+}$ resonance remained. Within experimental error, the line positions of the $\mathrm{Fe}^{3+}$ resonances are the same for doped and undoped samples, but the linewidths are narrower for the $\mathrm{Fe}^{3+}$ resonance produced in lithium doped samples in high temperature preparations as compared with the $\mathrm{Fe}^{3+}$ resonance in $\mathrm{NiO}(\mathrm{II})$. Fig. 11 shows the effect of adding $\mathrm{Cr}^{3+}$ to $\mathrm{NiO}(\mathrm{I}, \mathrm{II})$ prepared at $800^{\circ} \mathrm{C}$ in air. A reduction in the $\mathrm{Fe}^{3+} / \mathrm{Fe}^{2+}$ ratio was observed at $298^{\circ} \mathrm{K}$, while the ratio remained approximately the same at $81^{\circ} \mathrm{K}$. Fig. 12 shows similar results for $\mathrm{CoO}(\mathrm{I}, \mathrm{II})$ prepared at $1000^{\circ} \mathrm{C}$ in air, where adding $\mathrm{Li}^{1+}$ caused the $\mathrm{Fe}^{3+} / \mathrm{Fe}^{2+}$ ratio to increase at both $81^{\circ} \mathrm{K}^{2}$ and $298^{\circ} \mathrm{K}$. Adding $\mathrm{Ga}^{3+}$ caused the ratio $\mathrm{Fe}^{3+} / \mathrm{Fe}^{2+}$ to decrease slight $1 \mathrm{y}$ at $298^{\circ} \mathrm{K}$, while the pattern was essentially unchanged at $81^{\circ} \mathrm{K}$. Fig. 13 shows the Mössbauer spectra over a range of temperature for a sample of $\mathrm{NiO}$ prepared at $1000^{\circ} \mathrm{C}$ in air with:a $1 \% \mathrm{Li}^{1+}$ doping, which was high enough to completely suppress the $\mathrm{Fe}^{2+}$ resonance at all temperatures shown. Again the line positions are the same within experimental errors as for the $\mathrm{Fe}^{3+}$ resonance. in 


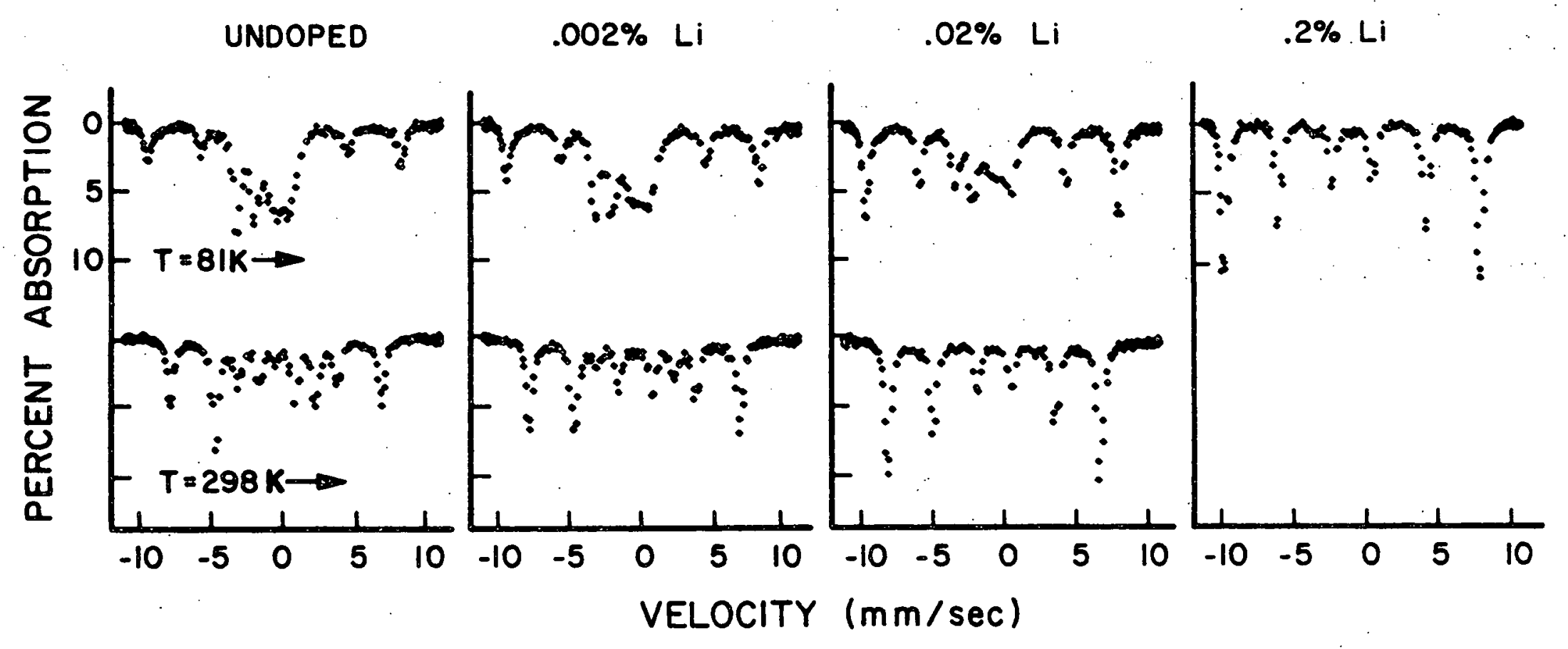

Figure 10. Effect of substitutionally doping with $\mathrm{Li}^{1+}$ on the Mössbauer spectra of Ni0(I, II) prepared at $800^{\circ} \mathrm{C}$. A $1.0 \mathrm{mg} / \mathrm{cm}^{2}$ sodium ferrocyanide absorber was used: 


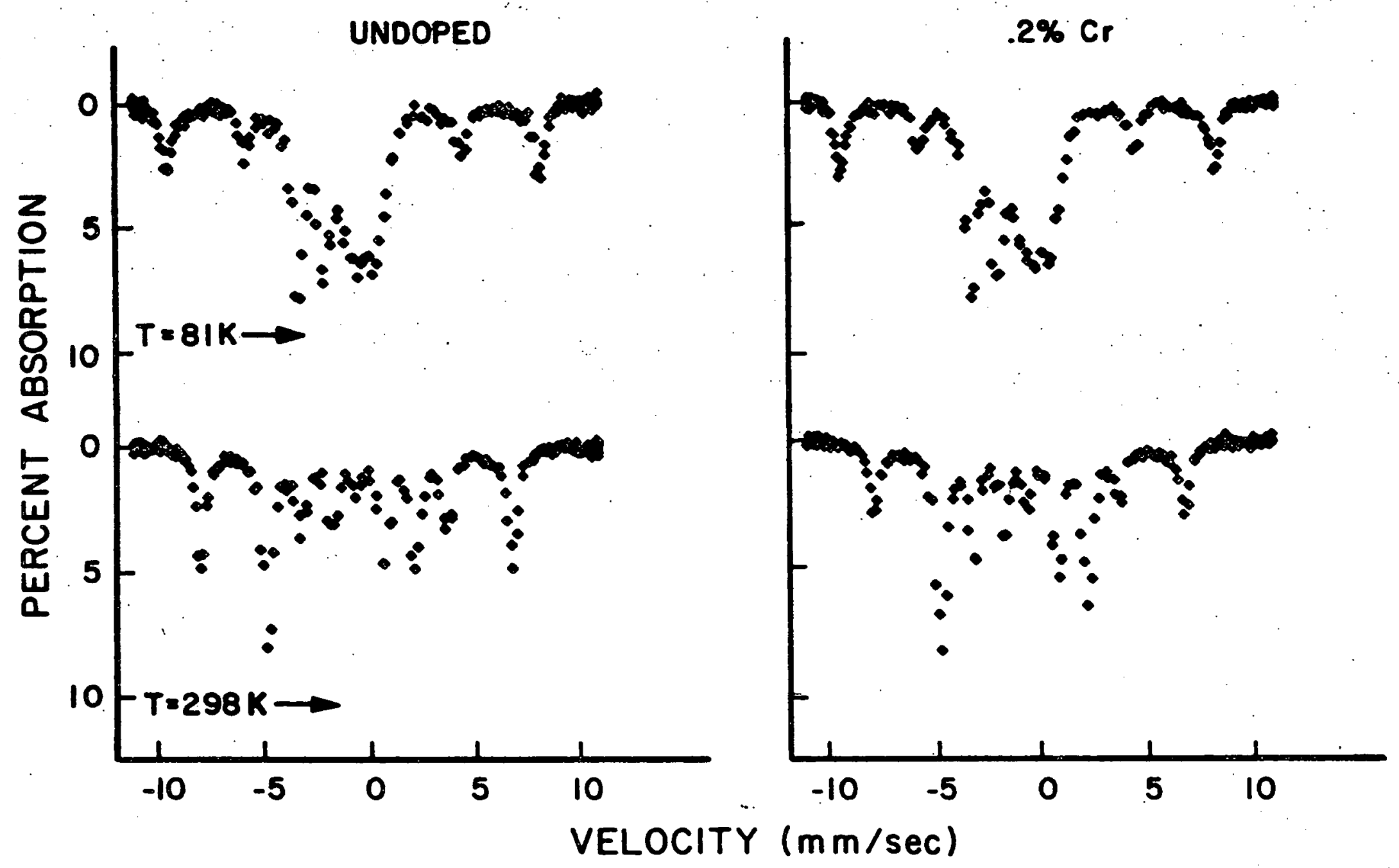

Figure 11. Effect of substitutiona11y doping with $\mathrm{Cr}^{3+}$ on the Mössbauer spectra of NiO(I,II) prepared at $800^{\circ} \mathrm{C}$. A $1.0 \mathrm{mg} / \mathrm{cm}^{2}$ sodium ferrocyanide absorber was used. 


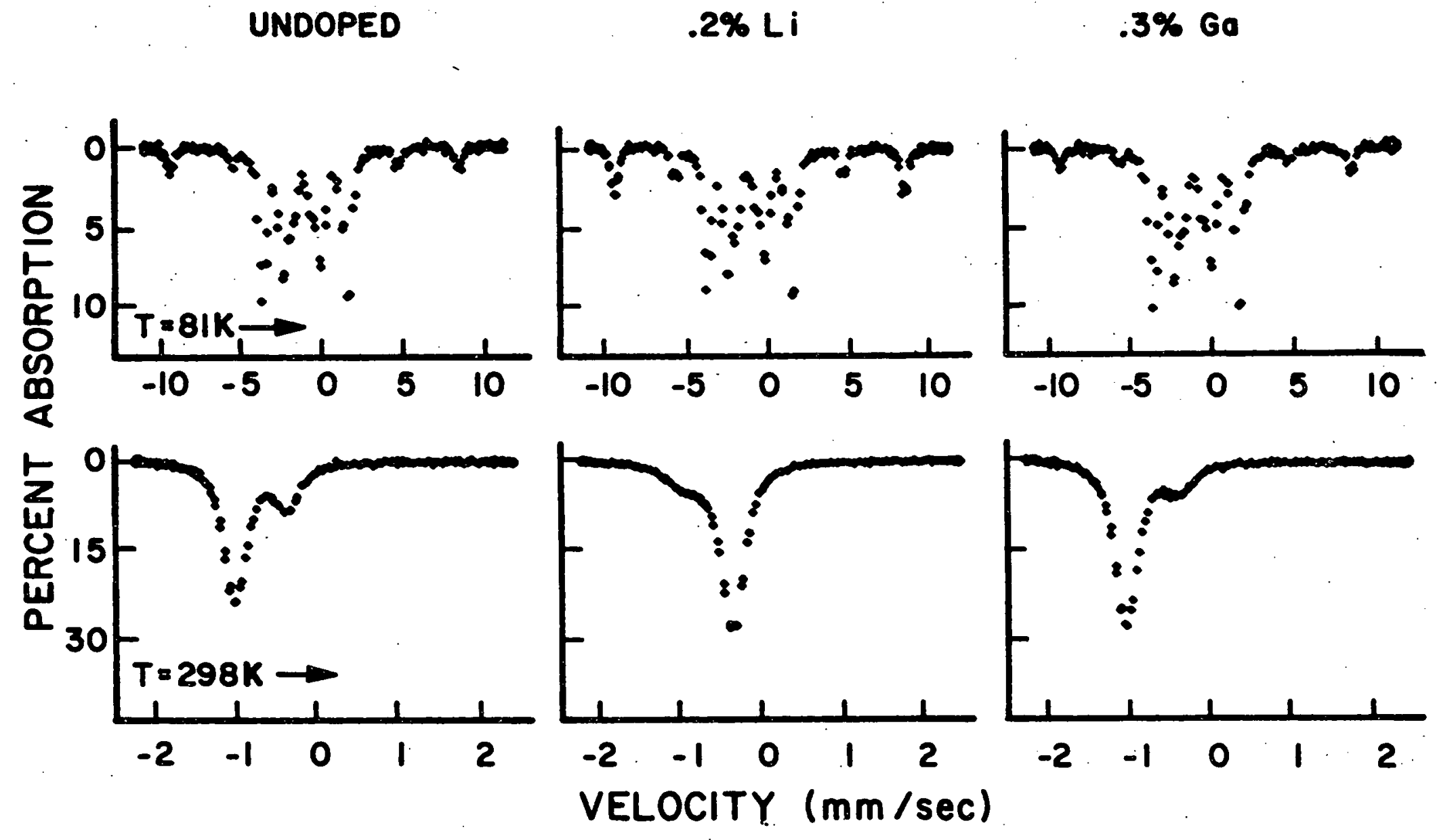

Figure 12. Effect of substitutionally doping with $\mathrm{Li}^{1+}$ and $\mathrm{Ga}^{3+}$ on the Mössbauer spectra of Co 0 (I, II) prepared at $1000^{\circ} \mathrm{C}$. A $1.0 \mathrm{mg} / \mathrm{cm}^{2}$ sodium ferrocyanide absorber was used at $81^{\circ} \mathrm{K}$ and a $0.5 \mathrm{mg} / \mathrm{cm}^{2}$ absorber at $298^{\circ} \mathrm{K}$. 


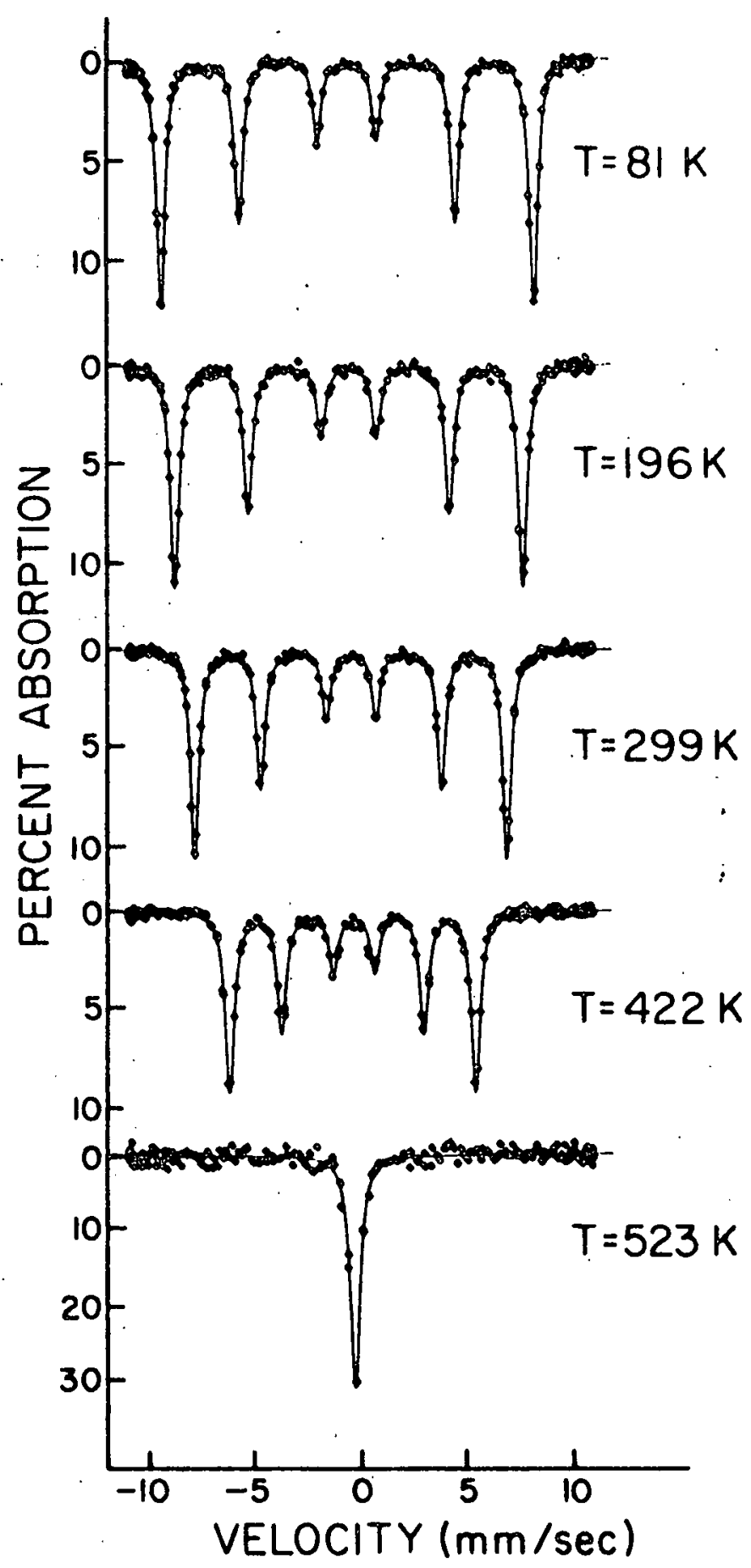

Figure 13. Temperature dependence of Mössbauer spectra for $\mathrm{NiO}$ prepared at $1000^{\circ} \mathrm{C}$ with a $1 \% \mathrm{Li}^{1+}$ doping. A $1.0 \mathrm{mg} / \mathrm{cm}^{2}$ sodium ferrocyanide absorber was used. 
NiO(II), but the linewidths are narrower by about .2 mm/sec on the average when measured with the same-absorber. A similar result was obtained for a sample of $\mathrm{CoO}$ prepared at $1000^{\circ} \mathrm{C}$ in air with a $1 \%$ doping of $\mathrm{Li}^{1+}$, and the use of such a sample at room temperature as a hot single-line source is discussed in Section V-H. Figs. 14 and 15 show, respectively, a comparison of the temperature dependence of the Mössbauer spectra for $\operatorname{CoO}(\mathrm{I}, \mathrm{II})$ and $\operatorname{CoO}(\mathrm{I}, \mathrm{II})$ with a $.1 \%$ doping of $\mathrm{Li}^{1+}$. In order to curve fit this data it was necessary to make certain assumptions to reduce the number of parameters because the spectra below the Néel temperature consisted of twelve lines (not counting two small lines resulting from mixing of $\mathrm{m}$ states) from the $\mathrm{Fe}^{2+}$ and $\mathrm{Fe}^{3+}$ resonances. The intensities of the six lines of each resonance were assumed to be in the ratio $3: 2: 1: 1: 2: 3$, and this assumption was made in the curve fitting analysis so that a single area parameter was associated with each six-line curve. Also it has been found that for $\mathrm{Fe}^{57}$ in a pure magnetic field, the ratio of the differences in position between the six lines is approximately $1: 1: 3 / 4: 1: 1$, and using this assumption the line positions could be specified by two parameters, the position of one line and an incrementing parameter. This approximation could not be made, however, for the $\mathrm{Fe}^{2+}$ resonance below :about $200^{\circ} \mathrm{K}$ because of the quadrupole interaction which shifted the line positions such that the differences in velocity were no longer in the ratio expected for:a pure magnetic interaction. The $\mathrm{Fe}^{2+}$ resonance thus required '́x line position parameters below $200^{\circ} \mathrm{K}$. Also, the assumption that each spectrum contained six lines of equal width was made in fitting the data. These assumptions kept the number 


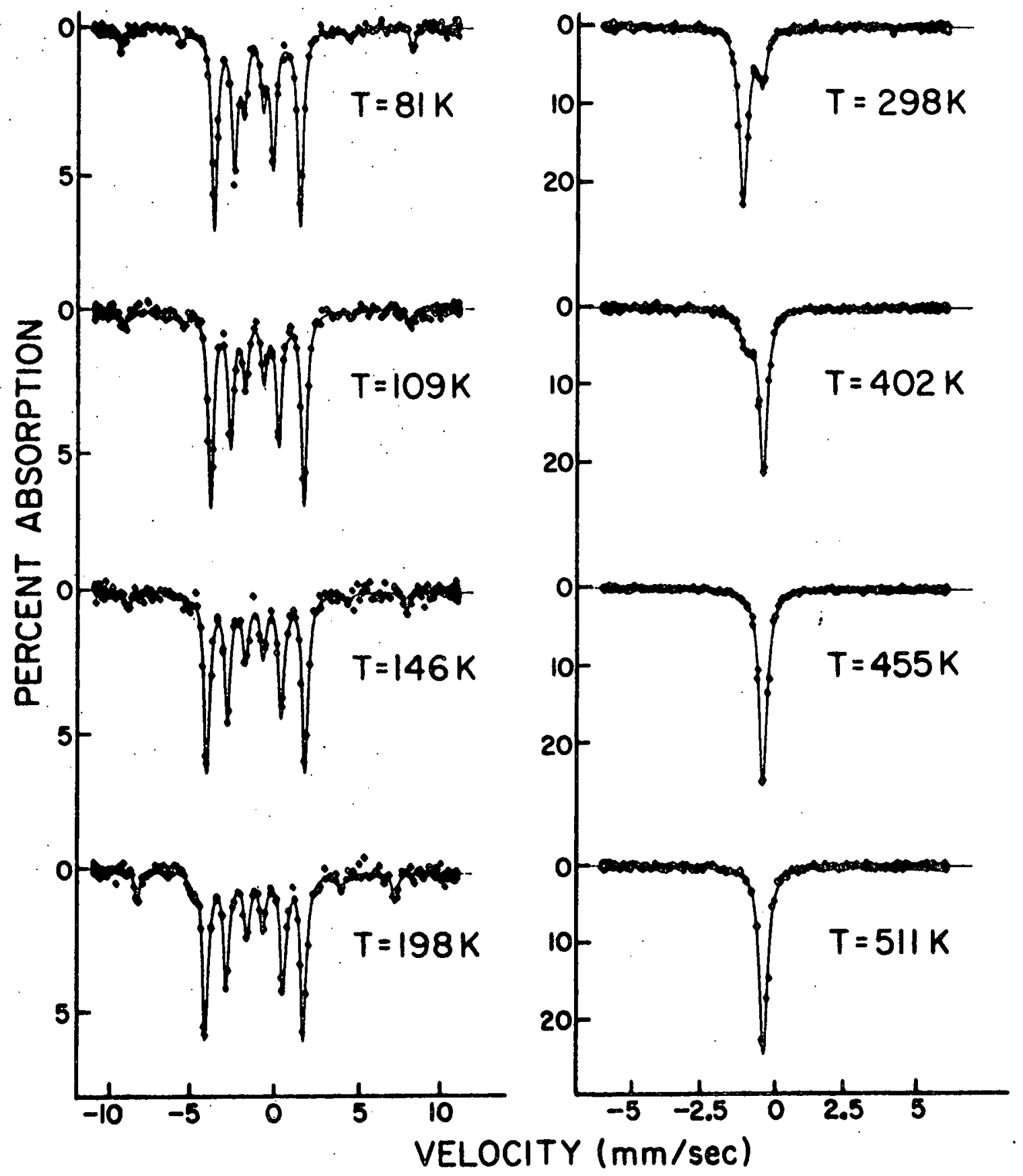

Figure 14. Temperature dependence of Mössbauer spectra for $\mathrm{CoO}(\mathrm{I}, \mathrm{II})$. A $0.75 \mathrm{mg} / \mathrm{cm}^{2}$ sodium ferrocyanide absorber was used. 


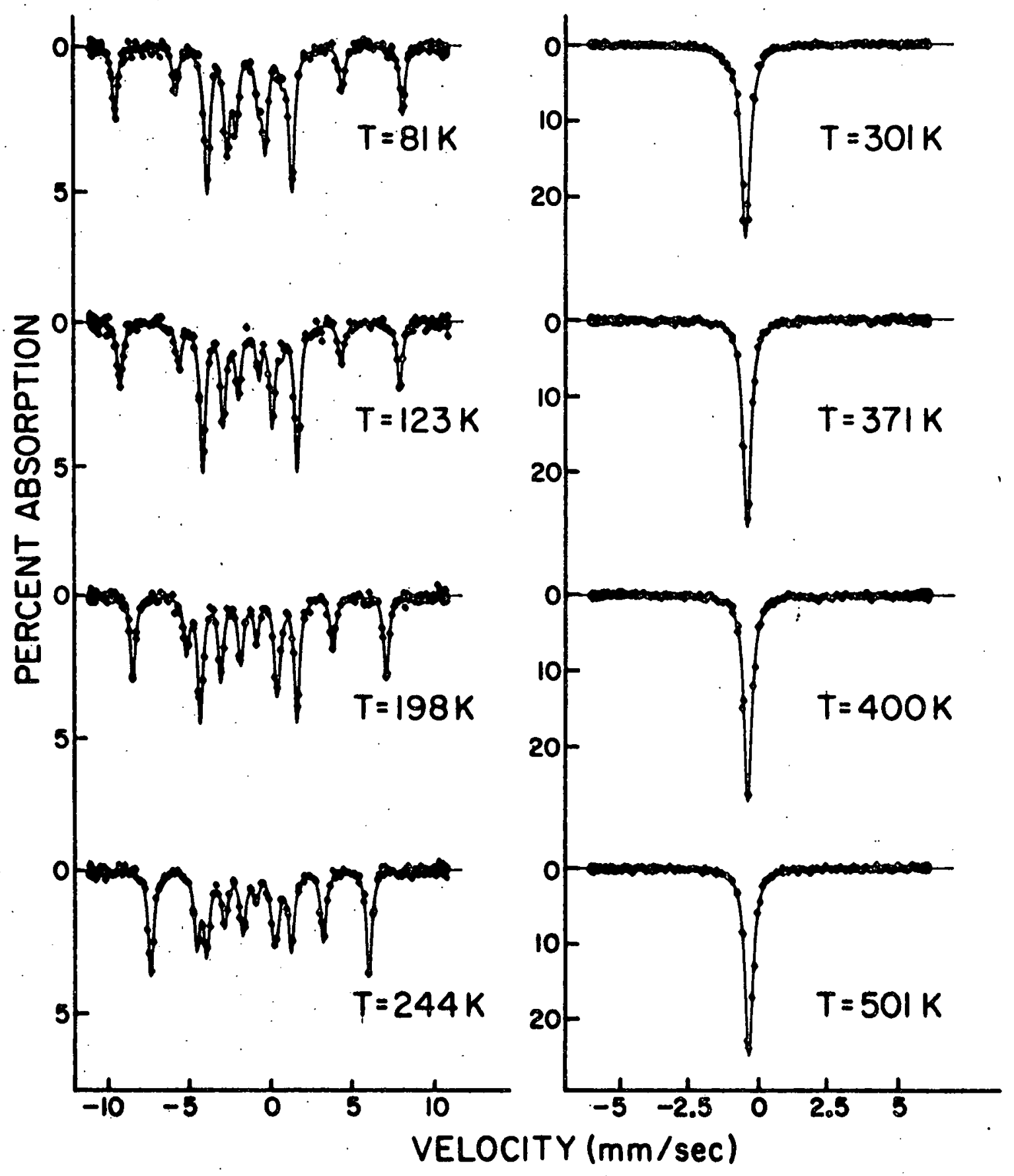

Figure 15. Temperature dependence of Mössbauer spectra for Co0(I, II) with . . $1 \%$ doping of $\mathrm{Li}^{1+}$ A $0.75 \mathrm{mg} / \mathrm{cm}^{2}$ sodium ferrocyanide absorber was used. 
of parameters within easy management, and an excellent fit to the data was obtained. The reason that it was necessary to reduce the number of parameters in this curve fitting was to 1 imit the degrees of freedom to a value consistent with the amount and accuracy of the data points.

\section{Temperature Dependence-of Recoil-free Fraction}

The theory of the recoil-free fraction has:already been discussed in Section II-A, where it was shown that the temperature dependence of the area under the Moossbauer curve is related to the binding of ions in the lattice, and may be characterized through the Mössbauer characteristic temperature, $\theta_{\mathrm{m}} \cdot$ Fig. 16 shows a plot of the natural logarithm of the area under the curve as:a function of $\mathrm{T}^{2}$ for five different samples, all normalized to the same area at $81^{\circ} \mathrm{K}$. The curves represent:as follows: (a) the $\mathrm{Fe}^{3+}$ resonance in NiO with:a $1 \% \cdot \mathrm{Li}{ }^{1+}$ doping, prepared at $1000^{\circ} \mathrm{C}$ in air, (b) the $\mathrm{Fe}^{3+}$ resonance in. Co0 with a $1 \% \mathrm{Li}^{1+}$ doping, prepared at $1000^{\circ} \mathrm{C}$ in air, (c) the $\mathrm{Fe}^{2+}$ resonance in $\mathrm{CoO}(\mathrm{I})$, (d) the $\mathrm{Fe}^{3+}$ resonance in $\mathrm{NiO}(\mathrm{II})$, and (e) the $\mathrm{Fe}^{3+}$ resonance in $\mathrm{CoO}(\mathrm{II})$. The characteristic temperature calculated for each of these cases is, to the nearest $10^{\circ} \mathrm{K}$, (a) $420^{\circ} \mathrm{K}$ for $\mathrm{NiO}(1 \% \mathrm{Li}$ ), (b) $410^{\circ} \mathrm{K}$ for $\operatorname{Co0}(1 \% \mathrm{Li})$, (c) $410^{\circ} \mathrm{K}$, for $\mathrm{CoO}(\mathrm{I})$, (d) $350^{\circ} \mathrm{K}$ for $\mathrm{NiO}$ (II), and (e) $230^{\circ} \mathrm{K}$ for $\mathrm{Co} 0(\mathrm{II})$. Some of the values are not in exact accord with earlier values reported by $\mathrm{MO}^{11}$, which is the result of their making the low temperature approximation in calculating $\theta_{\mathrm{m}}$. The present values do not make this approximation and should therefore be more. accurate. The significance of the curves is that the Mössbauer characteristic temperature, $\theta_{m}$, is significantly higher for the $\mathrm{Fe}^{3+}$ 


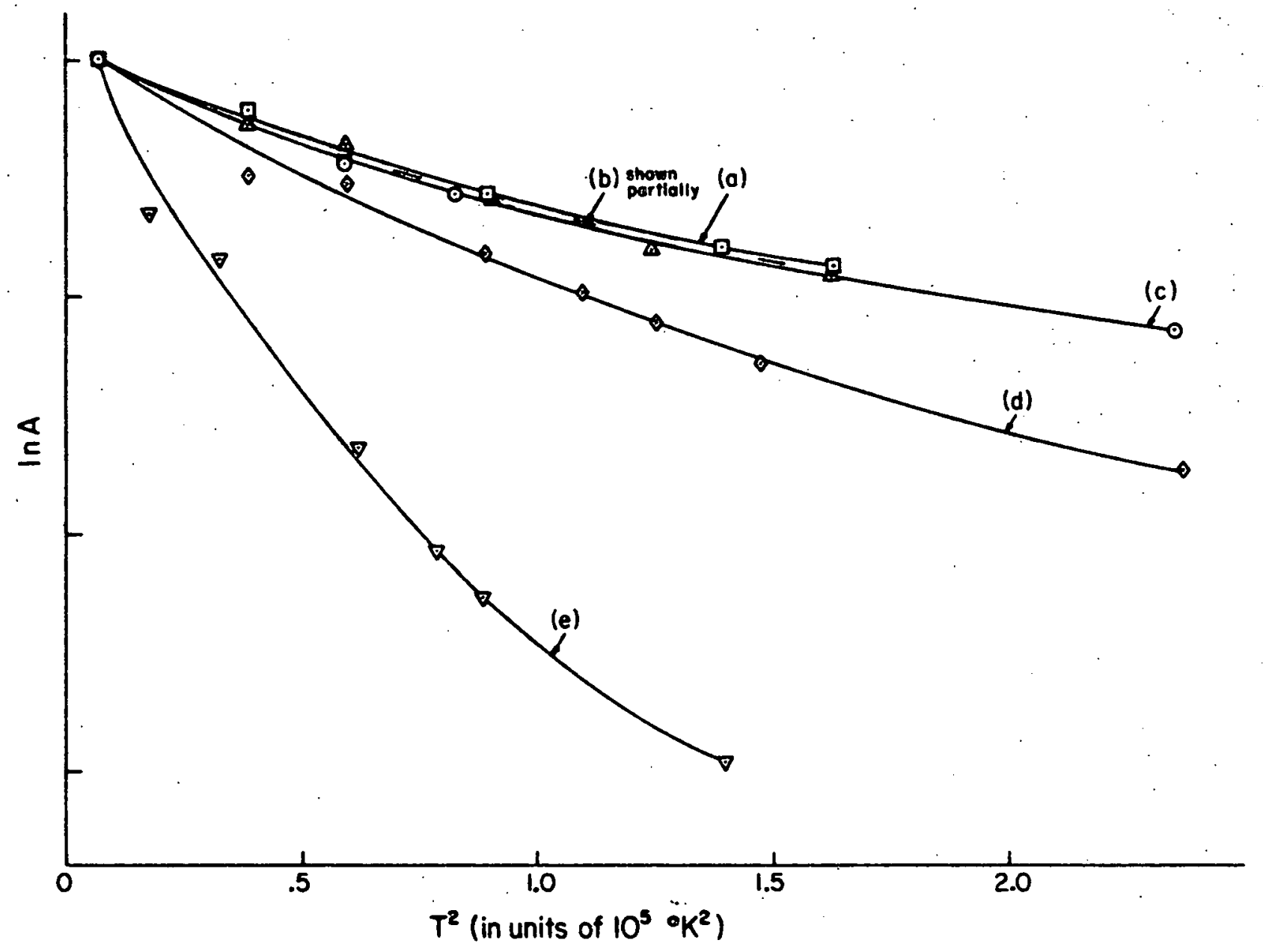

Figure 16. Temperature dependence of $\mathrm{In} \mathrm{A}$ for, (a) $\mathrm{Fe}^{3+}$ in $\mathrm{NiO}(1 \% \mathrm{Li})$, (b) $\mathrm{Fe}^{3+}$ in $\mathrm{CoO}(1 \% \mathrm{Li})$, (c) $\mathrm{Fe}^{2+}$ in $\mathrm{CoO}(\mathrm{I})$, (d) $\mathrm{Fe}^{3+}$ in $\mathrm{NiO}$ (II), (e) $\mathrm{Fe}^{3+}$ in $\mathrm{CoO}(\mathrm{II})$, based on area measurements normalized to unity at $81^{\circ} \mathrm{K}$. The first three samples were prepared at $1000^{\circ} \mathrm{C}$ and the last two at $300-400^{\circ} \mathrm{C}$. 
resonance induced by' $\mathrm{Li}^{1+}$ doping in the high temperature preparations, (a) and (b), than for the $\mathrm{Fe}^{3+}$ resonance in $\mathrm{CoO}$ (II) and $\mathrm{NiO}$ (II), (d) and (e). The $\mathrm{Fe}^{3+}$ resonance induced by $\mathrm{Li}^{1+}$ in high temperature samples has a Mössbauer characteristic temperature which is essentially the same as that of the $\mathrm{Fe}^{2+}$ resonance in $\mathrm{CoO}(\mathrm{I})$, (c). This strikingly demonstrates the structural differences between the high and low temperature forms of these oxides:and rules out merely ion-size or electronic effects as the cause of these differences. This will be discussed in detail in Section VI.

Fig. 17 shows the plot of the natural logarithm of the area under the curve for the $\mathrm{Fe}^{3+}$ resonance in $\mathrm{CoO}(\mathrm{I}, \mathrm{II})$ and $\mathrm{CoO}(I, I I)$ with a $.1 \%$ doping of $\mathrm{Li}^{1+}$. The initial value of $\ln \mathrm{A}$. is higher for the $\mathrm{Fe}^{3+}$ resonance in the second sample because of the lithium doping. The curves have different turning points, but they show basically the same type of dependence of area with temperature. Both curves show the unusual increase of area of the $\mathrm{Fe}^{3+}$ resonance with temperature which has been observed in these oxides. $4,5,11$ The present results appear to permit a simpler explanation of the increase of the area of the $\mathrm{Fe}^{3+}$ resonance in $\mathrm{COO}(\mathrm{I}, \mathrm{II})$ than the original suggestion ${ }^{11}$ that this effect might be the result of the dispersal of anion vacancies above $200^{\circ} \mathrm{K}$. This effect now appears to be best understood in terms of the semiconducting properties associated with these materials and will be discussed further in Section VI. 


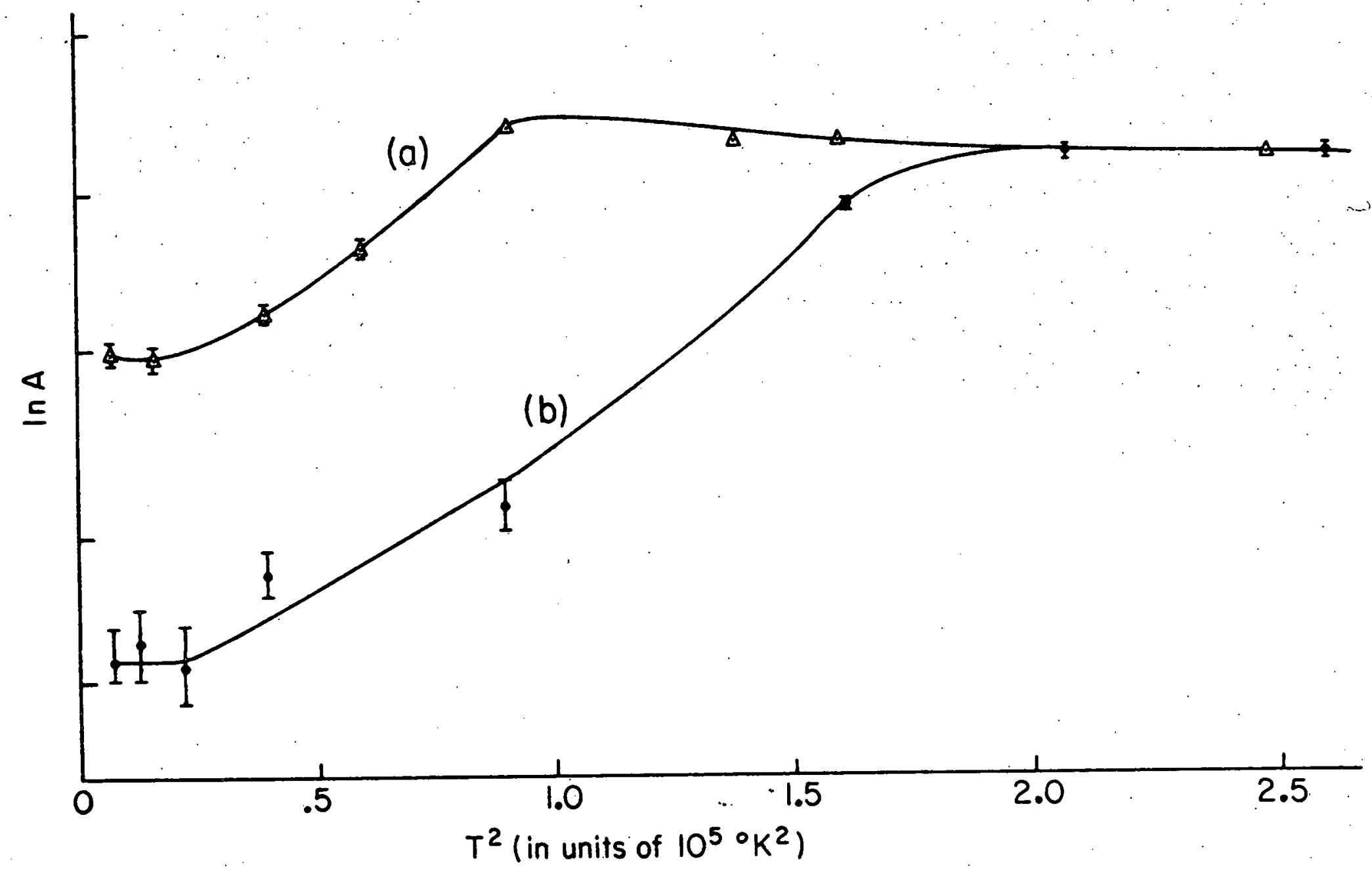

Figure 17. Temperature dependence of $\ln \mathrm{A}$ for $\mathrm{Fe}^{3+}$ in (a) $\mathrm{CoO}(\mathrm{I}, \mathrm{II})$ with a $.1 \%$ $\mathrm{Li}{ }^{17}$ doping and (b) $\mathrm{CoO}(\mathrm{I}, \mathrm{II})$. 


\section{E. Née1 Temperature}

As shown in Section $V-B$, the Néel temperature for a nominally stoichiometric sample of $\mathrm{NiO}$ (II) prepared at $400^{\circ} \mathrm{C}$ was measured to be $515 . \pm 5^{\circ} \mathrm{K}$. We determined the Néel temperatures of undoped and $\mathrm{Li}^{1+}$ doped samples prepared.at high temperatures in order to compare with the result for NiO(II). The procedure employed for determining the Néel temperature was to make comparative Mössbauer runs on the sample in increments of approximately $1^{\circ} \mathrm{K}$ over the temperature range in which the six-line antiferromagnetic pattern changed to a single paramagnetic line. When an undoped high temperature sample of Ni0 was run in this manner, the Néel temperature was determined to be $525.5 \pm 1^{\circ} \mathrm{K}$, which may be compared with the values $524 \pm 1^{\circ} \mathrm{K}$ and $525 \pm 1^{\circ} \mathrm{K}$ listed elsewhere 10,46 . The Néel transition was sharp, taking place within a range of about $2^{\circ} \mathrm{K}$. A sample of $\mathrm{NiO}$ prepared in an identical manner at high temperature except for a $0.9 \%$ doping of $\mathrm{Li}^{1+}$ was then run in the same manner. Identical geometry was used, which made it possible to determine any Néel temperature difference accurately, regardless of an estimated $1^{\circ} \mathrm{K}$ possible error in the absolute temperature. A similar sharp transition from the antiferromagnetic to the paramags netic state was:also observed, but corresponding changes in the pattern occurred an average of $4.3^{\circ} \mathrm{K}$ lower in temperature, which indicated a Néel temperature lowering of about $0.8 \%$, for a $\mathrm{Li}^{1+}$ doping of $0.9 \%$. A sample of CoO prepared at high temperature containing $1.1 \%$ Li was :also run, and the Néel temperature was found to be $284.5^{\circ} \mathrm{K}$, which, represents:a $1.2 \%$ lowering from the Néel temperature of $288^{\circ} \mathrm{K}$ measured 
for $\mathrm{CoO}(\mathrm{I})$ by $\mathrm{MO}^{11}$. The percentage Néel temperature lowering for high temperature samples is therefore nearly equal to the percent of lithium added, and the plausibility of this result has been discussed in Section II-D. These observations of the character of the Néel temperature lowering permit:an estimate of the relative fraction of volume associated with Schottky defects, as compared with porosity in the low density samples of $\mathrm{COO}(\mathrm{II})$ and $\mathrm{NiO}(\mathrm{II})$, which will be discussed in Section VI.

F. Search for Superparamagnetism and Particle Size Effects

The application of an external magnetic field and the constriction of particle size with the silica gel technique were done in order to look for and study small particle or microcrystal effects. Fig. 18 shows the effect of an external magnetic field of order $50 \mathrm{kG}$ on two samples. Part (a) shows the Mössbauer spectrum of a sample of $\mathrm{NiO}^{*}$ prepared by a very short anneal at $300^{\circ} \mathrm{C}$ in vacuum, which shows : combination of a partially resolved six-1ine spectrum and a broad single line at $282^{\circ} \mathrm{K}$. Upon the application of an external magnetic field of $51.5 \mathrm{kG}$, a significant amount of the broad single line was converted into the partially resolved six-1ine spectrum, as is seen in Fig. 18(b). The Mössbauer pattern of this sample at $282^{\circ} \mathrm{K}$ (well below the Née1 temperature) and the change in the pattern upon the application of an external magnetic field are indicative of superparamagnetism resulting from small particle size, as discussed in Section II-C. Part (c) of Fig. 18 shows a sample of $\mathrm{NiO}$ prepared at $600^{\circ} \mathrm{C}$ in air in a matrix of silica gel average diameter $140 \AA$, whose Mössbauer pattern at $289^{\circ} \mathrm{K}$ 


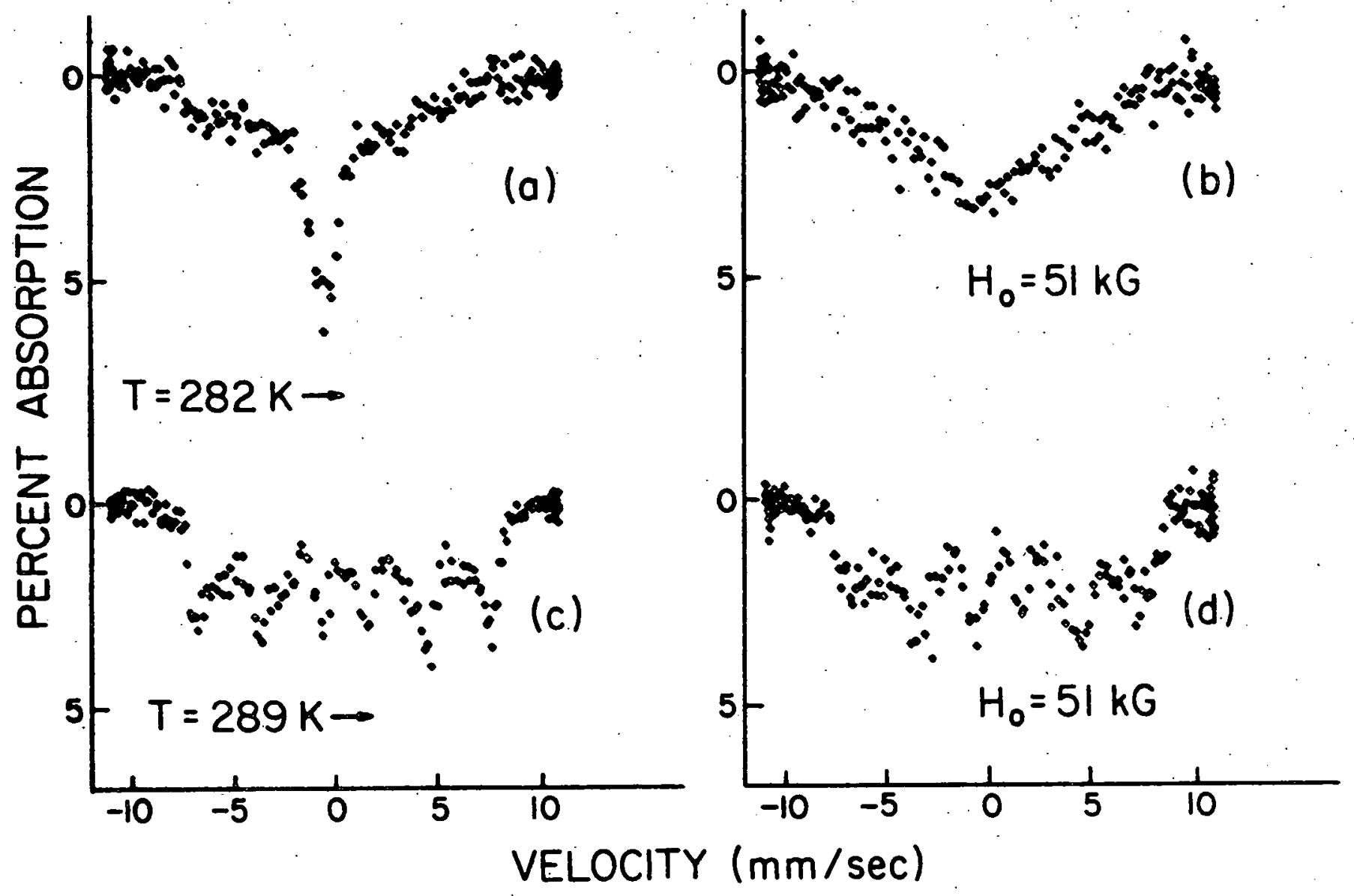

Figure 18. Effect of a $51 \mathrm{kG}$ external magnetic field on the Mössbauer spectra of $\mathrm{NiO}^{*}$ prepared by a very short anneal at $300^{\circ} \mathrm{C},(\mathrm{a})$ and (b), and on a sample of $\mathrm{NiO}$ prepared at $600^{\circ} \mathrm{C}$ in $140 \AA$ silica gel, (c) and (d). 
before the application of the external magnetic field contained a six-line spectrum and a broad unresolved line. The restriction of particle size-resulted in a broad unresolved line in addition to the six-line pattern and also gave a pattern resulting from only the $\mathrm{Fe}^{3+}$ resonance as measured by the isomer shift. In contrast, an anneal.at $600^{\circ} \mathrm{C}$ in air for:a bulk sample produced a NiO(I,II) sample exhibiting both $\mathrm{Fe}^{2+}$ and $\mathrm{Fe}^{3+}$ resonance with no broad unresolved line. The application of an external magnetic field (d) caused no significant change in the Mössbauer pattern in that the broad unresolved line was not converted into a more resolved spectrum. These two experiments will be discussed further in Section VI, and the results will be correlated with the earlier results obtained by $\mathrm{MO}^{14}$ upon applying an external magnetic field to $C \circ 0$ (II).

\section{G. Absorber Experiments}

Two absorbers of NiO doped with enriched $\mathrm{Fe}^{57}$ were made in addition to source experiments. The first absorber was prepared at $300^{\circ} \mathrm{C}$ in vacuum with a $3 \% \mathrm{Fe}^{57}$ doping, and its resonance against a $\mathrm{Co}^{57}$ in Pd source is shown in Fig. 19 (a). The pattern is complex, containing part six-line spectrum and part doublet pattern, and the separation of the' two outer peaks of the six-line pattern is greater than that of the six-line $\mathrm{Fe}^{3+}$ resonance in a Ni0 source at the same temperature. Comparison of the pattern with patterns which have been obtained for $\mathrm{Fe}^{57}$ in $\mathrm{FeO}$ and $\mathrm{Fe}_{2} \mathrm{O}_{3}$ :absorbers $44,47,48$ suggests that the $\mathrm{Fe}^{57}$ has precipitated out into $\mathrm{Fe}_{2}{ }^{0} \cdot 3$ and $\mathrm{FeO}$ inclusions in this preparation. This is not unreasonable because of the high level of $\mathrm{Fe}^{57}$ doping 


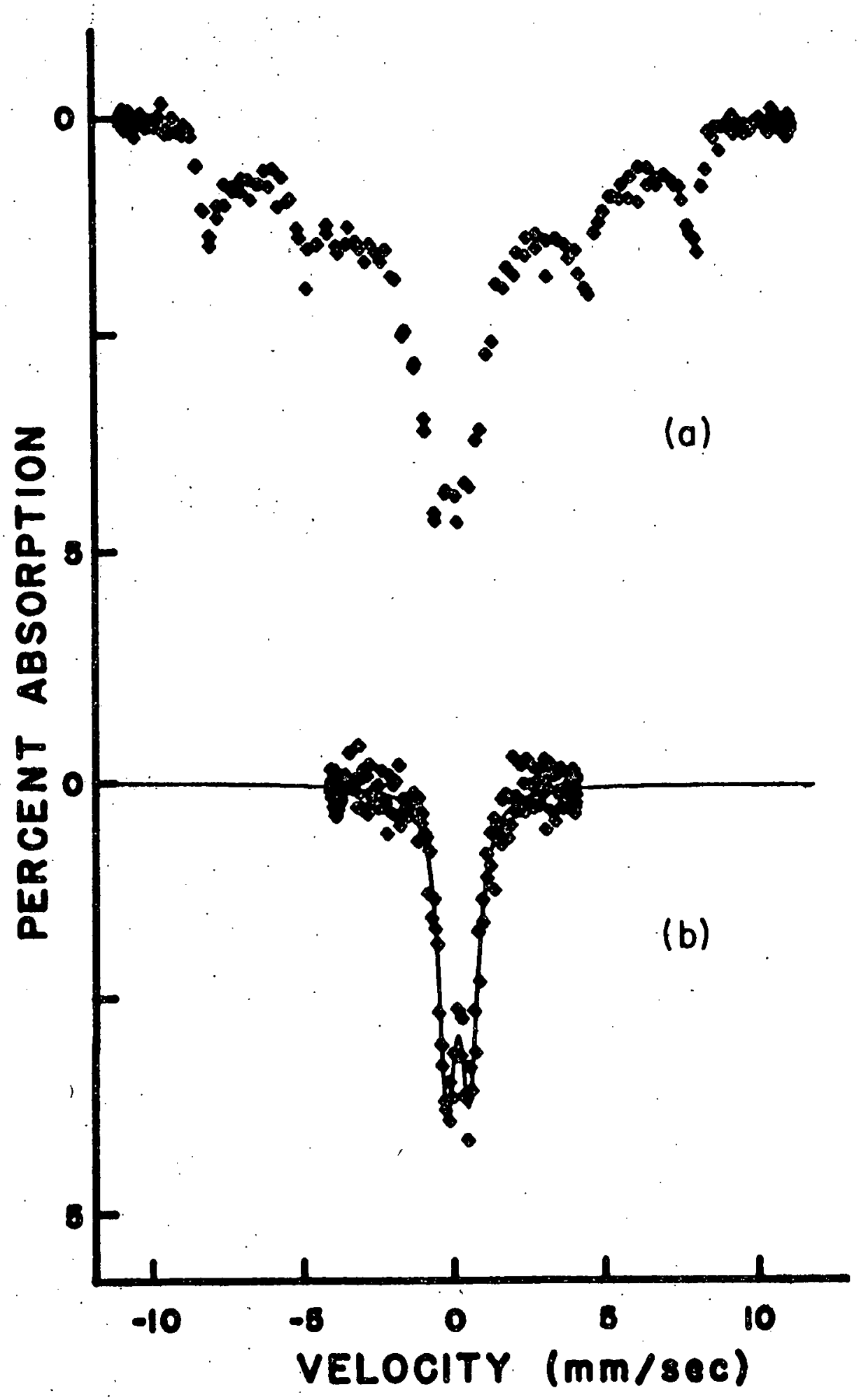

Figure 19. Two absorber resonances, at room temperature, of $\mathrm{Fe}^{57}$ in $\mathrm{NiO}$ prepared at $300^{\circ} \mathrm{C}$. A Co 57 in Pd source was used. 
required in absorber experiments. A second absorber was prepared at $300^{\circ} \mathrm{C}$ with a $2 \% \mathrm{Fe}^{57}$ doping, and in this case the initial solution of the nitrates of $\mathrm{Fe}^{57}$ and $\mathrm{Ni}$ was : sprayed into liquid nitrogen with an atomizer in order to freeze the solution very rapidly. The frozen solution was then sublimed before annealing by pumping on the sample with a diffusion pump vacuum while keeping the sample at ice temperature. This technique has been used in experiments with ferrites in an attempt to overcome the problem of inhomogeneous precipitation in a solution containing significant amounts of two different cations. The Mössbauer pattern of this:absorber against a $\mathrm{Co}^{57}$ in Pd source is shown in Fig. 19(b), and again the pattern is much different from that which would be obtained from:a NiO source prepared at the same temperature. The pattern appears to be the same doublet obtained in the first absorber and is similar to the doublet obtained in $\mathrm{FeO}$ absorber experiments. It appears, therefore, that the precipitation of $\mathrm{Fe}^{-57}$ into inclusions of $\mathrm{FeO}$ and $\mathrm{Fe}_{2} \mathrm{O}_{3}$ precludes the possibility of observing the $\mathrm{Fe}^{3+}$ source resonance of low temperature oxide preparations in absorbers.

The observation of relaxation effects:associated with the emission of Auger electrons by Cavanagh $^{49}$ and others ${ }^{50}$, motivated an attempt to carry out an experiment on $\mathrm{CoO}(\mathrm{I}, \mathrm{II})$ with a simultaneous $\mathrm{Co}^{57}$ and $\mathrm{Fe}^{57}$ doping. The sample was prepared under a $\mathrm{CO}_{2}$ atmosphere at $1000^{\circ} \mathrm{C}$, but with conditions such that a small $\mathrm{Fe}^{3+}$ resonance was expected in the source experiment. The Mössbauer results : are shown in Fig. 20. While the sample showed the expected resonance pattern, (a), when used as a source, it showed a substantially different pattern when used as an 


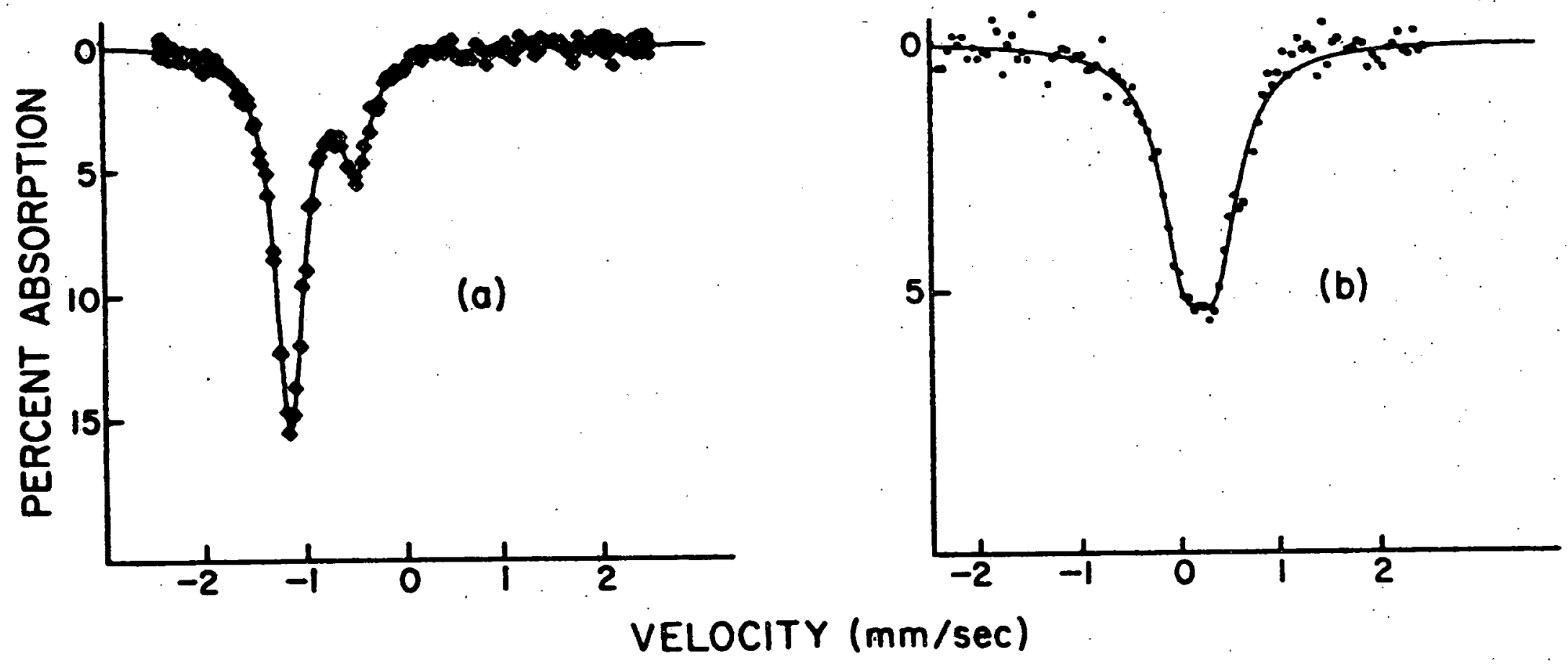

Figure 20. Simultaneous source and absorber Mössbauer spectra, at room temperature, for Co0 prepared at $1000^{\circ} \mathrm{C}$ in $\mathrm{CO}_{2}$. The source resonance, (a), was run with a $0.25 \mathrm{mg} / \mathrm{cm}^{2}$ sodium ferrocyanide absorber, and the absorber resonance, (b), with a $\mathrm{Co}^{57}$ in $\mathrm{Cu}$ source. 
absorber, (b), and the results seem to indicate a precipitation of iron oxide inclusions. This result is.:at variance with the earlier MO result ${ }^{11}$ showing symmetry between the source and absorber, when a very similar preparation technique was used, giving only $\mathrm{Fe}^{2+}$ for both the source and absorber experiments. The explanation of these results seems to be that an aging effect, due to: a delay in performing the absorber experiment, took place in the sample which resulted in the iron oxide inclusions. Thus, we were not able to determine whether the sma11 amount of $\mathrm{Fe}^{3+}$ resonance observed for the source wouldalso have been seen in the :absorber.

\section{H. Single-Line Sources}

One of the useful tools in Mössbauer spectroscopy is : a narrow, room temperature single-line-source, and we have found that our doping technique can be useful in the preparation of such sources from Co0. One of the primary motivations for making a source from $\mathrm{COO}$ is that the radioactive $\mathrm{Co}^{57}$ is not an impurity. Before the work on cobalt oxide the most common sources were made by diffusing $\mathrm{Co}^{57}$ into copper or palladium metal, which gave negligible line broadening and an absence of hyperfine interactions at the nucleus. However, the amount of $\mathrm{Co}^{57}$ that can be added to palladium or copper is limited because the quantity of $\mathrm{Co}^{57}$ must be kept low enough to avoid broadening from interactions between $\mathrm{Co}^{57}$ impurities. One way of reducing this impurity concentration is to diffuse the $\mathrm{Co}^{57}$ deeper into the metal, but then the source intensity is reduced because of electronic absorption of the gamma rays. If the source is a compound 


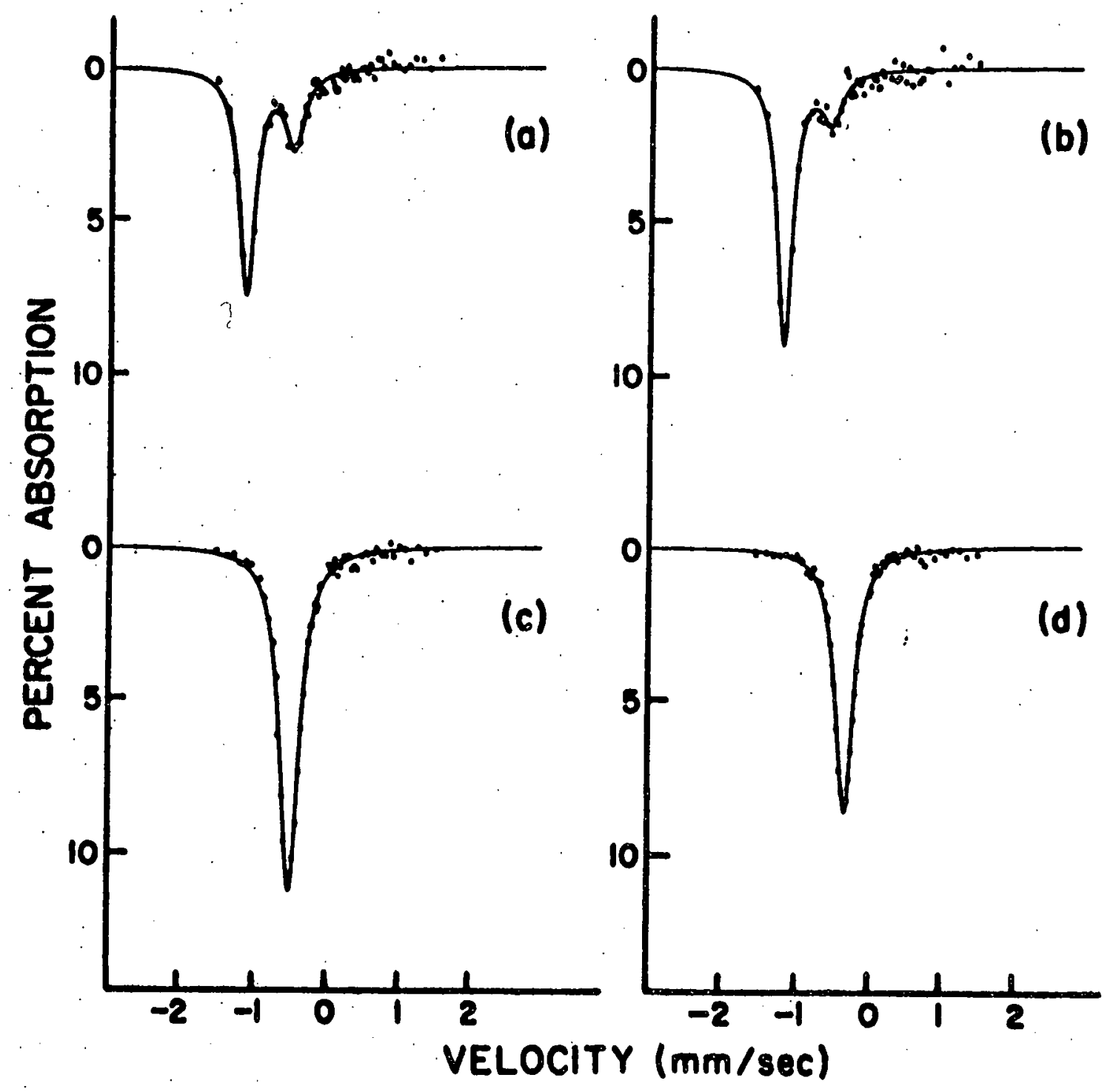

Figure 21. Effects of dopants on Mössbauer spectra at room temperature of $\mathrm{CoO}$, (a) $\mathrm{CoO}(i, \mathrm{II})$, (b) $\mathrm{CoO}(.3 \% \mathrm{Ga})$, (c) $\mathrm{CoO}(1 \% \mathrm{Li})$. All of the samples were prepared at $1000^{\circ} \mathrm{C}$. (d) an unsplit Pd source. A $0.1 \mathrm{mg} / \mathrm{cm}^{2}$ sodium ferrocyanide absorber was used in these experiments. 
of cobalt, however, the first of these problems does not occur and the second is minimized. $\mathrm{MO}^{51}$ have discussed the use of the $\mathrm{Fe}^{2+}$ resonance of $\mathrm{CoO}(\mathrm{I})$ as : a hot single-line source, and Stampfel and Flinn ${ }^{52}$ have shown that this $\mathrm{Fe}^{2+}$ source can be used to make a simple polarized source. However, the preparation of $\mathrm{CoO}(I)$ without any $\mathrm{Fe}^{3+}$ contamination is difficult in that a successful preparation depends somewhat on the geometry and details of the annealing tube and on the gas flow arrangement. Thus, a certain amount of technique and experimentation are required to prepare pure $\operatorname{CoO}(\mathrm{I})$. Fig. 21 (a) shows a sample of $\mathrm{CoO}(\mathrm{I}, \mathrm{II})$ annealed in air at $1000^{\circ} \mathrm{C}$, revealing a dominant $\mathrm{Fe}^{2+}$ resonance with about $20 \% \mathrm{Fe}^{3+}$ at room temperature. The same preparation except for the addition of $.3 \% \mathrm{Ga}^{3+}$ and $1 \% \mathrm{Li}^{1+}$ is shown in parts (b) and (c). In the first case the $\mathrm{Fe}^{2+}$ resonance is enhanced, and in the latter case it is completely suppressed. The $\mathrm{Ga}^{3+}$ doping should be useful in reducing the possibility of $\mathrm{Fe}^{3+}$ contamination when making a $\mathrm{CoO}(\mathrm{I})$ source, and the $1 \% \mathrm{Li}^{1+}$ doping allows the making of a $\mathrm{COO}$ source having only the $\mathrm{Fe}^{3+}$ resonance. This latter preparation appears to be insensitive to the exact annealing geometry or other experimental parameters. In contrast to $\mathrm{Co}(\mathrm{I})$, single line sources of $\mathrm{CoO}(\mathrm{Li})$ which have not been prepared with adequate care can stil1 be used in many cases because of the suppression of the $\mathrm{Fe}^{2+}$ line with increasing temperature. Thus, a small $\mathrm{Fe}^{2+}$ component can be eliminated by slightly heating the source above room temperature. When the $\mathrm{CoO}(1 \% \mathrm{Li})$ source is compared with a $\mathrm{Co}^{57}$ in Pd source, shown in Fig. 21(d), it is found that the linewidth is only slightly broader $(0.02 \mathrm{~mm} / \mathrm{sec})$ and the recoil-free fraction is substantially greater. 
VI. DISCUSSION

The Mössbauer effect has added.a powerful tool for probing the complexities of materials such as the transition metal oxides. Studies of this type have led to considerable debate about the properties of cobaltous oxide and nickelous oxide prepared at low temperatures. Considering all the data taken thus far on these systems, the structural model which seems most compatible with experiment involves a combination of point defects, or vacancies, and small pores. We will show how this picture can explain all of our present results, except for the large oxygen pickup of $\operatorname{CoO}(\mathrm{II})$. This latter phenomenon is very striking, and we have no satis factory explanation for it, thus far. The results indicate that the $\mathrm{CoO}$ (II) and $\mathrm{NiO}$ (II) samples definitely have significant structural differences from high temperature samples, because the differences between the high and low temperature forms cannot be explained by ion size or electronic effects. The low temperature preparations, stoichiometric $\mathrm{COO}(\mathrm{II})$ and $\mathrm{NiO}(\mathrm{II})$, may be viewed as a sponge-like structure formed from sintered microcyrstals, with a large concentration of dispersed point vacancies. The main features of the original MO mode $1^{11}$ are still indicated, in that point vacancies of both cation and anion appear to be the primary cause for most of the observed differences between high and low temperature preparations of these oxides. The data are consistent with the mechanism of charge stabilization for the $\mathrm{Fe}^{3+}$ ion proposed earlier,i.e., electron trapping 
by oxygen vacancies, analogous to $F$ centers in the alkali halides. (Centers of this type have been observed and studied in $\mathrm{Mg} 0 .{ }^{53}$ )" While our data indicate that small stoichiometric variations may be possible in $\mathrm{CoO}(\mathrm{II})$ and $\mathrm{NiO}(\mathrm{II})$, these do not appear to be the main cause of their differences.

The general aspects of the Mössbauer spectra, as well as $x$-ray and chemical data, for NiO samples were found to be similar to those obtained by $\mathrm{MO}^{11}$ for $\mathrm{CoO}$, indicating that the basic explanations for the properties of these two oxides are the same. We found that a nominally stoichiometric form of NiO, labelled NiO(II); showing only the $\mathrm{Fe}^{3+}$ Mössbauer resonance could be prepared at low temperature. Ni0(II) represents a saturated non-equilibrium density of Schottky defects and porosity, as in $\operatorname{CoO}(\mathrm{II})$. Attempts to increase the density of defects resulted in a non-stoichiometric material, labelled $\mathrm{Ni}^{*}$, with nitrate contamination from the starting material of nickel nitrate, analogous to $\mathrm{CoO}^{*}$. We found that the $\mathrm{Fe}^{3+}$ resonance in $\mathrm{NiO}$ (II) samples also had a lower Mössbauer characteristic temperature, $\theta_{m}$, than in high temperature preparations. The $x$-ray diffraction patterns for NiO(II) samples showed only the expected lines, although broadened. Other similarities, to $\mathrm{CoO}(\mathrm{II})$, such as density reduction, were observed for $\mathrm{NiO}(\mathrm{II})$. One important difference between $\mathrm{CoO}$ (II) and $\mathrm{NiO}$ (II) samples is the property of oxygen pickup. In contrast to CoO(II), which was found to pickup more-than $60 \%$ excess oxygen, Ni0(II) was found to be inert when placed in an oxygen atmosphere.

The results of measurements of the pickup of $\mathrm{Ar}$ and $\mathrm{Ne}$ gas by CoO(II) and NiO(II), discussed in Section IV-D, show that these low 
temperature forms physically adsorb a significant amount of these gases. These measurements show that $\mathrm{NiO}$ (II) and. $\mathrm{CoO}$ (II) have a large surface area, and the measurements give an estimate of a particle size of order $100 \AA$, which is consistent with the $x$-ray peak broadening shown in Fig. 5 of Section IV-C. In contrast to the physical adsorption of $\mathrm{Ar}$ and $\mathrm{Ne}$ by $\mathrm{COO}(\mathrm{II})$ and $\mathrm{NiO}(\mathrm{II})$, the pickup of oxygen in the early stages by $C o 0(I I)$, discussed in section IV-D, can be considered as either a chemical adsorption or some process in which the oxygen diffuses into the lattice, since the oxygen could not be removed by evacuating with a diffusion pump system. We also correlated the oxygen pickup of $\operatorname{CoO}(\mathrm{II})$ with $\mathrm{x}$-ray diffraction patterns and Mössbauer spectra, as discussed in Section IV-C. The results are suggestive of a two stage process, but we have not been able to propose a satisfactory explanation which will account for the enormous oxygen pickup and which is, at the same time, consistent with other data, such as the smal1 decrease in the Néel temperature for CoO(II) and the apparent continuous conversion of the Mössbauer pattern from a six line pattern to a two line pattern. Whatever the mechanism of oxygen pickup, we have concluded from the rest of our data that a large surface area and an appreciable quantity of Schottky defects are required. This dramatic pickup of oxygen:appears to be too great to be explained by either a simple surface adsorption or an absorption into anion vacancies. Also, a surface adsorption cannot easily account for the continuous transformation of the Mössbauer pattern with the amount of oxygen increase. Thus, further investigation will be required to understand this phenomenon. 
The application of an external magnetic field, shown in Fig. 18(a) and (b) of Section $\mathrm{V}-\mathrm{F}$, to a sample of $\mathrm{NiO}$ (prepared by a very short anneal at $300^{\circ} \mathrm{C}$ caused some of the broad single line to be converted into a partially resolved six-1ine spectrum, indicative of superparamagnetism of smal1. particles. The application of an external magnetic field to a second sample of Ni0 prepared in a matrix of $140 \AA$ A silica gel did not result in:a significant change in the Mo̊ssbauer pattern, as shown in Fig. 18 (c) and (d). This latter result seems to indicate that the particles of average diameter $140 \AA$ are too large for superparamagnetic effects to be observed with an external magnetic field of order $50 \mathrm{kG}$. This can be understood in terms of the discussion in Section II-C, where we indicated the strong dependence of the superparamagnetic relaxation time on particle size. It is also possible that we obtained:an alteration in the relaxation time due to the surface of the silica gel. $\mathrm{MO}^{14}$ found that the application of an external magnetic field to $\operatorname{CoO}($ II) did.not give any effect indicative of superparamagnetism. The observation of a change in spin.relaxation time for $\mathrm{NiO}^{*}$ and a failure to see such a change in $\mathrm{CoO}$ (II) may indicate that non-stoichiometric and impure materials such as $\mathrm{NiO}^{*}$ and $\mathrm{CoO}^{*}$ do indeed possess a microcrystal structure, of a type suggested by Schroeer and Triftshauser. ${ }^{12}$ Their model is not adequate to understand the pure and nominally stoichiometric materials, which we have designated as $\mathrm{CoO}(\mathrm{II})$ and $\mathrm{NiO}(\mathrm{II})$, although the evidence for porosity may indicate a sintered material whose initial components were of a microcrystalline form. 
The measured Néel temperature lowering in NiO(II) and $\mathrm{CoO}$ (II), as compared with high temperature samples, permits a first order estimate of the relative volume associated with Schottky defects as compared with porosity in these low temperature preparations. Our results, discussed in section V-E, indicated that the Néel temperature in high temperature lithium doped samples is reduced from the value found for undoped samples by a percentage nearly equal to that percentage of lithium which is substitutionally doped into the lattice for Co or Ni ions (at the level of $1 \%$ doping). The plausibility of this result was discussed in Section II-D, where we concluded that the Néel temperature was proportional to the number of second neighbor cations. It was : also pointed out that Co or $\mathrm{Ni}$ vacancies would be expected to have the same effect as 1ithium substitutional impurities provided the number of these point defects is:small compared to the number of cobalt or nickel ions. This condition is not rigorously satisfied, especially in $\operatorname{Co} 0(\mathrm{II})$, but this procedure does.allow:an estimate of the relative partitioning of point vacancies:and pores in $\operatorname{CoO}($ II) and $\mathrm{NiO}(\mathrm{II})$. The observation of a $6 \%$ reduction in $\mathrm{T}_{\mathrm{N}}$ for $\mathrm{CoO}(\mathrm{II})$ by $\mathrm{MO}^{11}$ would therefore indicate that about $1 / 4$ of the $25 \%$ reduction in density observed for $\operatorname{Co}($ II) is due to Schottky defects or point vacancies : and about $3 / 4$ is due to porosity. As discussed in Section $V-B, a$ sample of $\mathrm{NiO}$ (II) had a Néel temperature $2 \%$ less than a high temperature form. A similar analysis, therefore, indicates that about $1 / 6 \cdot$ of the $12 \%$ reduction in density observed for $\mathrm{NiO}(\mathrm{II})$ is due to point vacancies : and $5 / 6$ is due to porosity. 
Our data on the temperature dependence of the recoil-free fraction, which may be expressed as a Mössbauer characteristic temperature, $\theta_{\mathrm{m}}$, strikingly demonstrate the structural differences between the high and low temperature forms of these oxides, as presented in Section V-D and shown in Fig. 16. Since the $\mathrm{Fe}^{3+}$ ion is smaller than the $\mathrm{Fe}^{2+}$ ion, the lower $\theta_{\mathrm{m}}$ of the $\mathrm{Fe}^{3+}$ resonance in $\mathrm{CoO}$ (II) and $\mathrm{NiO}$ (II) as opposed to that of $\mathrm{Fe}^{2+}$ in high temperature preparations might be explained on the basis of ion size effects. Table 4 contains a summary of ion size data for ions considered in this study (also 1isted are ion sizes for the three dopants which have been added to $\mathrm{NiO}$ and $\mathrm{CoO}$ samples, and it can be seen that these ions should fit substitutionally into the cavities of the $\mathrm{Co}^{2+}$ or $\mathrm{Ni}^{2+}$ ions). If the impurity ion is smaller than the ion it substitutionally replaces it may have a large mean square displacement, ${ }^{54}$ which would cause $:$ lower $\theta_{\mathrm{m}}$. This effect will tend to be offset by the tendency of the extra charge of the $\mathrm{Fe}^{3+}$ to draw the oxygen ions closer, thereby reducing $\left\langle u^{2}\right\rangle$. If ion size or charge effects of this type are dominant, we should see the same $\theta_{\mathrm{m}}$ for $\mathrm{Fe}^{3+}$ in low temperature forms and for the $\mathrm{Fe}^{3+}$ resonance induced in high temperature preparations by 1ithium. In fact, $\theta_{\mathrm{m}}$ for $\mathrm{Fe}^{3+}$.in high temperature preparations is essentially the same as for $\mathrm{Fe}^{2+}$ in high temperature preparations, and is significantly higher than for $\mathrm{Fe}^{3+}$ in low temperature preparations. Thus, a comparison of $\theta_{\mathrm{m}}$ for $\operatorname{Co} 0(1 \% \mathrm{Li})$ and $\operatorname{Co} 0(\mathrm{I})$ shows no evidence for ion:size effects within experimental error, in that the $\mathrm{Fe}^{2+}$ and $\mathrm{Fe}^{3+}$ resonances in high temperature samples have the same $\theta_{\mathrm{m}}$. Schroeer and Triftshauser attempted to explain the lower value found for $\theta_{\mathrm{m}}$ in $\operatorname{CoO}$ (II). or 
Table 4

Compilation of ion sizes. Values listed are in $\AA$.

\begin{tabular}{|c|cc|c|c|c|c|c|}
\hline $\mathrm{Fe}^{2+}$ & $\mathrm{Fe}^{3+}$ & $\mathrm{Co}^{2+}$ & $\mathrm{Ni}^{2+}$ & $\mathrm{Li}^{1+}$ & $\mathrm{Cr}^{3+}$ & $\mathrm{Ga}^{3+}$ \\
\hline $.76 \mathrm{a})$ & $.64 \mathrm{a})$ & $.74 \mathrm{a})$ & $.72 \mathrm{~b})$ & $.68 \mathrm{c})$ & $.69 \mathrm{~b})$ & $.60 \mathrm{c})$ \\
$.76 \mathrm{~b})$ & $.64 \mathrm{~b})$ & $.74 \mathrm{~b})$ & $.68 \mathrm{c})$ & $.60 \mathrm{c})$ & $.55 \mathrm{c})$ & $.62 \mathrm{c})$ \\
$.76 \mathrm{c})$ & $.53 \mathrm{c})$ & $.70 \mathrm{c})$ & $(.69 \mathrm{c})$ & $.78 \mathrm{~d})$ & $.64 \mathrm{~d})$ & $.62 \mathrm{~d})$ \\
$.75 \mathrm{c})$ & -- & $.72 \mathrm{c})$ & $.78 \mathrm{~d})$ & -- & -- & - \\
\hline .76 & .60 & .73 & .72 & .69 & .63 & .61 \\
\hline
\end{tabular}
a) See $\cdot$ reference $\cdot 8$
b) See,reference 54
c) See $\cdot$ reference $\cdot 55$
d) See reference $\cdot 58$ 
Ni.O(II) by a microcrysta1 model, assuming modifications of the lattice vibrational spectrum. MO ${ }^{13}$ showed, using an analysis by $\mathrm{Rich}^{56}$, however, that this effect is much smaller than required to account for the observed lowering of $\theta_{\mathrm{m}^{\circ}}$ The data are best explained on the basis of Schottky defects, which would reduce the average binding of the $\mathrm{Fe}^{3+}$ ion in $\mathrm{CoO}(\mathrm{II})$ or $\mathrm{NiO}(\mathrm{II})$. It is noteworthy that the fractiona1 reduction in $\theta_{m}$ from high temperature forms for $\operatorname{CoO}($ II) is about 3 times that of $\mathrm{NiO}$ (II) and the density of Schottky defects estimated for these materials from the NEel temperature lowering is in the ratio 3:1, which supports the idea that Schottky defects cause the 1owering of $\theta_{\mathrm{m}}$

The data on the temperature dependence of the recoil-free fraction for $\mathrm{Fe}^{3+}$ in $\mathrm{CoO}(\mathrm{I}, \mathrm{II})$ and in $\mathrm{CoO}(\mathrm{I}, \mathrm{II})$ doped with $.1 \% \mathrm{Li}^{1+}$ give an indication of the reason for the increase of the $\mathrm{Fe}^{3+}$ resonance with temperature in $\mathrm{CoO}(\mathrm{I}, \mathrm{II})$ and $\mathrm{NiO}(\mathrm{I}, \mathrm{II})$. Bhide and Shenoy ${ }^{4,5}$ explained this behavior in terms of a monotonic increase with temperature of the relaxation time for $\mathrm{Fe}^{3+}$ going to $\mathrm{Fe}^{2+}$, resulting from a decrease in the capture cross section for the $\mathrm{Fe}^{3+}$ ion to obtain electrons. Their overail analysis involved assumptions about Auger aftereffects which were subsequent ly shown to be wrong. ${ }^{7,8}$ Triftshauser and $\mathrm{Craig}^{7,8}$ attempted to explain the increase of the $\mathrm{Fe}^{3+}$ resonance as due to increased mobility of the cation vacancies which they proposed to stabilize the $\mathrm{Fe}^{3+}$ resonance. Data on the magnitude of cation diffusion in $\mathrm{CoO}$ by Peterson ${ }^{57}$ rules out this explanation. MO ${ }^{11}$ explained this increase of $\mathrm{Fe}^{3+}$ resonance as due to a dispersal of anion vacancies out from simple clusters of $\operatorname{Co0}($ II) in:Co0(I,II), 
which they also invoked to account for the large oxygen pickup of Co0(II). As discussed in Section V-D and shown in Fig. 17, the increases of the $\mathrm{Fe}^{3+}$ resonance with temperature in $\mathrm{CoO}(\mathrm{I}, \mathrm{II})$ and $\operatorname{CoO}(I, I I)$ with a . $1 \%$ lithium doping are qualitatively similar. It is unlikely that the results for the $\mathrm{Li}^{1+}$ doped sample can involve a diffusion of lithium in the same temperature region as anion vacancies. These new results obtained with the lithium dopant, therefore, indicate that the increase of the $\mathrm{Fe}^{3+}$ resonance with temperature is caused by a shifting of the statistical equilibrium for the ratio of $\mathrm{Fe}^{2+} / \mathrm{Fe}^{3+}$. Thus, this effect is a consequence of the semiconducting properties of these materials.

Since $\mathrm{CoO}$ and $\mathrm{NiO}$ are II-VI compounds we may expect that their electronic behavior will 1 ie somewhere in between the ionic behavior of I-VII compounds and the covalent behavior of III-V compounds. In ionic compounds there is a complete transfer of electronic charge, and in purely covalent compounds there is a sharing of electrons. The effects of the $\mathrm{Li}^{1+}, \mathrm{Cr}^{3+}$, and $\mathrm{Ga}^{3+}$ dopants, presenced in Section $\mathrm{V}-\mathrm{C}$, can be explained by a band model for these semiconducting oxides. Other investigators have found that lithium acts as anacceptor, increasing the conductivity'significant $1 y$, and gallium or chromium act as donors, decreasing the conductivity.27,29,58-61 Regarding $\mathrm{Fe}^{2+}$ as a donor, we obtain a conversion from $2+$ to $3+$ upon substitutionally inserting:an acceptor such as lithium, as shown in Figures 10, 12, 13, 15, and 21. This is based on the assumption that the 1ithium leve1 lies lower in the band gap than the iron level. The equilibrium ratio $\mathrm{Fe}^{2+} / \mathrm{Fe}^{3+}$ goes in the opposite direction when donors such as chromium 
or gallium are added, as shown in Figures 11,12 , and 21 . This is based on the assumption that the chromium and gallium levels 1 ie higher in the band gap than the iron level. A monotonic dependence of the ratio of $\mathrm{Fe}^{2+} / \mathrm{Fe}^{3+}$ upon the concentration of the dopant was found, as illustrated in Figure 10. Our results indicate that Mössbauer measurements on these oxides might be a useful tool for studying their semiconducting properties, and optical measurements of impurity.and band levels in these materials should permit a quantitative comparison with our Mössbauer data. Our doping technique has also proved very use ful in the preparation of compact, single line sources from Co0, as discussed in Section $\mathrm{V}-\mathrm{H}$ and shown in Fig. 21. 
LIST OF REFERENCES 


\section{LIST OF REFERENCES}

1. R. L. Mössbauer, Z . Physik 151, 124 (1958).

2. G. K. Wertheim, Phys. Letters 30A, 237 (1969).

3. G. K. Wertheim, Phys. Rev. 124, 764 (1961).

4. V. G. Bhide and G. K. Shenoy, Phys. Rev. 143, 309 (1966).

5. V. G. Bhide and G. K. Shenoy, Phys. Rev. 147, 306 (1966).

6. J. G. Mullen and H. N. Ok, Phys. Rev. Letters 17, 287 (1966).

7. W. Triftshauser and P. P. Craig, Phys. Rev. Letters 16, 1161 (1966).

8. W. Triftshauser and P. P. Craig, Phys. Rev. 162, 274 (1967).

9. K. J. Ando et.a1., J..Phys. Chem. Solids 28, 2291 (1967).

10. J. D. Siegwarth, Phys. Rev. 155, 285 (1967).

11. H. N. Ok and J. G. Mullen, Phys. Rev. 168, 550 (1968); 168, 563 (1968); 181, 986(E) (1969).

12. D. Schroeer and W. Triftshauser, Phys. Rev. Letters 20, 1242 (1968).

13. H. N. Ok and J. G. Mullen, Phys. Rev. Letters 21, 823 (1968).

14. H. N. Ok, W. R. Helms, and J. G. Mullen, Phys. Rev. 187, 704 (1969).

15. G. K. Wertheim and D. N. E. Buchanan, Chem. Phys. Letters $\underline{3}, 87$ (1969).

16. H. Frauenfelder, The Mössbauer Effect (W. A. Benjamin Inc., New York, 1963).

17. S. Margulies.. and J. R.-Ehrman, Nucl. Instr.and Methods 12, 131 (1961). 
18. A. H. Muir, K. J. Ando, and H. M. Coogan, Mo̊ssbauer Effect Data Index 1958-1965 (Interscience Publishers, New York, 1966).

19. C..P. Bean and J. D. Livingston, J. App1. Phys. Supp1. 30, 120 (1959).

20. I. S. Jacobs: and C.P. Bean, Magnetism, edited by G. T. Rado and H. Suh1 (Academic Press Inc., New York, 1963) Vol. III.

21. J. S. Smart, Effective Field Theories of Magnetism (W. B. Saunders Co., Philadelphia, 1966).

22. D. C. Khan and K. A. Erickson, Phys. Rev. 1B, 2243 (1970)。

23. J. G. Mu1len, Phys. Rev. $\underline{131}, 1410$ (1963).

24. R. C. Knauer and J. G. Mullen, Rev. Sci. Instr. 38, 1624 (1967).

25. N. V. Sidgwick, Chemica1 Elements: and Their Compounds (Clarenden Press, Oxford, 1952). Vol. II.

26. J. W. Mellor, A Comprehensive Treatise on Inorganic and Theoretica1 Chemistry, (Longmans, Green and Co., 1935). Vols.XIV and XV.

27. E. J. W. Verwey et.a1。, Philips Res. Rep. 5, 173 (1950).

28. R. R. Heikes : and W. D. Johnson, J. Chem. Phys. 26, 582 (1957).

29. S. Koide, J. Phys. Soc. Japan 20, 123 (1965).

30. H. P. Klug and L. E. Alexander, X-ray Diffraction Procedures for Polycrystalline and Amorphous Materials (John Wiley and Sons, Inc, New York, 1954).

31. André Guinier, X-ray Crystallographic Technology (Hilger and Watts Ltd., London, 1952).

32. D. A. Skoog and D. M. West, Fundamentals of Analytica 1 Chemistry (Holt, Rinehart, and Winston, New York, 1963). pp. 356-357.

33. N. C. Tombs: and H. P. Rooksby, Nature 165, 442 (1950).

34. H. P. Rooksby, Nature 152, 304 (1943)。

35. H.P. Rooksby, Acta Crystallographica 1, 226 (1948).

36. A. H. Compton and S. K. Allison, $\underline{X}$-rays in Theory and Experiment (D. Van Nostrand Co., Inc., New York, 1935).

37. X-ray Powder Data File, ASTM Specia1 Technica1 Publication 48-J, 1960, Index Card 4-0835. 
38. Although these measurements :are reported for $\mathrm{NiO}$ (II) and CoO(II), there was : a small deviation from stoichiometry. This difficulty was the result of experimental problems involved in preparing large samples of $\mathrm{NiO}$ (II) and $\mathrm{CoO}$ (II). We do believe, however, that this difficulty was of no particular significance for these measurements.

39. S. Brunauer, The Adsorption of Gases and Vapors (Princeton University Press, Princ eton, N. J., 1945).

40. W. Heit ler, : Quantum Theory of Radiation (Clarendon Press, Oxford, 1949).

41. J. Heberle, Nuc1. Instr. and Methods $\underline{58}, 90$ (1968).

42. S. DeBeneditti, G. Lang, and R. Ingalls, Phys. Rev. Letters 6. 60 (1961).

43. O.C. Kistner and A. W. Sunyar, Phys. Rev. Letters 4 , 412 (1960)。

44. G. K. Wertheim, J. App1. Phys. Supp1. 32, 110 (1961).

45. K. Ono and A. Ito, J. Phys. Soc. Japan 19, 899 (1964).

46. Charles Kittel, Introduction to Solid State Physics (John Wiley and Sons, Inc., New York, 1967), p. 483.

47. R. W. Vaughan and H.G. Drickamer, J. Chem. Phys. 47, 1530 (1961).

48. G. Shirane, D. E. Cox, and S. L. Ruby, Phys. Rev. 125, 1158 (1962)。

49. J. F. Cavanagh, Phys. Stat. So1. 36, 657 (1969).

50. P. Jung and W. Triftshauser, Phys. Rev. 175, 512 (1968).

51. J. G. Mullen and H. N. Ok, Mössbauer Effect Methodology, edited by I. J. Gruverman (Plenum Press, New York, 1968), Vo1. 4.

52. J. P. Stamp fe1 and P. A. F1inn, Mössbauer Effect Methodology (Plenum Press, New York, 1970), Vo1. 6.

53. L. A. Kappers, R. L.Kroes, and E. B. Hensley, Phys. Rev. (to be published).

54. P. Auzins, J. W. Orton, and J. E. Wertz, Paramagnetic Resonance, edited by W. Low (Academic Press, New York, 1963), Vo1. I.

55. F. A. Cotton and G. Wilkinson, Advanced Inorganic Chemistry (Intersicience.Publishers, New York, 1966).

56. M. Rich, Phys. Letters 4, 153 (1963). 
57. W. K. Chen, N. L. Peterson, and W. T. Reeves, Phys. Rev.: $\underline{186}$, 887 (1969).

58. G. M. Schwab and H. Schmid, J. Appl. Phys. 33S, 426 (1962).

59. I. G. Austin, A. J. Springthorpe, and B. A. Smith, Phys. Letters 21, 20 (1966).

60. A. J. Bosman and C. Crevecoeur, Phys. Rev. 144, 763 (1965).

61. S. Van Houten, J. Phys. Chem. Solids 17, 7 (1960). 
APPENDIX A

A GEOMETRICAL EFFECT IN MÖSSBAUER SPECTROSCOPY 


\section{APPENDIX A}

\section{A GEOMETRICAL EFFECT IN MÖSSBAUER SPECTROSCOPY}

In actual Mössbauer experiments the detector samples a range of doppler velocities for any horizontal velocity'v of the absorber, which is a geometrical effect arising from perpendicular components of the gamma ray momentum relative to the doppler motion; This is an inevitable consequence of the finite size of the source and detector. The experimental geometry is shown in Fig.: 22, where only the effects of detector size are considered. The source is considered as a point source, and the gamma rays make angles of 0 to $\theta_{1}$ with the horizontal line between the source and center of the detector window. The average. doppler velocity may be calculated by averaging over the solid angle subtended by the detector as follows:

$$
E_{d}=\frac{E}{c}\langle v \cos \theta\rangle=\frac{E^{*}}{c}\left\langle v_{x}\right\rangle .
$$

The quantity $\left\langle v_{x}\right\rangle / v$ may be calculated as follows:

$$
\frac{\left\langle v_{\mathrm{x}}\right\rangle}{\mathrm{v}}=\frac{\int_{0}^{\theta_{1}}(\mathrm{v} \cos \theta) 2 \pi r^{2} \sin \theta d \theta}{v \int_{0}^{\theta^{1}} 2 \pi r^{2} \sin \theta d \theta},
$$




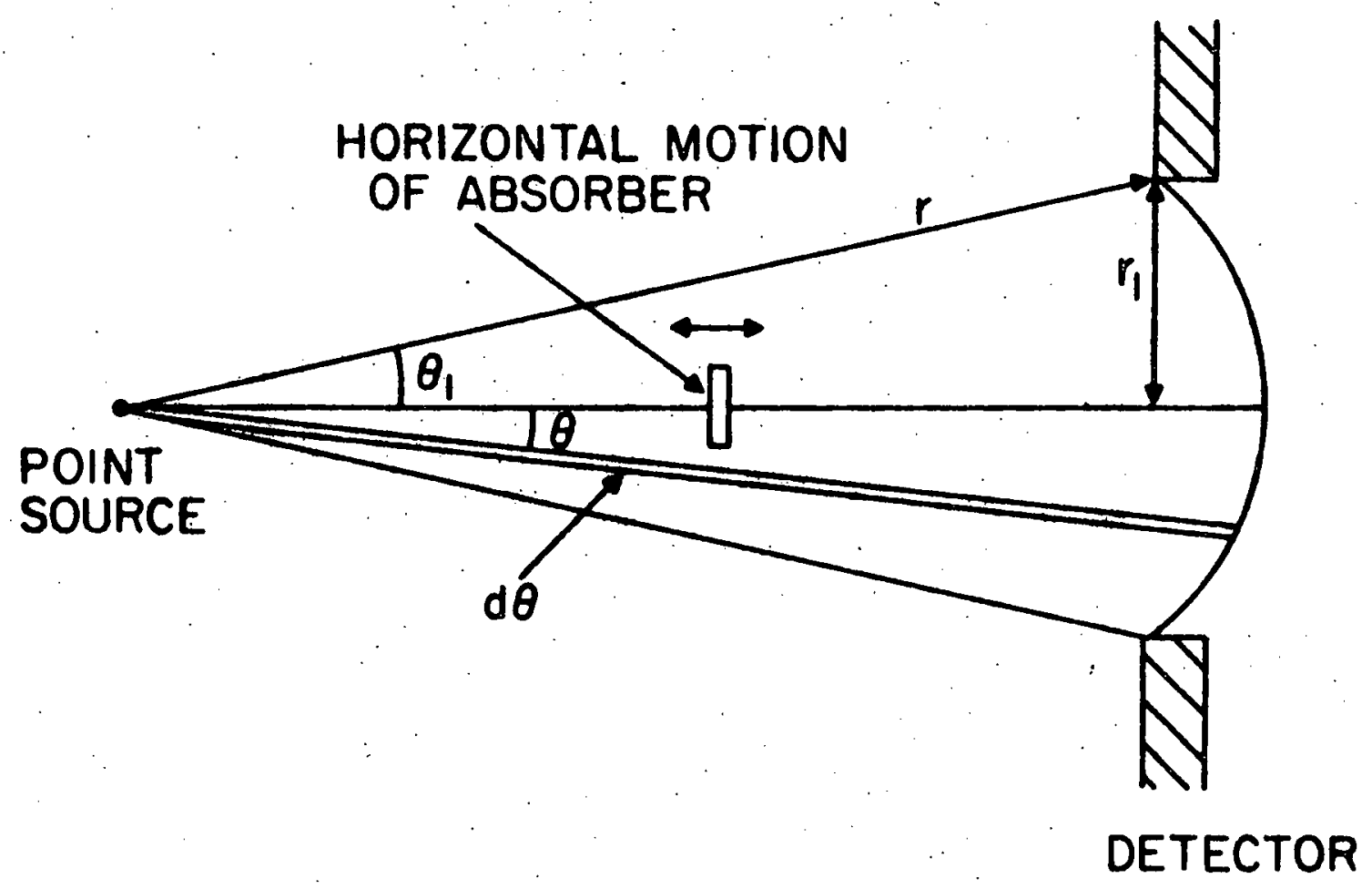

F1gure 22. Experimental geometry illustrating the solid angle subtended by the detector of a Mössbauer spectrometer. 
which reduces to:

$$
\frac{\left\langle v_{\dot{x}}\right\rangle}{v}=\frac{\int_{0}^{\theta} \cos \theta \sin \theta d \theta}{\int_{0}^{\theta_{1}} \sin \theta d \theta}=\frac{1}{2}\left(1+\cos \theta_{1}\right) .
$$

Since $\theta_{1}$ will almost certainly be a small:angle, the following approximation can be made:

$$
\frac{\left\langle v_{x}\right\rangle}{v}=\frac{1}{2}\left(1+\cos \theta_{1}\right) \cong 1-\frac{\theta_{1}^{2}}{4}
$$

The effective doppler velocity is thus reduced by the factor $\frac{\theta_{1}{ }^{2}}{4}$, and to obtain the correct doppler velocity we must multiply the experimental velocity by the factor $\left(1-\frac{\theta_{1}^{2}}{4}\right)$. Table 5 gives this correction term for various values of $\sin \theta_{1}=\frac{r_{1}}{r}$. The intensity of the Mössbauer absorption lines as a function of any angle $\theta$ of the absorber will be:

$$
I=\frac{S \Gamma / 2 \pi}{\left(v_{0}-v \cos \theta\right)^{2}+\Gamma^{2} / 4}
$$

which may be averaged over solid angle to obtain an average intensity. as follows:

$$
\langle I\rangle=\frac{S \Gamma / 2 \pi \int_{0}^{\theta_{1}} \frac{2 \pi r^{2} \sin \theta d \theta}{\left(v_{0}-v \cos \theta\right)^{2}+\Gamma^{2} / 4}}{\int_{0}^{\theta_{1}} 2 \pi r^{2} \sin \theta d \theta},
$$


Table 5

Correction factors for geometrical effect.

\begin{tabular}{|c|c|c|}
\hline $\sin \theta_{1}=\frac{r_{1}}{r}$ & $1-\frac{\theta_{1}^{2}}{4}$ & $\%$ Effect \\
\hline .05 & .9994 & .06 \\
.10 & .9970 & .3 \\
.15 & .9940 & .6 \\
.20 & .9895 & 1.1 \\
.25 & .9850 & 1.5 \\
.30 & .9775 & 2.3 \\
\hline
\end{tabular}


which partially reduces to:

$$
\langle I\rangle=\frac{\mathrm{S} \Gamma}{2 \pi\left(1-\cos \theta_{1}\right)} \int_{0}^{\theta_{1}} \frac{\sin \theta d \theta}{\left(\mathrm{v}_{0}-\mathrm{v} \cos \theta\right)^{2}+\Gamma^{2} / 4}
$$

The integration may be performed by a change of variables:

$$
\alpha=\left(v_{0}-v \cos \theta\right)
$$

to yie1d:

$$
\langle I\rangle=\frac{\mathrm{S}}{\pi \mathrm{v}\left(1-\cos \theta_{1}\right)}\left[\tan ^{-1}\left(\frac{\mathrm{v}_{0}-\mathrm{v} \cos \theta_{1}}{\Gamma / 2}\right)-\tan ^{-1}\left(\frac{\mathrm{v}_{0}-\mathrm{v}}{\Gamma / 2}\right)\right]
$$

Numerical computer calculations were made in order to calculate the area under the curve using the above expression for $\langle I\rangle$. It was found that the experimental area must be multiplied by the factor, $\left(1-\frac{\theta_{1}^{2}}{4}\right)$, to obtain the correct area. A look at Table.5 indicates that the correction factor, $\left(1-\frac{\theta_{1}^{2}}{4}\right)$, will be 1 ess than $1 \%$ for a separation of 3 inches between source and a one inch diameter de- . tector. However, the correction for this effect may be necessary in experiments involving very careful measurement of lineshape or peak position. 